\title{
Control of E-cadherin Function in Cell Intercalation by ER Glucosylation Enzymes
}

\author{
Dissertation \\ for the award of the degree \\ "Doctor of Philosophy” (PhD) \\ Division of Mathematics and Natural Sciences \\ of the Georg-August-University Goettingen \\ Submitted by \\ Yujun Zhang
}

From Shanxi, China

Goettingen, 2012 
Members of the Thesis Committee:

Prof. Dr. Joerg Grosshans (Reviewer)

Developmental Biochemistry, University Medicine

Prof. Dr. Andreas Wodarz (Reviewer)

Stem Cell Biology, University Medicine

Dr. Halyna Shcherbata

Gene Expression and Signaling, MPI-bpc 


\section{Affidavit}

Herewith I declare that I prepared the $\mathrm{PhD}$ thesis "Control of E-cadherin Function in Cell Intercalation by ER Glucosylation Enzymes" on my own and with no other sources and aids than quoted.

Submission date

Göttingen, 31.07.2012

Yujun Zhang 

Summary

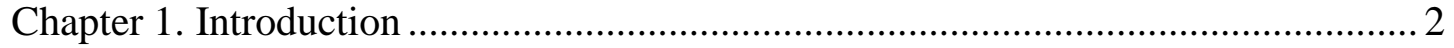

1.1 Cell intercalation during germ band extension in Drosophila .......................... 2

1.1.1 Drosophila germ band extension ..................................................... 3

1.1.2 Mechanism involved in cell intercalation ............................................. 4

1.2 E-cadherin and its post-translational modification ..................................... 7

1.2.1 E-cadherin and adherens junctions ..................................................... 7

1.2.2 Post-translational modification of E-cadherin ........................................ 8

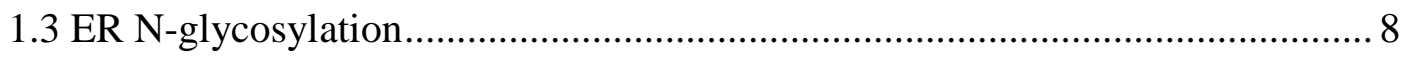

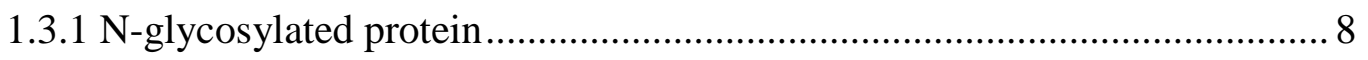

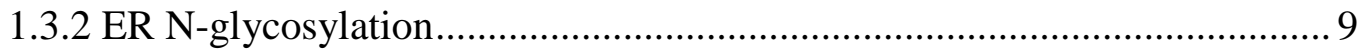

1.3.3 Protein folding and ER quality control .............................................. 10

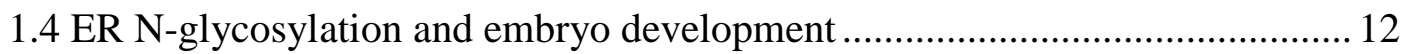

1.4.1 Wollknäuel is required for embryo patterning and cuticle differentiation 12

1.4.2 Congenital disorder of glycosylation (CDG) ....................................... 13

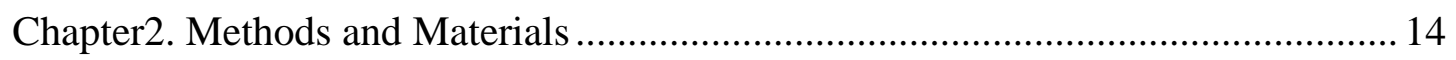

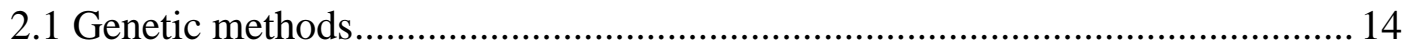

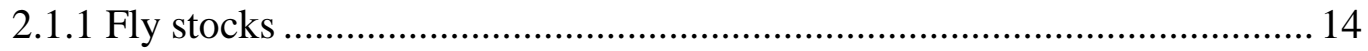

2.1.2 Gene mapping with Duplications and Deficiencies............................... 15

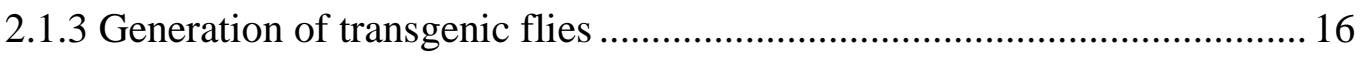

2.1.4 FLP-FRT system and germline clones.............................................. 17

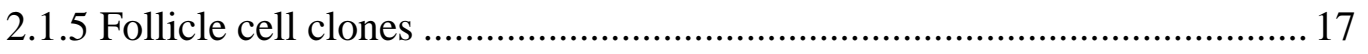

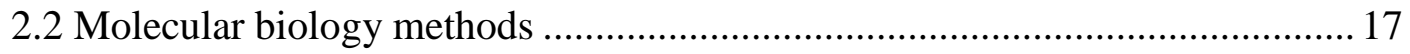

2.2.1 PCR sequencing of the $3 \mathrm{kd}$ segment in the $\mathrm{X}$ chromosome $6 \mathrm{D}$ region..... 17 


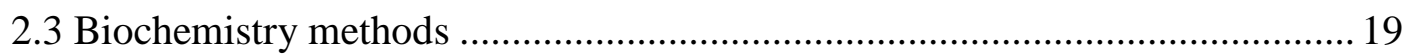

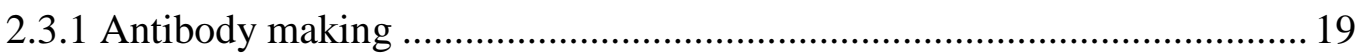

2.3.2 Western blot and N-Glycosidase treatment ........................................ 21

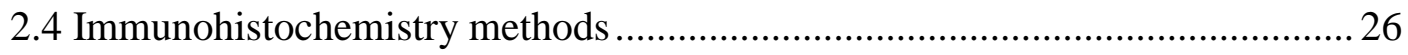

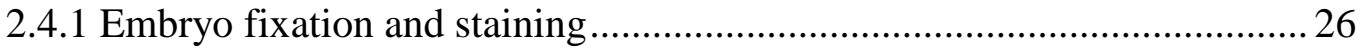

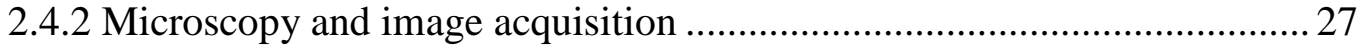

2.5 In situ hybridization with alkaline phosphatase ............................................. 27

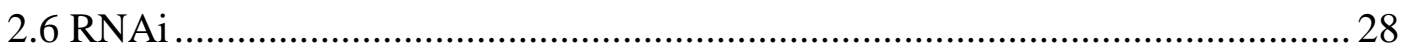

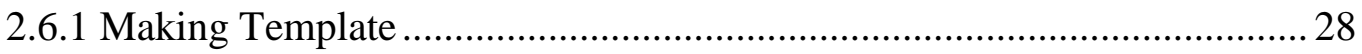

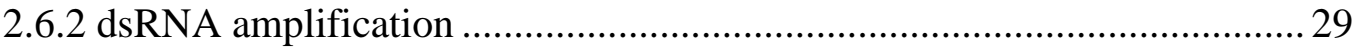

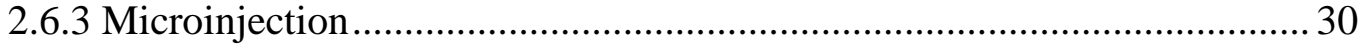

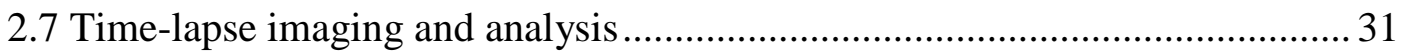

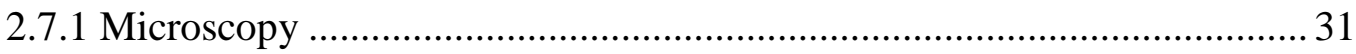

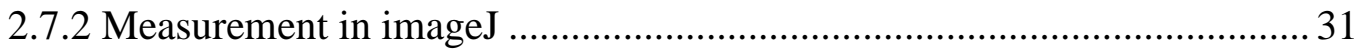

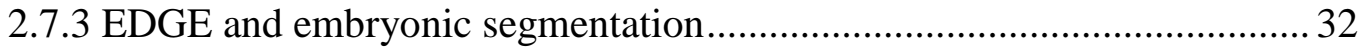

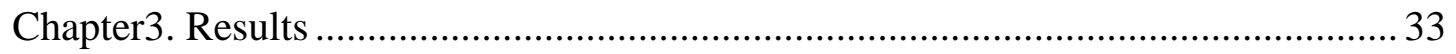

3.1 X-330 is a mutant of ER membrane protein CG4542 .................................... 33

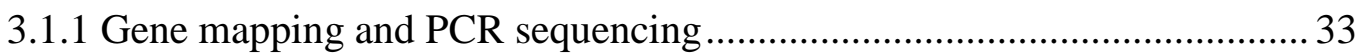

3.1.2 Genomic DNA of CG4542 could rescue X-330 lethality and its phenotype

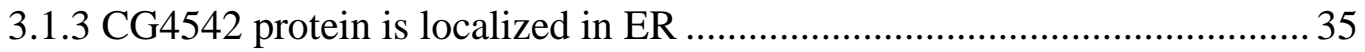

3.2 Germ band extension is abnormal in X-330 mutant ..................................... 39

3.2.1 Germ band extension is abnormal in the mutants of X-330, Wol or Gny . 40

3.2.2 Removing N-glycans from proteins induces germ band extension defect 42

3.2.3 Not all the mutants of N-glycosylation enzymes affect gastrulation......... 43 
3.3 Cell intercalation is abnormal during germ band extension in X-330 mutant.. 44

3.3.1 Cell intercalation is decreased in X-330 mutant 44

3.3.2 $\mathrm{T} 1$ process is affected in $\mathrm{X}-330$ mutant 46

3.4 Anterior-posterior polarity and planar cell polarity has no obvious defect in X-

330 mutant 47

3.4.1 AP polarity is not obviously affected in X-330 mutant 47

3.4.2 Planar cell polarity is normal in X-330 mutant 48

3.5 E-cadherin is a target of $\mathrm{X}-330$ mutant. 49

3.5.1 E-cadherin protein is reduced in adherens junctions in X-330 mutant ...... 50

3.5.2 E-cadherin is partially glycosylated in X-330 mutant 51

3.5.3 Expression and localization of some ER synthesized membrane proteins are normal, while the others are abnormal in X-330 mutant ..... .53

3.5.4 Adherens junctions are normally localized in X-330 mutant .55

3.5.5 Knockdown of E-cadherin induces cell intercalation defect during germ band extension 57

3.6 New horizontal borders are formed by pulsed manner and stabilized by Ecadherin 58

3.6.1 New horizontal borders extend by pulsed behavior. .58

3.6.2 E-cadherin is gradually accumulated in the new adherens junctions during the new border formation. 62

3.6.3 Myosin enrichment in vertical junctions is delayed in X-330 mutant 68

3.7 Other phenotypes in X-330 mutant 70

3.7.1 Ventral furrow could not form normally in X-330 mutant 70

3.7.2 Dorsal-Ventral polarity is abnormal in X-330 mutant 71

3.7.3 Mesoderm patterning is normal in X-330 mutant. 72 


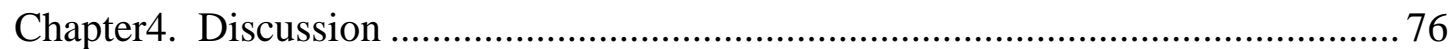

4.1 Different functions of E-cadherin in Drosophila embryogenesis ..................... 76

$4.2 \mathrm{~N}$-glycosylation of E-cadherin affects adherens junctions ............................ 77

4.3 E-cadherin accumulation is not the cause of new contacts formation .............. 78

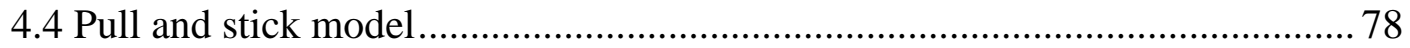

4.5 Membrane proteins are affected differently by $\mathrm{N}$-glycosylation defect ........... 80

4.6 Some glycoproteins, which are essential for ventral furrow formation, are

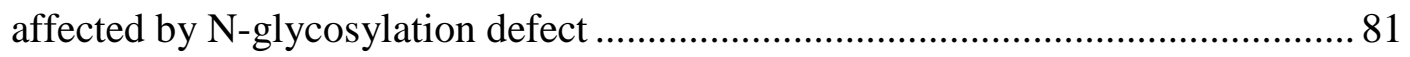

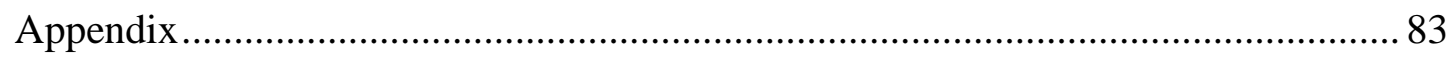

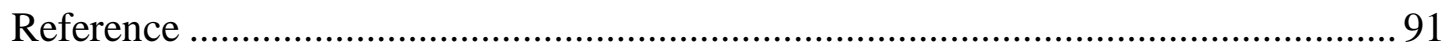

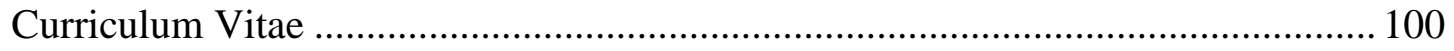

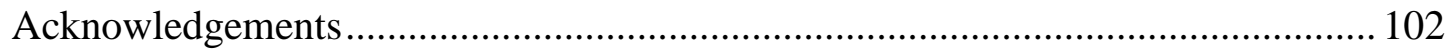




\section{Summary}

Three consecutive glucosylations are the last steps in formation of the dolichol-PPglycans before the glycans are transferred to nascent proteins in the ER. These three glucosyl residues are assumed to function in protein folding and ER quality control since they are consecutively cleaved to allow folding before the mono-glucosylglycan is recognized by the calreticulin/calnexin system. Finally, all glucoses are clipped off before ER exit. In my studies, the function of these glucosylation enzymes (Alg5/wol, Alg6/gny and Alg8/X-330) has been analyzed in the movement and morphogenesis of gastrulation and in Drosophila embryonic development. I have focused on their function in cell intercalation and found the expression of the integral membrane protein E-Cadherin strongly reduced and partially glycosylated in the mutants. Consistently, reduced expression of E-cadherin induced by RNAi leads to a comparable phenotype, which indicates that E-cadherin is a relevant down stream target of the X-330 mutant for the cell intercalation defect. To study the mechanism of new border formation in cell intercalation, I have observed the new borders extended via pulsed manner with E-cadherin accumulated soon after. Ecadherin intensity and the length of new borders are anticorrelated. We propose that E-cadherin could not provide the force for new border extension, but functions to stabilize the extended borders. 


\section{Chapter 1. Introduction}

\subsection{Cell intercalation during germ band extension in Drosophila}

In embryonic development of multicellular animals, cell intercalation is a kind of movement to change the dimensions of cell sheets, including radial intercalation and mediolateral intercalation. Radial intercalation begins in the midblastula stage and through gastrulation. It occurs in several cell layers. Inner cells move outwards (radially) and intercalate into more superficial cells. It contributes to epiboly thinning and blastoderm spreading in zebrafish and Xenopus (Solnica-Krezel, 2006; Warga and Kimmel, 1990). Mediolateral intercalation occurs in a single cell layer in gastrulation stage. The polarized movement of cells is perpendicular to the direction of elongation of cell sheets (Fig.1). In many vertebrates, cell intercalation shapes the body axis by convergent extension, like in Xenopus and zebrafish (Keller et al., 2000; Solnica-Krezel, 2005; Wallingford et al., 2002). It also drives epithelial tissue elongating in Drosophila germ band (Irvine and Wieschaus, 1994), the ascidian notochord (Munro and Odell, 2002), the chick primitive streak and organ systems like the gut, lung, spinal cord and inner ear (Hardin, 1989; Iwaki et al., 2001; Ribeiro et al., 2004; Wang et al., 2006).

Comparing germ band extension in Drosophila and convergent extension in Xenopus and zebrafish, first difference is that the former one is within epithelium, while the latter one is in mesenchyme (Keller, 1980; Warga and Kimmel, 1990). Second difference is that convergent extension is a very dynamic process, cells have protrusive activity and the attachments are resolved and re-established very rapidly. However, in Drosophila germ band extension, cells are tightly packed, the integrity of epithelium is fully maintained (Hammerschmidt and Wedlich, 2008). Third difference is that radial intercalation can also contribute to convergent extension, whereas germ band extension only includes mediolateral intercalation. 


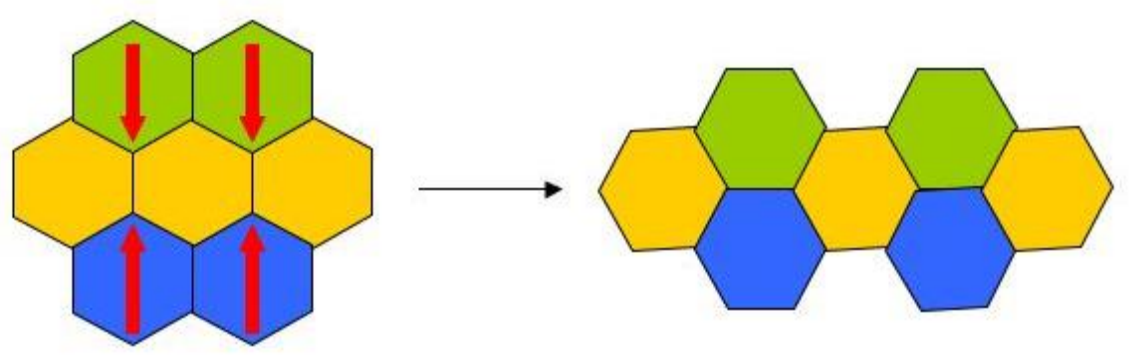

Figure 1. Model of mediolateral cell intercalation. During cell intercalation, several rows of cells change their relative positions and neighbors by polarized movement (red arrows). The cell sheet is prolonged along the axis perpendicular to the direction of cell movement.

\subsubsection{Drosophila germ band extension}

Gastrulation begins three hours after fertilization, which is a universal and important stage in Drosophila embryo development. This stage only lasts for half an hour. However, it includes several morphogenetic events: ventral furrow formation, cephalic furrow formation, germ band extension, midgut invaginations and dorsal folds formation (Fig.2a, b). At first, ventral cells (presumptive mesoderm) invaginate inside and form two germ layers (ectoderm and mesoderm), which is driven by cell shape changes. Between germ band and head, a line of cells get shorter than its neighbor cells and form the so-called cephalic furrow (Fig.2a). In germ band extension, directed cell intercalation leads to narrowing in dorsal-ventral (DV) axis and elongation in anterior-posterior (AP) axis (Hammerschmidt and Wedlich, 2008; Irvine and Wieschaus, 1994; Leptin, 1995; Zallen and Blankenship, 2008).

The process of germ band extension begins shortly after ventral furrow formation. Most part of the extension finishes in the beginning 30 minutes, while the remaining part finishes in the following 70 minutes. This movement includes ectoderm in germ band region and the underlying mesoderm. Ventral germ band extends around the posterior end of the embryo, folding over onto the dorsal side of the embryo (Fig.2). Posterior end folds inward and germ cells move into the midgut. Germ band extension continues until posterior end moves to approximately the cephalic furrow position (Leptin, 1995). 


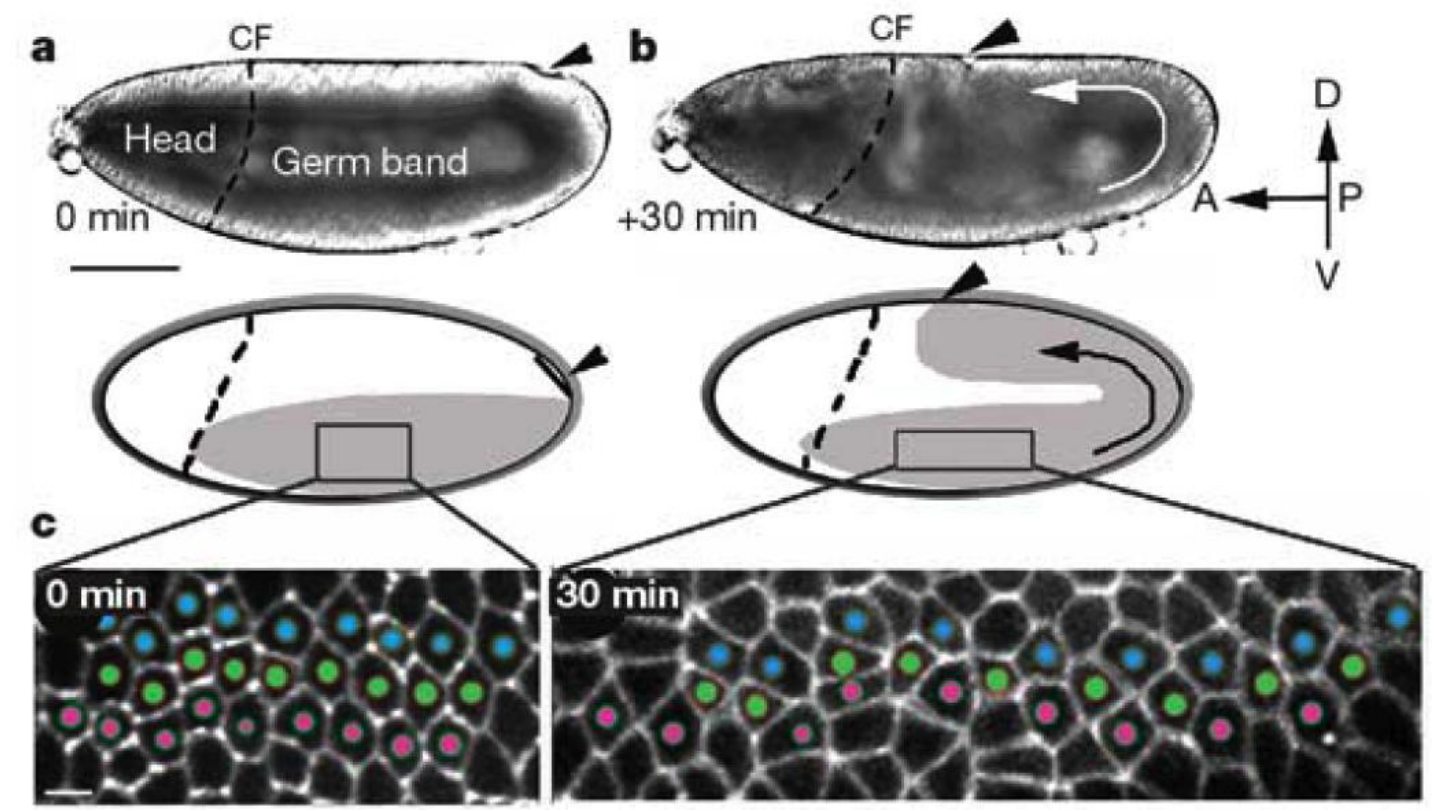

Figure 2. Schematic model of Drosophila germ band extension. A-B. Beginning of Drosophila germ band extension (a) and 30min later (b). CF is cephalic furrow. Arrowhead marks the frontier of the extended germ band. Schematic model of germ band extension is shown below the DIC images. The germ band region (grey part) folds dorsally (arrow) upon cell intercalation. C. Intercalation of germ band cells. Three rows of germ band cells are marked with different colors. They are intercalated in 30 minutes during germ band extension. (Bertet et al., 2004)

\subsubsection{Mechanism involved in cell intercalation}

Which cellular behaviors are involved in germ band extension? Several cell behaviors have been discussed. Cell intercalation is already universally accepted as the driving force for germ band extension. By multiple individual cells intercalating mediolaterally, the AP axis elongates for more than 2 folds. The width along the DV axis narrows (Fig.2) (Bertet et al., 2004; Irvine and Wieschaus, 1994; Zallen and Wieschaus, 2004). Another contributory factor is the oriented cell division, which is also dependent on the planar cell polarity (da Silva and Vincent, 2007). Shortly after the beginning of germ band extension, mitoses are oriented along the AP axis in the posterior region of the germ band. Inhibition of mitoses induces the reduction of germ band extension. In addition, cell shape change contributes about one-third of the total germ band extension in the first 30 minutes (Blanchard et al., 2009; Butler et al., 2009). In AP segmentation mutants, cell intercalation is either reduced (eve 
and $\mathrm{kr}$ mutants) or abolished ( $\mathrm{kni} \mathrm{hb}$ ), while cell shape change is increased. It is proposed that cell shape change is driven by some external force dependent on DV patterning, because it is decreased in the twist mutant. Interestingly, cell intercalation is also decreased about $30 \%$ in twist mutant. It suggests cell intercalation is also related with the external force. Cell intercalation could release some stress of the external force. In AP-patterning mutant, the stress could not be released and the cell shape change is increased (Butler et al., 2009).

\subsubsection{AP patterning affects cell intercalation}

It is found that reducing AP segmentation affects germ band extension and cell intercalation, while DV patterning is not required for cell intercalation. In Bicoid Nanos Torso-like (BNT) mutant, AP patterning is disrupted. Germ band cells have no intercalation behavior. Similar phenotype is observed in knirps, Krüppel or evenskipped mutant (Irvine and Wieschaus, 1994). In the dorsalized or lateralized embryos, cell intercalation in epithelium is observed. However, in ventralized embryos, which make only mesoderm, the germ band extension fails. It indicates that the rearrangement of mesodermal cells is caused by attaching to ectodermal cells during germ band extension, instead of active intercalation (Lohs-Schardin et al., 1979; Roth et al., 1991; Schupbach, 1987). In addition, in the twist and snail mutant embryos, which are lack of mesoderm, the germ band extension in the ectoderm is normal (Leptin and Grunewald, 1990; Simpson, 1983).

\subsubsection{Planar cell polarity is involved in the cell intercalation}

Planar cell polarity is found during germ band extension in response to the striped patterns of the gene expression (Zallen and Wieschaus, 2004). It is marked by planar polarized proteins, which function in adherens junctions and cytoskeleton. Ecadherin and its associated proteins Armadillo and Bazooka are more localized in horizontal cell borders, while actin-myosin network is more enriched in vertical cell borders (Fig.3). F-actin represents the first break of planar symmetry from stage6 (Blankenship et al., 2006). Planar cell polarity is only limited to the germ band region and appears shortly before germ band extension. Normal AP patterning is required for planar cell polarity (Zallen and Blankenship, 2008). 

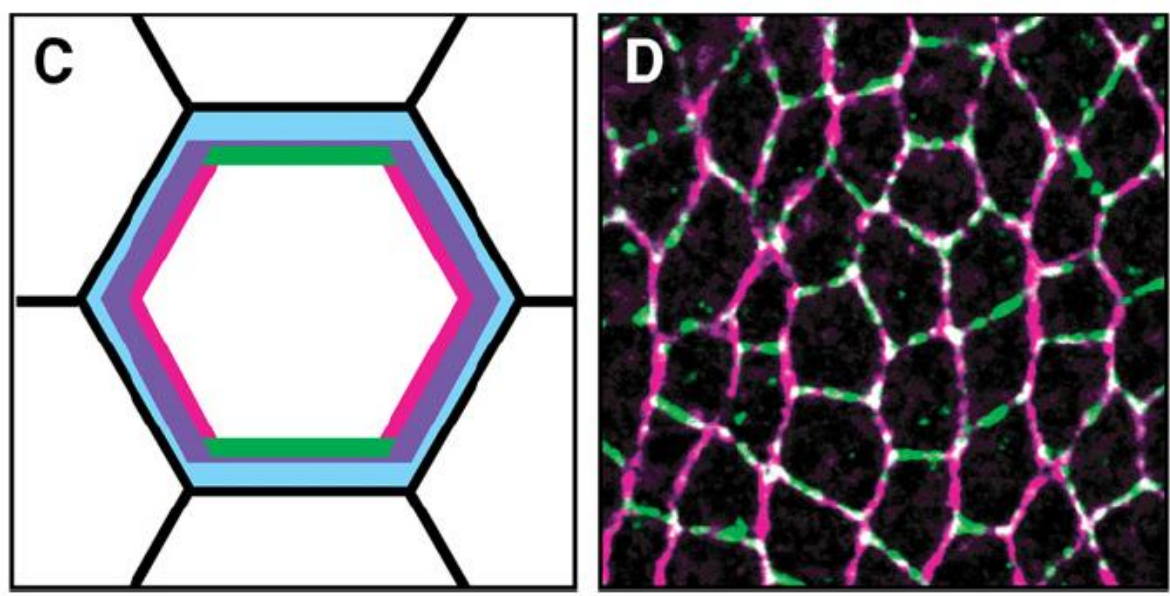

Figure 3. Planar cell polarity in germ band extension. C. Planar cell polarity is showed in the central cell. F-actin is the first symmetry-breaking marker (purple) at the vertical borders. Bazooka (green) and myosinII (red) are accumulated in the complementary domains. By the onset of intercalation, E-cadherin and Armadillo (blue) are enriched in horizontal cell borders. D. Confocal image of germ band cells. MyosinII (red) is enriched in the vertical borders, whereas Bazooka (green) is more localized in the horizontal borders (Zallen and Blankenship, 2008).

\subsubsection{Cell intercalation depends on myosin-actin network}

In either myosin inhibitor (Y-27632) injected embryos or myosin heavy chain (zip) mutants, cell intercalation is severely affected, which suggests that myosin is required for cell intercalation (Bertet et al., 2004). However, the junctional myosinII contributes no constriction force. It is the medial myosinII flow generates the polarized contractile force for vertical cell border shrinkage, which is oriented by Ecadherin planar polarity (Rauzi et al., 2010).

\subsubsection{Adherens junctions and the new border formation}

It is well known that the shrinkage of old vertical cell borders is caused by myosinactin network. However, how does new horizontal cell borders form is still unclear. One possibility is that the increased adherens junctions at the new borders could facilitate the formation of the new borders. Our results give some clues for answering this question. 


\subsection{E-cadherin and its post-translational modification}

\subsubsection{E-cadherin and adherens junctions}

E-cadherin is a conserved protein in multicellular animals, which functions in the cell-cell adhesion and communication (Knust and Bossinger, 2002; Lecuit and Wieschaus, 2002). Shotgun gene encodes E-cadherin protein in Drosophila. Drosophila E-cadherin protein comprises a single-transmembrane domain, 6 repeated domains (EC0 to EC5) (Fig.4). It is predicted to be cleaved between the EC0 domain and the EC1 domain. Therefore, its mature form should contain no EC0 domain. Its 150kDa band in SDS gel was shown glycosylated (Oda et al., 1994; Tepass et al., 1996).

By binding of E-cadherin extracellular domains with adjacent cells and forming homophilic complexes in a calcium-dependent manner, E-cadherin organizes the adhesion junctions, which play an important role in epithelial cell formation and cell polarity. Intracellular part of E-cadherin associates with actin cytoskeleton via catenins. $\beta$-catenin and $\gamma$-catenin bind directly to E-cadherin cytoplasmic tail in a mutually exclusive manner. They recruit $\alpha$-catenin, which links actin cytoskeleton. Although actin is not required in the binding of extracellular part of E-cadherin, $\alpha$ catenin and actin provide strength to adherens junctions by holding together the clustered E-cadherin at adherens junctional sites (Liwosz et al., 2006).

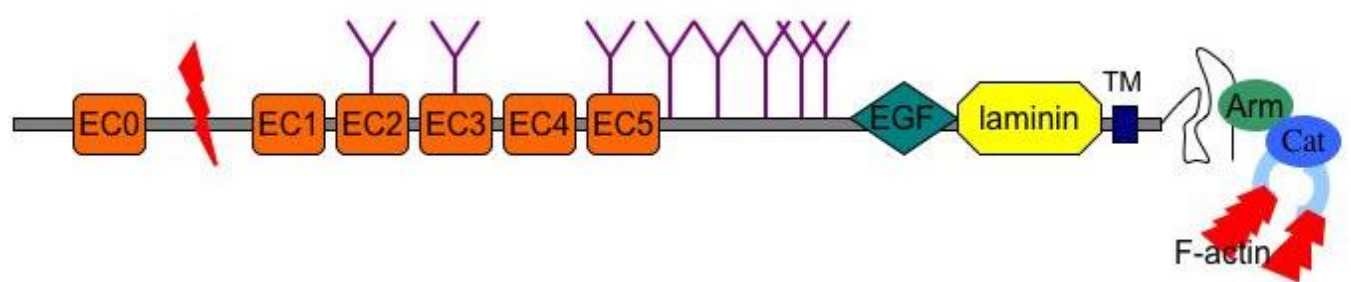

Figure 4. Schematic model of Drosophila E-cadherin and its associated proteins. In extracellular part, Drosophila E-cadherin has six cadherin-specific repeats (EC0-EC5). It is predicted that EC0 is cleaved off during maturation. In addition, it has one epidermal growth factor-like domain (EGF) and a lamininA globular repeat (laminin). Eight predicted Nglycosylation sites are marked (purple lines). It has a single transmembrane domain (blue bar). 
Drosophila E-cadherin intracellular part has high similarity with other vertebrate E-cadherin. Ecadherin interacts with F-actin via Armadillo and $\alpha$-Catenin.

\subsubsection{Post-translational modification of E-cadherin}

Post-translational modification of E-cadherin includes phosphorylation, Oglycosylation and $\mathrm{N}$-glycosylation. Casein kinaseII phosphorylates the cytosolic tail of E-cadherin and enhances its binding with $\beta$-catenin. O-glycosylation of Ecadherin occurs in ER stress response and prevents E-cadherin to transfer to the cell membrane. E-cadherin also has several N-glycosylation sites: mouse E-cadherin has three (one in EC4, two in EC5). Human and canine have four sites (two in EC4, two in EC5). Drosophila E-cadherin is predicted to have eight sites (Fig. 4) by NetNGlyc 1.0 server (http://www.cbs.dtu.dk/services/NetNGlyc/). Since N-glycans contribute to $20 \%$ of human E-cadherin total mass, it should have some important roles for regulation of adherens junctions. Some study has been carried out in this area. Proper $\mathrm{N}$-glycosylation is required for E-cadherin folding, trafficking, expression and stability of adherens junctions. Removal of N-glycan at Asn633 dramatically affects E-cadherin stability. N-glycan absence at Asn554 and Asn566 leads to failure of cell cycle arrest in G1 phase in human cells (Pinho et al., 2011; Zhao et al., 2008a; Zhao et al., 2008b; Zhou et al., 2008). Extensively modified with N-glycans makes E-cadherin form dynamic but weak adherens junctions, while diminish of $\mathrm{N}$ glycosylation promotes the formation of the stable adherens junctions. It is proposed that $\mathrm{N}$-glycosylation state and intracellular adhesion has inverse correlation (Liwosz et al., 2006; Vagin et al., 2008).

\subsection{ER N-glycosylation}

\subsubsection{N-glycosylated protein}

More than half of all eukaryotic protein species are glycosylated, within which $90 \%$ carry N-linked glycans (Fig.5). The glycans help proteins folding, passing ER quality control, degradation and secretion. They also function as a "tag" for 
glycoproteins to interact with other lectins, glycosidases and glycosyltransferases. Nglycans modify proteins at asparagine residues in a sequence Asn-X-Ser/Thr, where $\mathrm{X}$ is any amino acid other than proline. $\mathrm{N}$-glycosylation could help protein to fold correctly, to increase the solubility, which inhibit protein aggregation. In addition, $\mathrm{N}$-glycans help protein secretion and affect intracellular signaling.

\subsubsection{ER N-glycosylation}

Glycans are synthesized in ER and Golgi apparatus. In ER, the glycans are added to the dolichol-pyrophosphate (lipid carrier) step by step. They form a mature sugar tree, which is later transferred to nascent peptides (Fig.5). After folding correctly, the glycoprotein is transferred to the Golgi apparatus, in which the $\mathrm{N}$-glycan is further modified. This pathway is conserved in eukaryotes (Helenius and Aebi, 2004).

The oligosaccharide unit is made of three glucoses, nine mannoses, and two Nacetylglucosamines (Glc3Man9GlcNAc2) (Fig.5). The beginning seven steps of Nglycosylation are on the cytosolic surface of ER (Fig.6). Afterwards, the lipid carrier flips into the luminal side of ER and goes on the linear stepwise biosynthetic pathway of the branched oligosaccharide. The last three steps are adding three glucose residues. The last glucose is needed for efficient recognition by the oligosaccaryltransferase (OST), which transfers the sugar tree to the nascent protein.

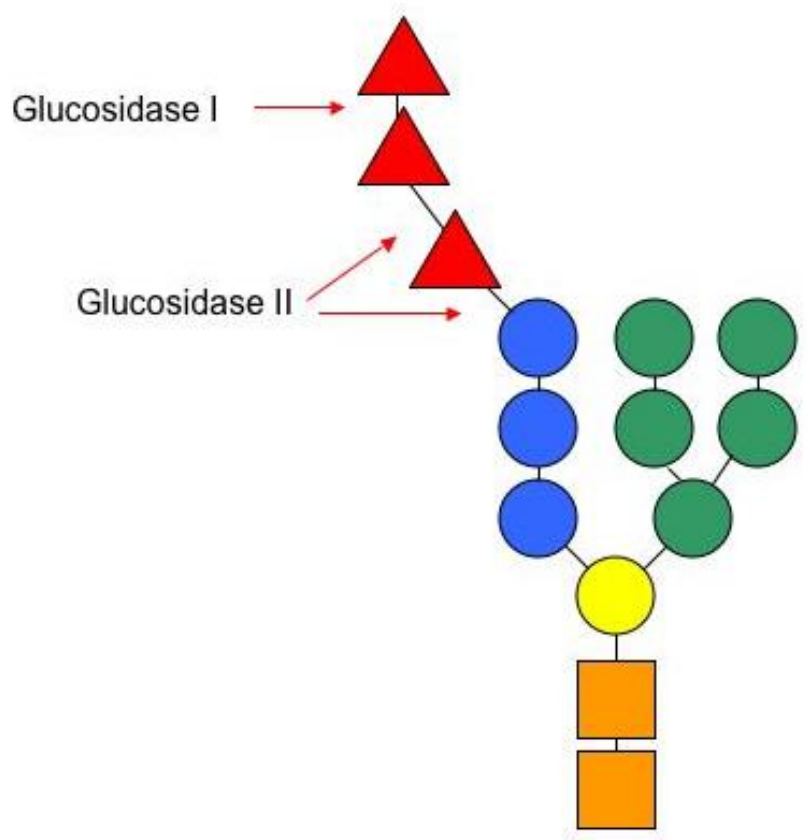


Figure 5. The N-linked core oligosaccharide. The core glycan has 14 saccharides: 3 glucoses (red triangles), 9 mannoses (circles), and $2 \mathrm{~N}$-acetylglucosamines (squares). The cleavage sites of Glucosidase I and II are indicated (red arrows) (Helenius and Aebi, 2004).

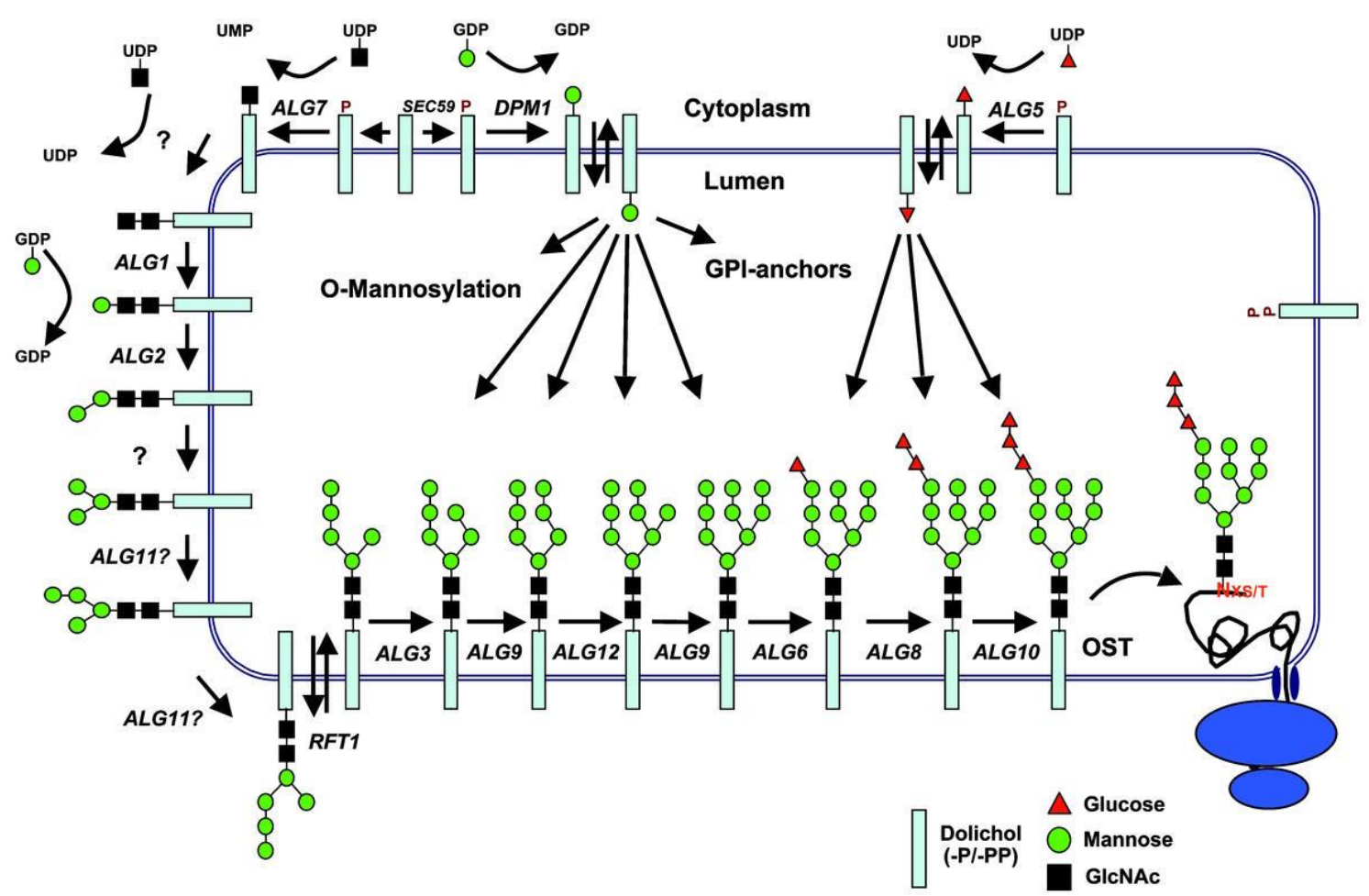

Figure 6. Synthesis of the N-linked core oligosaccharide in ER. This schematic model is in yeast and conserved in all the eukaryotic animals. The glycan synthesis starts from GlcNAc-1phosphate transferred to dolichol-pyrophosphate in cytoplasmic side, followed by another GlcNAc and five mannose residues. Then the sugar tree is flipped into the lumen side of ER and added three more mannoses and the tip three glucoses. Finally, the finished oligosaccharide is transferred to the nascent peptide (Helenius and Aebi, 2004).

\subsubsection{Protein folding and ER quality control}

Folding starts from protein's synthesis process and continues after its dissociation from the ribosome. Most of the proteins, which are synthesized in ER, need disulfide bonds for folding. Correct folding helps proteins pass the ER quality control.

When a core glycan is added to the protein, the glucosidase I and II removes the first and the second glucose separately (Fig.7). The monoglucosylated ligand binds the Calnexin (a transmembrane protein) or Calreticulin (a luminal protein). Calnexin and Calreticulin are molecular chaperons, which function in preventing aggregation of 
proteins, exporting of the incompletely folded proteins and protecting the premature proteins to be degraded. They exposed proteins to Erp57, which helps them to form a proper disulfide bond. Proteins are released from the cycle when Glucosidase II removes the last remaining glucose. Once the protein is folded completely, it would be exported out of ER and transferred to the Golgi apparatus. Otherwise, it would be recognized and reglucosylated by UDP-Glc: glycoprotein glucosyltransferase (GT), which functions as a folding sensor and sends the incompletely folded proteins back to the Calnexin/Calreticulin cycle. This cycle is so-called quality control. If the cycle is broken down, the protein-folding rate is increased, but the folding efficiency is decreased and the incomplete folded protein would be exported out of ER.

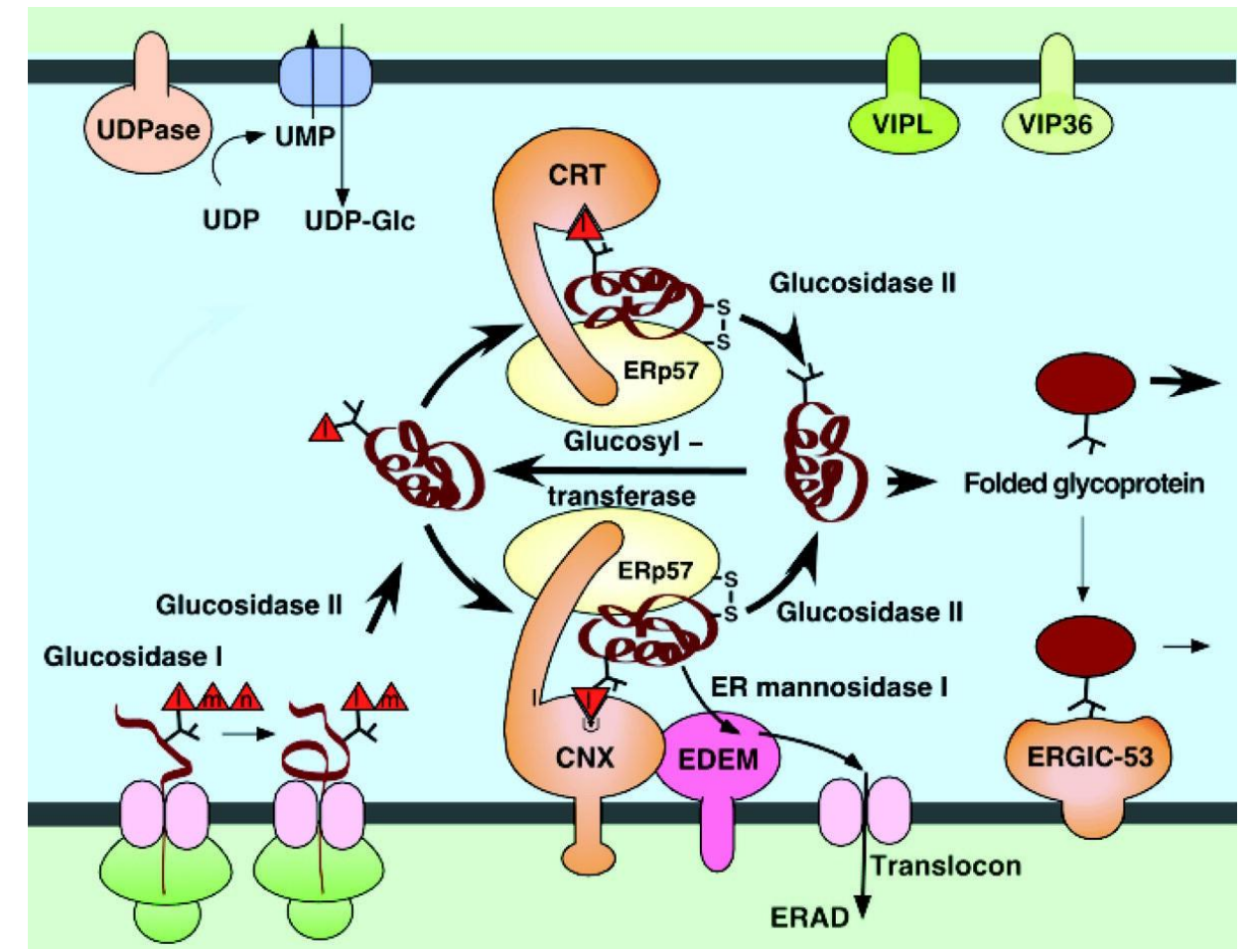

Figure 7. The calnexin/calreticulin cycle. The glucosidase I and II removes the first and the second glucose separately. The monoglucosylated ligand binds the Calnexin or Calreticulin, which exposes proteins to Erp57 and help them to form a proper disulfide bond. Proteins are released from the cycle and transferred to Golgi when Glucosidase II removes the last remaining glucose. If the protein fails to pass quality control, it would be reglucosylated and refolded again. After certain time remaining in the cycle, misfolded or unassembled proteins would be sent to ER-associated protein degradation (ERAD). (Helenius and Aebi, 2004) 
If glycoproteins fail to fold or oligomerize, they would retain in ER and eventually be degraded, namely ER-associated degradation (ERAD). It contains three steps: recognition of misfolded protein, transferring to cytoplasm and ubiquitin-dependent degradation by the proteasome. ER may use time length to control the ERAD and give chances to new proteins to refold and reassemble before degradation. The timer of ERAD is linked with trimming of mannose. Once the mannoses in B and C branches are trimmed, the substrates are more likely to go to ERAD instead of being interacted with GT and glucosidase II and entering calnexin/calreticulin circle.

\subsection{ER N-glycosylation and embryo development}

\subsubsection{Wollknäuel is required for embryo patterning and cuticle differentiation}

Wollknäuel (Wol) is an UDP-glucose: dolichol-phosphate glucosyltransferase in Drosophila, which is the homolog of Alg5 in yeast. Its mutations (2L-284 and 2L267) in germline clones cause caudal protein reduction, posterior segmentation phenotypes, reduced Dpp signaling, impaired mesoderm invagination and germ band elongation defect in gastrulation stage of Drosophila embryos. The unfolded protein response is triggered in wol mutant embryos, which may cause the attenuation of protein translation (Haecker et al., 2008)

Garnysstan (Gny) is the homologue of Alg6, which functions in a common pathway with wol. The zygotic mutant of wol and gny could produce normally hatched larvae and wild-type-like cuticle. They eventually die after one moult without any obvious phenotype. In maternal germline clone of wol mutant and gny mutant, cuticle formation has a defect. It is caused by affecting glucosylation and protein amounts of cuticle-organizing factor knickkopf, without affecting its localization. In wol mutants, transcriptional factor's mRNAs are down-regulated. Glycosylation of the total protein extracts is reduced and glucans contain less glucose in wol mutants (Shaik et al., 2011). 


\subsubsection{Congenital disorder of glycosylation (CDG)}

N-glycosylation is very essential for embryonic development. The completely absence of N-glycosylation leads to embryonic lethal (Ioffe and Stanley, 1994). CDG is a group of disorders of abnormal glycosylation. Glycoproteins are required for normal growth and basic functions of different tissues and organs. Defect of one enzyme may cause the whole glycosylation malfunction. Since hundreds of enzymes are involved in the glycosylation process and glycans are added to thousands of proteins, it is not easy to make the CDG mechanism clear. Most disorders show in early development stage and most types are only described in a few cases. Therefore, understanding of them is limited. It is believed that a lot of patients are underdiagnosed, because their symptoms resemble other genetic disorders.

19 types of CDG are found with different malfunction enzymes. Most of them are involved in $\mathrm{N}$-glycosylation. Based on whether the mutant gene functions before glycan transfers to protein or after, CDG are subdivided to type I and type II. For example, CDG-Ih is caused by ALG8 mutation. Its key features are hepatomegaly, protein-losing enteropathy, renal failure, hypoalbuminemia, edema and ascites. CDG-Ic is caused by Alg6 mutation. Its key features are moderate developmental delay, hypotonia, esotropia and epilepsy (Haeuptle and Hennet, 2009; Jaeken, 2010; Theodore and Morava, 2011) 


\section{Chapter2. Methods and Materials}

\subsection{Genetic methods}

\subsubsection{Fly stocks}

Most fly stocks were obtained from the Bloomington Drosophila Stock Center at Indiana University (http://flystocks.bio.indiana.edu/) unless otherwise mentioned. UAS lines were expressed using the Gal4 system (Brand and Perrimon, 1993).

\begin{tabular}{|c|c|}
\hline Name & Reference \\
\hline Oregon-R & Wild type lab stock \\
\hline X-330, Frt, Flp/FM7, B & from Vogt EMS collection \\
\hline $2 \mathrm{~L}-284\left(\mathrm{Wol}^{1}\right) / \mathrm{CyO}$ & \multirow{4}{*}{ from Luschnig lab } \\
\hline $2 \mathrm{~L}-267\left(\mathrm{Wol}^{2}\right) / \mathrm{CyO}$ & \\
\hline $\mathrm{Gny}^{\mathrm{f} 04215} / \mathrm{CyO}$ & \\
\hline $\mathrm{Gny}^{\mathrm{f} 04215}, \mathrm{Wol}^{1} / \mathrm{CyO}$ & \\
\hline Cad::GFP ${ }^{\text {ubiquitin }}$ & (Oda and Tsukita, 2001) \\
\hline Cad::GFP ${ }^{\text {cadherin }}$ & from Luschnig lab \\
\hline Cad::Cherry ${ }^{\text {USP/Cyo }}$ & from our lab \\
\hline Spaghetti squash (Sqh)-mCherry & (Martin et al., 2009) \\
\hline 117GFP & GFP exon trap in CG8668 \\
\hline Flp;Ovo2L, Frt [2L]/If/Cyo, hishid & from Luschnig lab \\
\hline OvoX, Frt $[18 \mathrm{E}] / \mathrm{C}(1) / \mathrm{Y}$ & (Chou and Perrimon, 1996) \\
\hline RtulGFP/Cyo; Dr/TM3 & From Bloomington \\
\hline Myo-cherry,117GFP/Cyo & \multirow{6}{*}{ Made by myself } \\
\hline X-330/FM7; If/Cyo & \\
\hline $\mathrm{X}-330 / \mathrm{FM} 7 ; \mathrm{Dr} / \mathrm{TM} 3$ & \\
\hline $\mathrm{X}-330 / \mathrm{FM} 7$; moesin/Cyo & \\
\hline X-330/FM7; mat67Gal4 & \\
\hline X-330/FM7; Cad::Cherry ${ }^{\text {UASp }} /$ Cyo & \\
\hline
\end{tabular}




\begin{tabular}{|l|l|}
\hline X-330/FM7; 117GFP & \multirow{2}{*}{ Made by myself } \\
\cline { 1 - 1 } X-330; CG4542/TM3 & \\
\cline { 1 - 1 } OvoX, Frt/C(1)/Y; 117GFP/Cyo & \\
\cline { 1 - 2 } OvoX, Frt/C(1)/Y; myo-cherry/Cyo & \\
\cline { 1 - 2 } OvoX, Frt/C(1)/Y; myo-cherry,117GFP/Cyo & \\
\cline { 1 - 2 } OvoX, Frt/C(1)/Y; mat67Gal4/Cyo & \\
\hline
\end{tabular}

\subsubsection{Gene mapping with Duplications and Deficiencies}

Duplications we used are the gain of a segment of the $\mathrm{X}$ chromosome linked to the $\mathrm{Y}$ chromosome. If it could rescue F1 males' lethality, the segmentation must cover the mutant gene (Cook et al.).

Deficiencies we used are the loss of a segment of the $\mathrm{X}$ chromosome. A deficiency line was crossed with the mutant. The F1 females' viability was tested. If they are lethal, this deficiency probably lost the region, which covers the mutant gene (Ryder et al., 2007; Ryder et al., 2004). Duplication and deficiency stocks we used are in the following table.

\begin{tabular}{|c|c|}
\hline Name & Region \\
\hline Dp5281 Df(1)dx81,w[*]/Dp(1;Y)dx[+]1/C(1)M5 & $5 \mathrm{~A} 8-9 ; 6 \mathrm{D} 8$ \\
\hline Dp5279 Df(1)JC70/Dp(1;Y)dx[+]5, y[+]/C(1)M5 & 4C11; 6D8 \\
\hline $\begin{array}{l}\text { Dp948 Df(1)ct-J4, In(1)dl-49, f[1]/C(1)DX, y[1] } \\
\text { w[1] f[1]; Dp(1;3)sn[13a1]/+ }\end{array}$ & 6C;7C9-D1 \\
\hline Df(1)ED6878 & $6 \mathrm{C} 12 ; 6 \mathrm{D} 8$ \\
\hline Df(1)BSC351 & 6C11;6D7 \\
\hline Df(1)BSC285 & $6 \mathrm{C} 11 ; 6 \mathrm{D} 3$ \\
\hline Df(1)BSC276 & $6 \mathrm{C} 12 ; 6 \mathrm{D} 4$ \\
\hline Df(1)BSC297 & 6C12;6D6 \\
\hline Df(1)BSC286 & $6 \mathrm{C} 12 ; 6 \mathrm{D} 3$ \\
\hline $\mathrm{Df}(1) \Delta 225$ & \multirow{4}{*}{$\begin{array}{l}\text { 6D } \\
\text { (from Yuh-Nung Jan's lab) }\end{array}$} \\
\hline $\mathrm{Df}(1) \Delta 291$ & \\
\hline $\operatorname{Df}(1) \Delta 96$ & \\
\hline $\operatorname{Df}(1) \Delta 17$ & \\
\hline
\end{tabular}




\subsubsection{Generation of transgenic flies}

\subsubsection{Transgenic construct making}

We ordered a Drosophila BAC clone from P[acman] (http://www.pacmanfly.org/). It was attB-P[acman]-CmR-BW with Drosophila genomic DNA region CH321-61D01, which is in X chromosome from 6614945 to 6722475 . The plasmid was extracted from the BAC clone. To get the $7.1 \mathrm{~kb}$ region covering CG4542 gene, restriction enzymes NotI and Acc65I were used to digest the plasmid (Fig.8). We got a $3 \mathrm{~kb}$ region and a $4.1 \mathrm{~kb}$ region, which were inserted into PattB vector separately (Spp Fig.1). Then the $3 \mathrm{~kb}$ insertion was cut out and ligated into the PattB plasmid, which included the $4.1 \mathrm{~kb}$ insertion. A pair of primers (YZ19 and YZ25 in appendix) was used to do cloning PCR to check the CG4542 gene. The final construct is PattBCG4542.

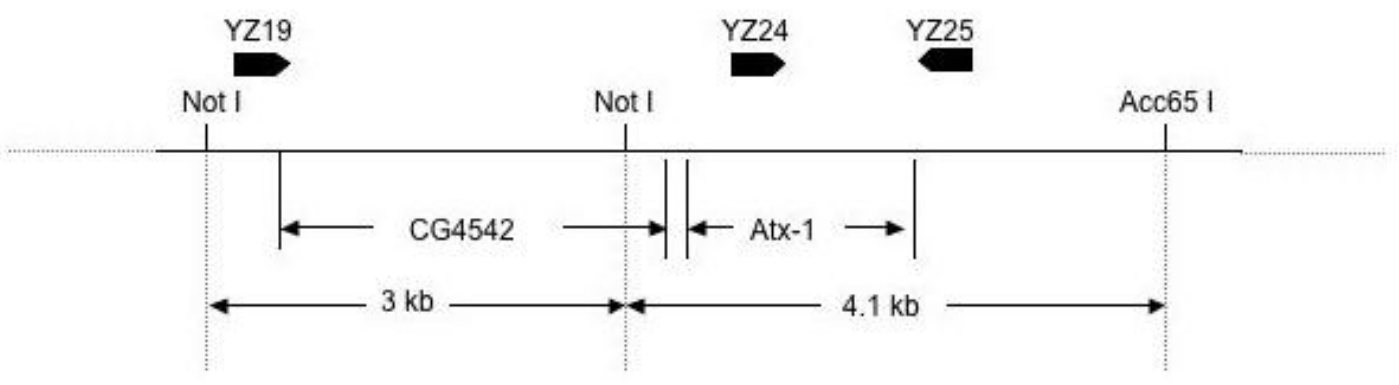

Figure 8. The schematic construction for making transgenic flies. $7.1 \mathrm{~kb}$ construct with CG4542 and Ataxin-1 inside is separated into $3 \mathrm{~kb}$ and $4.1 \mathrm{~kb}$ regions using restriction enzymes NotI and Acc65I. Primers used are YZ19, YZ24 and YZ25.

\subsubsection{Making transgenic flies}

AttB/phi-C31 system was used to make site-specific insertion (Bischof et al., 2007). The transgenic plasmid pAttB-CG4542 was injected into embryos with the target site and phi-C31 gene. Embryos of attP-zh86Fb/nos- $\varphi$-zh102D (integrated in 3rd chromosome) were used for injection. The embryos were collected from an applejuice plate, lined up on an agar plate and transferred to a glass slide. They were dried for $10 \mathrm{~min}$, covered by $10 \mathrm{~S}$ voltalef oil. $0.8 \mu \mathrm{g} / \mu \mathrm{l}$ DNA was injected with a glass needle into the posterior end of the embryos, in which germ cells still did not form. Then the injected embryos ( $\mathrm{G} 0$ generation) were incubated at room temperature with 
high moisture. In the next one or two days, the hatched larvae were transferred from the oil to a small food vial with yeast. G0 adult flies were crossed with TM3/TM6B balancer flies. They were flipped over to new vials after 3 to 4 days. The F1 flies were screened until we got the transgenic flies with red eyes. A stable stock was set up.

\subsubsection{FLP-FRT system and germline clones}

The genetic scheme for making germline clones is as follows: First, virgins of a balanced mutant line were crossed with males of the FRT, ovo/balancer. To induce germline clones in F1 females, 24 h-72 h larvae were heat-shocked twice: one heatshock per day and half an hour each time at $37^{\circ} \mathrm{C}$ in water bath. After 10 days, F1 flies came out. Females of FRT, mutation/FRT ovoD were collected and crossed with the wild type males. We set up a cage to collect embryos and test their phenotype. (Chou and Perrimon, 1992; Chou and Perrimon, 1996)

\subsubsection{Follicle cell clones}

Follicle cell clones were generated by the FLP/FRT technique (Chou et al., 1993; Chou and Perrimon, 1996). X-330-FRT/FM7 females were crossed with nlsGFPFRT males. Clones were induced by heat-shocking third instar larvae or adult females of X-330-FRT/nlsGFP-FRT at $37^{\circ} \mathrm{C}$ for 2 hours on two consecutive days. Females were dissected in PBT 1 day after the last heat-shock. Ovaries were fixed in $4 \%$ formaldehyde and stained.

\subsection{Molecular biology methods}

\subsubsection{PCR sequencing of the $3 \mathrm{kd}$ segment in the $X$ chromosome $6 \mathrm{D}$ region}

\subsubsection{DNA template making}

X-330/FM7 and X-220/FM7 flies were used to extract the genomic DNA as the PCR sequencing template. Several flies were ground in $200 \mu \mathrm{l}$ buffer A. The tube was 
spun for one minute. The supernatant was removed. The pellet was resuspended in $18 \mu \mathrm{l}$ buffer B (containing proteinase K). $2 \mu 1$ 10\% SDS was added inside. It was incubated for 2 hours at $37^{\circ} \mathrm{C}$. Afterwards, $3 \mu \mathrm{l} \mathrm{M} \mathrm{NaCl}$ was added. Then, the phenol/chloroform extraction was performed with 1:1 volume. The aqua phase was transferred to a new tube. $50 \mu \mathrm{EtOH}$ was added and incubated on ice for 20 minutes. The DNA was precipitated by centrifuging for $10 \mathrm{~min}$ at $14,000 \mathrm{rpm}$ and dissolved into $30 \mu \mathrm{l}$ TE buffer after washed with $70 \%$ EtOH. $1 \mu 1$ of the solution was used for PCR to check the DNA. We used the genomic DNA as the template to do PCR, getting CG4542 gene region (3 kD), which is used for sequencing PCR template. Primers are YZ19 and YZ25 (Appendix).

\section{Buffer A:}

$30 \mathrm{mM}$ Tris/HCl [pH 8], $100 \mathrm{mM} \mathrm{NaCl}, 19 \mathrm{mM}$ EDTA, 0.5\% Triton X-100

Buffer B:

$30 \mathrm{mM}$ Tris/HCl [pH 8], $100 \mathrm{mM} \mathrm{NaCl}, 19$ mM EDTA

\subsubsection{PCR sequencing:}

We used $3 \mathrm{~kb}$ PCR product as the template for sequencing. The reaction system is as follows:

\begin{tabular}{|l|l|}
\hline component & amount \\
\hline PCR -Product & $10-30 \mathrm{ng}$ \\
\hline Primer & 8 pmol \\
\hline Seq-Mix & $1.5 \mu \mathrm{l}$ \\
\hline Seq-Buffer & $1.5 \mu \mathrm{l}$ \\
\hline $\mathrm{H}_{2} \mathrm{O}$ & Add to $10 \mu \mathrm{l}$ \\
\hline
\end{tabular}

The program for Sequence-PCR is: 


\begin{tabular}{|l|l|}
\hline temperature & time \\
\hline $96^{\circ} \mathrm{C}$ & $10 \mathrm{sec}$ \\
\hline $50-55^{\circ} \mathrm{C}$ & $15 \mathrm{sec}$ \\
\hline $60^{\circ} \mathrm{C}$ & $4 \mathrm{~min}$ \\
\hline
\end{tabular}

For 25 Cycles

Primers for sequencing are YZ20, YZ21, YZ22, YZ23 and YZ26 (Appendix).

After PCR Sequencing, the product was purified. $1 \mu \mathrm{l}$ 125mM EDTA, $1 \mu \mathrm{l} 3 \mathrm{M} \mathrm{NaAc}$ and $50 \mu 1100 \% \mathrm{EtOH}$ were added to the Seq-PCR product. It was gently mixed and incubated at room temperature for $5 \mathrm{~min}$. Then, it was centrifuged at $14000 \mathrm{U} / \mathrm{min}$ for 15 minutes. The supernatant was removed. The pellet was washed with $70 \mu \mathrm{l}$ $70 \% \mathrm{EtOH}$ for another 5 minutes and dried for 2 minutes. $15 \mu \mathrm{l}$ Hidi was added. Then the following steps were done in cooperation with the sequencing service of the developmental biochemistry department, GZMB, University of Göttingen.

\subsection{Biochemistry methods}

\subsubsection{Antibody making}

\subsubsection{Expression construct making}

We picked two fragments of CG4542 gene to clone into the expression plasmid pGEX-60H (Spp.Fig.2). The two fragments were frg.1 (26-93aa) and frg.2 (231299aa) (Fig.14). They were amplified using PCR from the template plasmid PattBCG4542. Primers were designed with restriction enzyme sites. YZ27 and YZ29 were with NcoI restriction sites. YZ28 and YZ30 were with BglII restriction sites. The primers for cloning the frg. 1 are YZ27 and YZ28 (Appendix, underline marks the restriction enzyme sites). The primers for cloning the frg.2 are YZ29 and YZ30 (Appendix).

High fidelity PCR was used to get the two fragments. Restriction enzymes of NcoI and BgIII were used to digest the two fragments and the vector pGEX-60H 
separately. The two fragments were ligated into the pGEX-60H vector separately, getting the two expression vectors: CG4542 frg.1-pGEX-60H and CG4542 frg.2pGEX-60H. The two new constructs were transformed into E.coli DH-5 $\alpha$ to get target proteins.

\subsubsection{Determination the solubility of target proteins}

Transformed E.coli DH-5 $\alpha$ was inoculated into $10 \mathrm{ml} \mathrm{LB}$ and cultured overnight. 2.5 $\mathrm{ml}$ overnight cultures was inoculated into $50 \mathrm{ml}$ pre-warmed LB until OD600 $=0.5$ 0.7. $1 \mathrm{ml}$ was taken as non-induced sample for SDS-PAGE. IPTG was added into the system with the concentration of $1 \mathrm{mM}$. It was incubated for 4-5 hrs. $1 \mathrm{ml}$ was taken as induced sample for SDS-PAGE. For harvesting the cells, it was centrifuged $4000 \mathrm{~g}$ for $20 \mathrm{~min}$. The cell pellet was re-suspended in $5 \mathrm{ml}$ lysis buffer $(50 \mathrm{mM}$ $\mathrm{NaH} 2 \mathrm{PO} 4,300 \mathrm{mM} \mathrm{NaCl}, 10 \mathrm{mM}$ imidazole) for native purification. $1 \mathrm{mg} / \mathrm{ml}$ lysozyme was added into the suspension and it was incubated on ice for 30 minutes. Sonicate the suspension for 6 times, each time for 20 seconds at 200-300w, keeping the lysate on ice. The lysate was centrifuged at $10,000 \times \mathrm{g}$ at $4^{\circ} \mathrm{C}$ for 30 minutes. The supernatant was collected as extract A. The pellet was resuspended in $5 \mathrm{ml}$ lysis buffer and collected as extract B. SDS-PAGE was done for analysis of the four samples. If the target protein appeared in extract B instead of extract A, the protein is insoluble protein.

\subsubsection{Protein purification under denaturing conditions}

CG4542 protein fragments with His-tag were purified under denaturing conditions. The plasmids were transformed into E.coli BL21, which was incubated in $100 \mathrm{ml} \mathrm{LB}$ in $37^{\circ} \mathrm{C}$ on shaker overnight. In the next day, the culture was enlarged to $500 \mathrm{ml}$ plus Amp. The protein expression was induced by IPTG. After about 4 or 5 hours, the OD600 value reached 0.7 . The cells were collected by centrifugation (20 min, 4000g) and re-suspended in $25 \mathrm{ml}$ of lysis buffer. A drop of DNase was added. The cells were lysed by microfluidizer. It was centrifuged for $20 \mathrm{~min}$ at $4000 \mathrm{~g}$. The pellet was suspended thoroughly in $25 \mathrm{ml}$ buffer A. $3 \mathrm{ml} \mathrm{Ni}$ beads were equilibrated with buffer A. Carefully removed the supernatant. The solubilised pellet extract was added to the beads and incubated for 60 minutes at room temperature. It was gently mixed on a wheel. It was filled into a drop column. The flow through was collected and saved. 
The beads were washed with $3 \times 6 \mathrm{ml}$ buffer $\mathrm{C}$ and eluted with buffer $\mathrm{E}$. The elution was collected in different tubes. The protein would start to elute at 1-2 volumes and should be collected in total about 15 fractions. Amido Black staining was used on nitrocellulose to test the protein in fractions. The protein concentration was tested using NanoDrop.

Lysis buffer: $20 \mathrm{mM}$ Na-Phosphate $\mathrm{pH} 8,500 \mathrm{mM} \mathrm{NaCl}, 20 \mathrm{mM}$ imidazole

Buffer A: 0,1M Na-Phosphate, $10 \mathrm{mM}$ Tris pH $8(\mathrm{NaOH}), 6 \mathrm{M} \mathrm{GuHCl}$

Buffer C: $0.1 \mathrm{M}$ Na-Phosphate, $10 \mathrm{mM}$ Tris pH $6.3(\mathrm{HCl}), 8 \mathrm{M}$ urea

Buffer E: 0.1 M Na-Phosphate, $10 \mathrm{mM}$ Tris pH $4.5(\mathrm{HCl}), 8 \mathrm{M}$ urea

\subsubsection{Protein concentration}

To concentrate the protein, dialysis tube was filled with the protein solution and placed in a beaker, which contains water inside. For every 3 hours, the water was changed until the white cotton-like protein show up in the tube. The protein suspension was transferred into a $50 \mathrm{ml}$ tube and centrifuged (20 min, 8500prm). We carefully removed the supernatant and resolved the pellet in $500 \mu \mathrm{l}$ buffer E. Test the concentration by the Bradford method or running a SDS-PAGE gel.

\subsubsection{Immunization of animals and getting serum}

Highly concentrated proteins were sent to a company (Charles River) to inject into a rabbit and a guinea pig. After several weeks, we got the serum, which contains antibodies of the proteins.

\subsubsection{Western blot and N-Glycosidase treatment}

\subsubsection{Protein sample preparation}

Drosophila embryos (3-6 h) were collected on a mesh and treated with 50\% klorix for 1 minute. They were washed and dried on a tissue paper. The embryos were weighed or counted. They were ground in $2 \times$ laemmli buffer $(0,09 \mathrm{M}$ Tris- $\mathrm{HCl} \mathrm{pH}$ 6,8, 6\% SDS, 0,6\% bromophenol blue, 20\% glycerol, 6\% ß-mercaptoethanol) and boiled in $100^{\circ} \mathrm{C}$ or $65^{\circ} \mathrm{C}$ (for E-cadherin and Crumbs) for 10 minutes. The suspension was centrifuged for 1 minute before use. 


\subsubsection{SDS-PAGE}

The separating gel was prepared based on the protein size. For E-cadherin (150 kDa), $\alpha$-Catenin $(102 \mathrm{kDa})$ and Crumbs $(270 \mathrm{kDa})$, we used 6\% gel. For Armadillo (96kd$110 \mathrm{kd}$ ) and $\alpha$-Tubulin $(55 \mathrm{kd})$, we used $8 \%$ gel. The gel composition is as the following table.

\begin{tabular}{|l|l|l|l|l|}
\hline components & $6 \%$ & $8 \%$ & $10 \%$ & $12 \%$ \\
\hline water & $3 \mu \mathrm{l}$ & $2.75 \mu \mathrm{l}$ & $2.5 \mu \mathrm{l}$ & $2.25 \mu \mathrm{l}$ \\
\hline $1.5 \mathrm{M}$ Tris, PH 8.8, 0.4\% SDS & $1.25 \mu \mathrm{l}$ & $1.25 \mu \mathrm{l}$ & $1.25 \mu \mathrm{l}$ & $1.25 \mu \mathrm{l}$ \\
\hline PAA (40\%) & $0.75 \mu \mathrm{l}$ & $1 \mu \mathrm{l}$ & $1.25 \mu \mathrm{l}$ & $1.5 \mu \mathrm{l}$ \\
\hline TEMED & $3 \mu \mathrm{l}$ & $3 \mu \mathrm{l}$ & $3 \mu \mathrm{l}$ & $3 \mu \mathrm{l}$ \\
\hline APS (10\%) & $50 \mu \mathrm{l}$ & $50 \mu \mathrm{l}$ & $50 \mu \mathrm{l}$ & $50 \mu \mathrm{l}$ \\
\hline
\end{tabular}

The gel was overlaid by 2-Propanol during polymerization for 30 minutes. The stacking gel (921 $\mu \mathrm{l}$ water, $375 \mu \mathrm{l} 0.5 \mathrm{M}$ Tris $\mathrm{pH}$ 6.8, 0.4\% SDS, 187 $\mu 1$ 40\%PAA, $1.5 \mu 1$ TEMED, $15 \mu$ l APS) was added with the comb. It was waited for another 30 minutes to remove the comb.

Running buffer (150g Glycin, 10g SDS, 32.8g Tris base, add to 1liter water) was added to the gel. $12 \mathrm{~mA}$ was used to run the gel.

\subsubsection{Wet transfer to membranes}

Large proteins are more efficiently transferred by wet transfer.

The following stack was prepared:

- Three Whatman filter papers in cathode buffer

- Gel

- Filter (nitrocellulose or PDVF)

- Three Whatman filter papers in anode buffer

A Pasteur pipette was rolled on the stack back and forth to make sure that no air bubbles were enclosed. The stack was enclosed into the presoaked sponges and put into the cassette of the BIORAD apparatus, which filled with transfer buffer. The proteins were transferred at $110 \mathrm{~V}$ for 2 hours. The transfer-box was placed into an 
ice container to absorb the heat. A stir bar was used in the transfer-apparatus for better heat exchange.

Cathode buffer: 0.1 M Tris, 0.1 M Tricine, 0.1\% SDS, H2O

Anode buffer: $0.2 \mathrm{M}$ Tris, $500 \mathrm{~mL} \mathrm{H2O,} \mathrm{pH}$ to 8.9 with $\mathrm{HCl}$

Transfer buffer: $25 \mathrm{mM}$ Tris, $190 \mathrm{mM}$ glycine [pH 8.3]

\subsubsection{Antibodies binding and detection}

The membrane was transferred into blocking buffer (5\% milk powder in PBT) and shaken for more than 1 hour. Then, it was transferred to the primary antibody diluted in PBT and $0.5 \% \mathrm{BSA}$, incubated for $2 \mathrm{~h}$ at room temperature. It was rinsed 3 times with PBT and washed $4 \times 15$ min with PBT. Then membrane was transferred into the secondary antibody diluted in PBT and incubated for 1 hour. PBT was used to rinse and wash $4 \times 15$ min. $1 \mathrm{ml}$ solution A was mixed with $25 \mu 1$ solution B (ECL Plus Western Blotting Detection system) to incubate the filter for $1 \mathrm{~min}$. The membrane was wrapped in a foil. An X-ray film was exposed and developed.

The antibodies used are in the following table.

\begin{tabular}{|c|c|c|c|c|}
\hline name & type & concentration & source & reference \\
\hline DCAD1 & $\begin{array}{l}\text { E-cadherin } \\
\text { first } \\
\text { antibody }\end{array}$ & 1:200 in use & Rat & $\begin{array}{l}\text { from Dr. Tadashi } \\
\text { Uemura' s lab } \\
\text { (Oda et al., 1994; } \\
\text { Oda et al., 1993; } \\
\text { Uemura et al., } \\
\text { 1996) }\end{array}$ \\
\hline $\mathrm{Cq} 4$ & $\begin{array}{l}\text { Crumbs } \\
\text { first } \\
\text { antibody }\end{array}$ & $1: 500$ in use & mouse & (Tepass et al., 1990) \\
\hline Armadillo & $\begin{array}{l}\text { first } \\
\text { antibody }\end{array}$ & $1: 1000$ in use & mouse & $\begin{array}{l}\text { (Riggleman et al., } \\
\text { 1990) }\end{array}$ \\
\hline$\alpha$-Catenin & $\begin{array}{l}\text { first } \\
\text { antibody }\end{array}$ & $\begin{array}{l}\text { Serum 1:2000 } \\
\text { in use }\end{array}$ & rat & (Oda et al., 1993) \\
\hline$\alpha$-Tubulin & $\begin{array}{l}\text { first } \\
\text { antibody }\end{array}$ & $\begin{array}{l}3.6 \mathrm{mg} / \mathrm{ml} \\
1: 500000 \text { in use }\end{array}$ & mouse & $\begin{array}{l}\text { B-512 Sigma } \\
\text { T5168 }\end{array}$ \\
\hline
\end{tabular}


Second antibodies: Goat-a-rabbit-IgG-POD 1:10000 (pre-absorbed),

Goat-a-mouse-IgG-POD 1:10000 (pre-absorbed),

Goat-a-Rat-IgG-POD 1:10000 (pre-absorbed)

\subsubsection{Glycosidase treatment}

$\mathrm{N}-$ Glycosidase $\mathrm{F}$, also known as PNGase $\mathrm{F}$, is an amidase that cleaves between the innermost GlcNAc and asparagine residues of high mannose, hybrid, and complex oligosaccharides from N-linked glycoproteins (Fig.9) (Maley et al., 1989; Plummer and Tarentino, 1991).

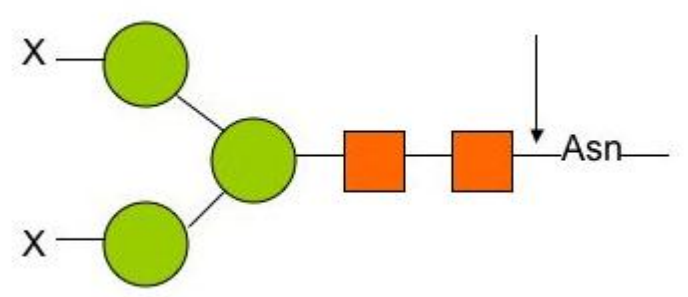

Figure 9. PNGase F could cleave between N-glycan and Asn

500 embryos (3-6h) were taken and treated with klorix for 1 minute. They were lysed and ground in $100 \mu 1$ lysis buffer in one eppendorf tube. Then, the tube was left on ice for 10 minutes and centrifuged for 10 minutes. The sample was separated into two tubes. One was treated with PNGase F, while another one was used as a control. $9 \mu 1$ lysed sample was mixed with $1 \mu 110 \times$ denaturing buffer and incubated in $60^{\circ} \mathrm{C}$ for 10 minutes. Then the reaction system was set up as the following table and incubated in $37^{\circ} \mathrm{C}$ for 1 hour. Western blot was used to compare the treated one and the control.

\begin{tabular}{|l|l|}
\hline components & Volume $(\mu \mathrm{l})$ \\
\hline Denatured sample & 10 \\
\hline $10 \times$ G7 reaction buffer & 2 \\
\hline $10 \%$ NP40 & 2 \\
\hline PNGase F & 2 \\
\hline $\mathrm{H}_{2} \mathrm{O}$ & 4 \\
\hline
\end{tabular}


Lysis buffer: 50mM Hepes-NaOH, pH7.5; 150mM NaCl; $1 \%(\mathrm{v} / \mathrm{v})$ Triton X-100; $10 \%$ (v/v) glycerol; $1.5 \mathrm{mM} \mathrm{MgCl}_{2} ; 2 \mathrm{mM}$ EGTA; $1 \mathrm{mM}$ phenylmethylsulfonyl fluoride, $10 \mu \mathrm{g} / \mathrm{ml}$ aprotinin

$10 \times$ denaturing buffer: $5 \%$ SDS; 0.4M DTT; Tris. $\mathrm{HCl}$ was added to adjust $\mathrm{pH}$

$10 \times \mathrm{G} 7$ reaction buffer: $50 \mathrm{mM}$ sodium phosphate, $\mathrm{pH} 7.5$

\subsubsection{EndoH treatment}

Endoglycosidase $\mathrm{H}$ is a recombinant glycosidase which cleaves within the chitobiose core of high mannose and some hybrid oligosaccharides from $\mathrm{N}$-linked glycoproteins (Fig.10) (Maley et al., 1989).

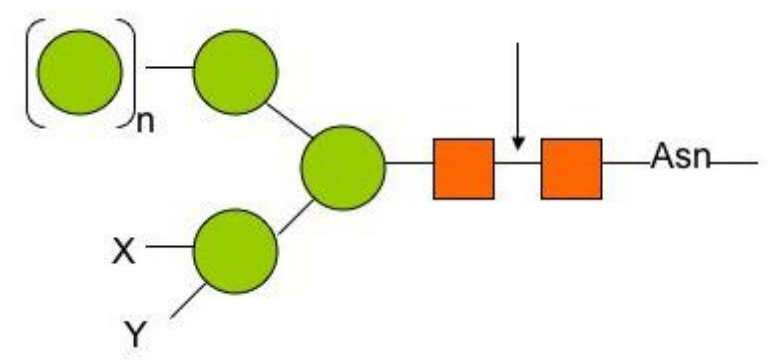

Figure 10. EndoH cleaves only high mannose structures and hybrid structure

200 embryos were collected and treated with klorix. They were lysed and ground in $50 \mu \mathrm{l}$ lysis buffer at $4^{\circ} \mathrm{C}$ for 10 minutes. It was centrifuged for 15 minutes. $36 \mu 1$ sample was mixed with $4 \mu 110 \times$ denaturing buffer and incubated in $60^{\circ} \mathrm{C}$ for 10 minutes. Some sample was taken as control. The reaction system was set up as the following table and incubated in $37^{\circ} \mathrm{C}$ for 1 hour.

\begin{tabular}{|l|l|}
\hline components & Volume $(\mu \mathrm{l})$ \\
\hline denatured sample & 10 \\
\hline $10 \times$ G5 reaction buffer & 2 \\
\hline Endo H & 3 \\
\hline $\mathrm{H}_{2} \mathrm{O}$ & 5 \\
\hline
\end{tabular}

10× G5 reaction buffer: 0.5M Sodium Citrate, $\mathrm{pH} 5.5$ 


\subsection{Immunohistochemistry methods}

\subsubsection{Embryo fixation and staining}

\subsubsection{Collecting embryos}

Embryos of the appropriate stage were collected on an apple juice plate. Klorix (100\%) was added to cover all the embryos, incubating 1-2 minutes. The klorix with the embryos was poured through a mesh. It was washed with water. The mesh with the embryos was left on a tissue to remove the remaining liquid.

\subsubsection{Formaldehyde fixation}

The embryos were transferred to a scintillation vial with $5 \mathrm{ml}$ heptane and $4.5 \mathrm{ml}$ PBS. $0.5 \mathrm{ml}$ formaldehyde (37\%) was added to fix the embryos for 20 minutes with constantly shaking. The lower layer was removed thoroughly. $5 \mathrm{ml}$ methanol was added inside, shaking vigorously for 30 seconds. After the popped embryos all sank on the bottom, they were transferred to an eppendorf tube. They were washed twice with methanol and stored at $-20^{\circ} \mathrm{C}$.

\subsubsection{Heat fixation}

A scintillation vial was filled with $3 \mathrm{ml}$ salt solution and heated in the microwave for about 10 seconds. The mesh with embryos was added into the boiling solution and incubated for 10 seconds. Then ice pieces and cold salt solution were quickly added inside to make embryos cool down. The mesh was removed. Embryos sank down. Salt solution was replaced by $5 \mathrm{ml}$ heptane and $5 \mathrm{ml}$ methane. The vial was shaken vigorously to make embryos pop out. Embryos were washed with methanol and stored at $-20^{\circ} \mathrm{C}$.

Salt solution: $0.4 \% \mathrm{NaCl}, 0.03 \%$ Triton $\mathrm{X}-100$

\subsubsection{Fixation for phalloidin staining}

Formaldehyde fixation was done without methanol. Embryos were collected in a mesh and dipped on a paper towel. They were transferred with a fine brush to a double sticky tape in a small petri dish, covering with PBS buffer. Embryos were 
released from the vitelline membrane with a sharp needle and collected into an eppendorf tube in PBT.

\subsubsection{Protein staining}

The fixed embryos were rinsed 3 times and washed 5 minutes in PBT. They were blocked with 5\% BSA in PBT for 1 hour. First antibody was diluted in PBT with $0.1 \% \mathrm{BSA}$, in which embryos were incubated for 2 hours at room temperature or in $4^{\circ} \mathrm{C}$ overnight. Afterwards, embryos were rinsed 3 times and washed $4 \times 15 \mathrm{~min}$ in PBT. Embryos were incubated for 2 hours in the diluted secondary antibody with $0.1 \%$ BSA. Then, they were rinsed 3 times and washed $4 \times 15$ min in PBT. They were stained with DAPI $(8 \mathrm{mg} / \mathrm{ml})$ for 2-3 minutes and washed in PBT for 5 minutes. Then, the embryos were lined up and mounted in Aqua-Poly/Mount.

\subsubsection{Microscopy and image acquisition}

We used Carl Zeiss Imaging System LSM 780 to take images of stained embryos. Softwares of ImageJ and Photoshop were used to arrange and regulate the images.

\subsection{In situ hybridization with alkaline phosphatase}

The embryos are collected and dechorionated with 50\% Clorox for 1.5 minutes. Then, they are fixed in the mix of $5 \mathrm{ml} 4 \%$ formaldehyde in PBS and $5 \mathrm{ml}$ heptanes for 30 min on the shaker. After fixation, they are stored in methanol at $-20^{\circ} \mathrm{C}$.

When doing the in situ hybridization, rinse once with fresh methanol and wash with $50 \%$ methanol/PBT for $5 \mathrm{~min}$. Rinse in PBT for 3 times and wash $2 \times 5$ min with PBT. Wash with 50\% hybridization solution (hyb sol) in PBT for $10 \mathrm{~min}$ at room temperature. Then wash with $100 \%$ hyb sol for $10 \mathrm{~min}$ at room temperature. Prehybridization with $100 \%$ hyb sol for $1 \mathrm{hr}$ at $55^{\circ} \mathrm{C}$ or higher temperature. Meanwhile, prepare the probe. Add $2 \mu 1$ dig-labeled probe and $1 \mu 1$ tRNA into $20 \mu 1$ water and boil for $5 \mathrm{~min}$ then chill on ice, then add $200 \mu \mathrm{l}$ ice-cold hyb sol. Incubate the embryos in the hyb sol with probe at selected temperature overnight. Rinse 3 times with pre-warned hyb sol and wash 3 times for $30 \mathrm{~min}$. Then rehydrate with 
series of pre-warmed hyb sol and PBT mixture: $80 \%, 60 \%, 40 \%$ and $20 \%$. Afterward, block for 30 min with 5\% BSA in PBT. Then incubate with Dig antibody at 1 to 1000 dilutions for $1 \mathrm{hr}$. Rinse 3 times and wash 4 times for 15 min with PBT. Wash 3 times for 5 min with AP buffer. Incubate the embryos in $1 \mathrm{ml} \mathrm{AP}$ buffer with $4.5 \mu 1 \mathrm{NBT}$ and $3.5 \mu \mathrm{l}$ BCIP until the signal becomes visible. Terminate the reaction with PBT and dehydrate with ethanol and incubate in $100 \%$ ethanol for 20 min to remove the non-specific staining. Then rehydrate with series of ethanol/PBT mixture with gradually increased concentration of PBT.

The RNA probe used in this study is Dig $\alpha$ Rho, which is labeled with digoxigeninUTP (DIG-UTP).

Hybridisation solution: $50 \%$ formamide, $5 \times \mathrm{SSC}$, $50 \mu \mathrm{l}$ heparin, $100 \mu \mathrm{g} / \mathrm{ml}$ tRNA NBT/BCIP: 75 mg/ml Nitrobluetetrazolium, 50 mg/ml BCIP (X-phosphate, Sigma) AP buffer: $100 \mathrm{mM} \mathrm{NaCl}, 50 \mathrm{mM} \mathrm{MgCl} 2,100 \mathrm{mM}$ Tris $\mathrm{pH}$ 9.5, 0.2 \% Tween 20

\subsection{RNAi}

\subsubsection{Making Template}

The DNA was amplified by PCR to make the template for dsRNA. The components of the reaction system are listed in the following table:

\begin{tabular}{|l|l|}
\hline Ingredient & Volume $(\mu \mathrm{l})$ \\
\hline up stream primer $(10 \mathrm{mM})$ & 4 \\
\hline down stream primer $(10 \mathrm{mM})$ & 4 \\
\hline dNTPs $(10 \mathrm{mM})$ & 2 \\
\hline $10 x B u f f e r\left(-\mathrm{MgCl}_{2}\right)$ & 10 \\
\hline Template (genomic DNA 1ug/ul) & 1 \\
\hline $\mathrm{H}_{2} \mathrm{O}$ & 69 \\
\hline $\mathrm{Taq}_{\text {polymerase }}$ & 2 \\
\hline $\mathrm{MgCl}_{2}(25 \mathrm{mM})$ & 8 \\
\hline total & 100 \\
\hline
\end{tabular}


The reaction condition is as following table.

\begin{tabular}{|c|c|c|}
\hline temperature & Time & circle \\
\hline $95^{\circ} \mathrm{C}$ & $2 \min$ & $1 \times$ \\
\hline $95^{\circ} \mathrm{C}$ & $30 \mathrm{sec}$ & \multirow{3}{*}{$6 x$} \\
\hline $55^{\circ} \mathrm{C}$ & $1 \mathrm{~min}$ & \\
\hline $72^{\circ} \mathrm{C}$ & $1.5 \mathrm{~min}$ & \\
\hline $95^{\circ} \mathrm{C}$ & $30 \mathrm{sec}$ & \multirow{3}{*}{$30 \times$} \\
\hline $55^{\circ} \mathrm{C}$ & $1 \mathrm{~min}$ & \\
\hline $72^{\circ} \mathrm{C}$ & $40 \mathrm{sec}$ & \\
\hline $72^{\circ} \mathrm{C}$ & $5 \mathrm{~min}$ & $1 \times$ \\
\hline
\end{tabular}

The PCR product was purified using QIAquick PCR purification kit (QIAGEN). 5 volumes of Buffer PBI were added into 1 volume of the PCR product and mixed. The sample was applied to the QIAquick column and centrifuged for $1 \mathrm{~min}$. Flowthrough was discarded. The column was added with $0.75 \mathrm{ml}$ buffer PE and centrifuged for $1 \mathrm{~min}$. Flow-through was discarded. The column was centrifuged for additional $1 \mathrm{~min}$. To elute DNA, The column was placed in a new eppendorf tube, added with $15 \mu \mathrm{l}$ water and centrifuged for $1 \mathrm{~min}$. NanoDrop was used to test the DNA concentration. Primers used are E-cad-T7-F, E-cad-T7-R, $\alpha-C a t-T 7-F$ and $\alpha-$ Cat-T7-R (Appendix) (Rauzi et al., 2010).

PCR Buffer: $750 \mathrm{mM}$ Tris- $\mathrm{HCl}\left(\mathrm{pH} 8.8\right.$ at $\left.25^{\circ} \mathrm{C}\right), 200 \mathrm{mM}(\mathrm{NH} 4) 2 \mathrm{SO} 4,0.1 \%(\mathrm{v} / \mathrm{v})$ Tween 20

\subsection{2 dsRNA amplification}

T7 RiboMAX Express RNAi System was used to produce the double stranded RNA (dsRNA). The components of the synthesis system are listed in the following table: 


\begin{tabular}{|l|l|}
\hline component & Volume $(\mu \mathrm{l})$ \\
\hline DNA & $2 \mu \mathrm{g}$ \\
\hline $10 \times$ transcription buffer & $5 \mu \mathrm{l}$ \\
\hline dNTP $($ ATP, UTP, CTP, GTP $)$ & $7.5 \mathrm{mM}$ \\
\hline RNAase inhibitor $(1 \mathrm{u} / \mu \mathrm{l})$ & $1.25 \mu \mathrm{l}$ \\
\hline $100 \times$ pyrophosphatase & $0.5 \mu \mathrm{l}$ \\
\hline T7 RNA polymerase $(0.5 \mathrm{unit} / \mu \mathrm{l})$ & $2 \mu \mathrm{l}$ \\
\hline DEPC water & Remaining volume \\
\hline Total volume & $50 \mu \mathrm{l}$ \\
\hline
\end{tabular}

The system was incubated in $37^{\circ} \mathrm{C}$ for 4 hours. $3 \mu \mathrm{l}$ DNase I was added and incubated for $15 \mathrm{~min}$ in $37^{\circ} \mathrm{C}$ to remove template DNA. The reaction was stopped by adding $2 \mu 10.5 \mathrm{M}$ EDTA (PH8.0), incubating $10 \mathrm{~min}$ in $65^{\circ} \mathrm{C}$.

RNA product was purified using phenol/chloroform extraction and ethanol precipitation. The RNA product was added with $85 \mu \mathrm{LEPC}$ water, $15 \mu \mathrm{NaAc}(3 \mathrm{M})$ and phenol/chloroform (1:1). It was vortexed for $1 \mathrm{~min}$ and centrifuged for $15 \mathrm{~min}$. The up-layer was transferred to a new tube and added chloroform (1:1). Then, it was vortexed and centrifuged again. The up-layer was transferred to a new tube. 2 volumes ethanol was added inside and incubated for 6 hours in $-20^{\circ} \mathrm{C}$. Afterwards, it was centrifuged in $4{ }^{\circ} \mathrm{C}$ for $20 \mathrm{~min}$. The pellet was washed using cold $70 \%$ ethanol and centrifuged for another $5 \mathrm{~min}$. Ethanol was removed. After drying for $3 \mathrm{~min}, 50$ $\mu 1$ DEPC water was added to dissolve the pellet. NanoDrop was used to measure its concentration.

Transcription buffer: $50 \mathrm{mM}$ Tris-HCl, $\mathrm{pH}$ 7.5; $15 \mathrm{mM} \mathrm{MgCl} 2,5 \mathrm{mM}$ dithiothreitol (DTT), $2 \mathrm{mM}$ spermidine, Make $10 \times$ stock and store at $-20^{\circ} \mathrm{C}$.

\subsubsection{Microinjection}

Embryos (0-30 min) were collected and treated with 50\% klorix for $1.5 \mathrm{~min}$. They were transferred on a piece of apple juice agar using a brush and aligned in two lines with the same orientation. A cover slide coated with self-made glue was gently placed on the embryos, sticking them up. The embryos should be placed in a dry 
environment for 10 minutes. Then, the embryos were covered with 10S Voltalef oil (use as little as possible). dsRNA was injected into the posterior end of the embryos.

\subsection{Time-lapse imaging and analysis}

Live embryos on an apple juice plate were covered with Voltalef $3 \mathrm{~S}$ oil. The embryos in a certain stage were picked by a needle and transferred on a self-made mesh. They were treated with klorix and washed several times using water. The embryos were transferred on a piece of apple juice agar using a brush. Then, the embryos were aligned (lateral side up). A cover slide coated with glue sticked the embryos up. The embryos were covered with $10 \mathrm{~S}$ Voltalef oil. The slide with embryos was taken to the microscope to photo live images.

\subsubsection{Microscopy}

\begin{tabular}{|l|l|l|}
\hline Image type & microscope & camera \\
\hline $\begin{array}{l}\text { Differential } \\
\text { interference contrast } \\
\text { microscopy (DIC) }\end{array}$ & $\begin{array}{l}\text { Zeiss Axiovert 200 M Ultra-View } \\
\text { Spinning Dsisc confocal microscope }\end{array}$ & $\begin{array}{l}\text { Camera: Zeiss } \\
\text { AxioCam Icc 1 }\end{array}$ \\
\hline $\begin{array}{l}\text { Spinning disc } \\
\text { confocal microscopy }\end{array}$ & $\begin{array}{l}\text { Zeiss Axiovert 200 M Ultra-View } \\
\text { Spinning Dsisc confocal microscope }\end{array}$ & $\begin{array}{l}\text { Camera: Zeiss } \\
\text { AxioCam MRm }\end{array}$ \\
\hline $\begin{array}{l}\text { Confocal laser } \\
\text { scanning microscopy }\end{array}$ & $\begin{array}{l}\text { Carl Zeiss Imaging System LSM } \\
780\end{array}$ & \\
\hline
\end{tabular}

For confocal images, usually we use the $63 \times$ objective. Spinning disc images usually were taken by the $40 \times$ objective. DIC images were taken by the $25 \times$ or the $40 \times$ objective.

\subsubsection{Measurement in imageJ}


Time-lapse images were saved as tiff files. Stack and hyperstack functions in ImageJ were used to make movies with different channels. Measure function was used for measuring cell border length, cell area and grey value (signal intensity).

\subsubsection{EDGE and embryonic segmentation}

Embryo Development Geometry Explorer (EDGE) is a program working in MATLAB, allowing users to quantitatively analyze embryo development data taken from the confocal microscopes. The key idea is to identify the cell shapes, track them across space and time and compute properties related with cell shape. Additional channels could also be entered.

EDGE program was installed in MATLAB. Sequences of images in tiff format were imported inside. The parameters were set, like space and time limits. Reference image was set. Segmentation was processed to the images. Usually, segmentation was not good enough to be directly used. It needed to be manually corrected. After correction, segmented images were exported to the EDGE browser with cell shape property information. Data was analyzed using MATLAB. This work is collaborated with Prof. Dr. Fred Wolf, Dr. Lars Reichl, and Lutz Künneke. 


\section{Chapter3. Results}

\subsection{X-330 is a mutant of ER membrane protein CG4542}

\subsubsection{Gene mapping and PCR sequencing}

To further detect the molecular mechanisms controlling morphogenesis at the gastrulation stage, we did genetic screens in existing collections of EMS induced mutation stocks for important and interesting maternal-effect genes affecting early embryonic patterning in Drosophila Melanogaster (Luschnig et al., 2004). Based on the FLP-FRT technique to make germline clones, we found several different phenotypes of maternal-effect mutants. An X-linked lethal mutation X-330, which shows phenotype at the gastrulation stage, attracted our attention. We used genetic methods to map this mutant gene. Three duplications (Dp5279, Dp948 and Dp5281) could rescue the lethality and the phenotype of X-330 (Fig.11B). Their overlapping region was in $6 \mathrm{C}$ to $6 \mathrm{D}$. Deficiencies in this region were crossed with X-330 mutant, in which Df(1)ED6878, Df(1)BSC351, Df(1)BSC276, Df(1)BSC297 and Df(1)BSC286 were not complementary with X-330 mutant. This indicates that X330 mutant is in their overlapping region. In addition, the mutation is not in the region of $\mathrm{Df}(1) \mathrm{BSC} 285$, which is complementary with $\mathrm{X}-330$. Therefore, the suspicious region was limited to five genes: pod1, iav, Nf-YC, CG4542, Atx-1 (Fig.11B). By another two shorter deficiencies, which are Df(1)pod1(delta225) and $\operatorname{Df}(1)$ delta96, three genes were ruled out. The mutant map was minimized to two genes: CG4542 and Atx-1. PCR sequencing was used to search the point mutation site. Genomic DNA of X-330/FM7 adult fly was used as PCR template to clone the $3 \mathrm{~kb}$ region, which includes CG4542 and Atx-1. X-220/FM7 was used as a wild type control in the same region. One mutation site was found in CG4542, which changed the Tyrosine codon (TAT) into a stop codon (TAA) (Fig.11B, C). In X-330 mutant, truncated CG4542 protein should be 402 aa, while the whole length of CG4542 is 511aa. 


\section{A}
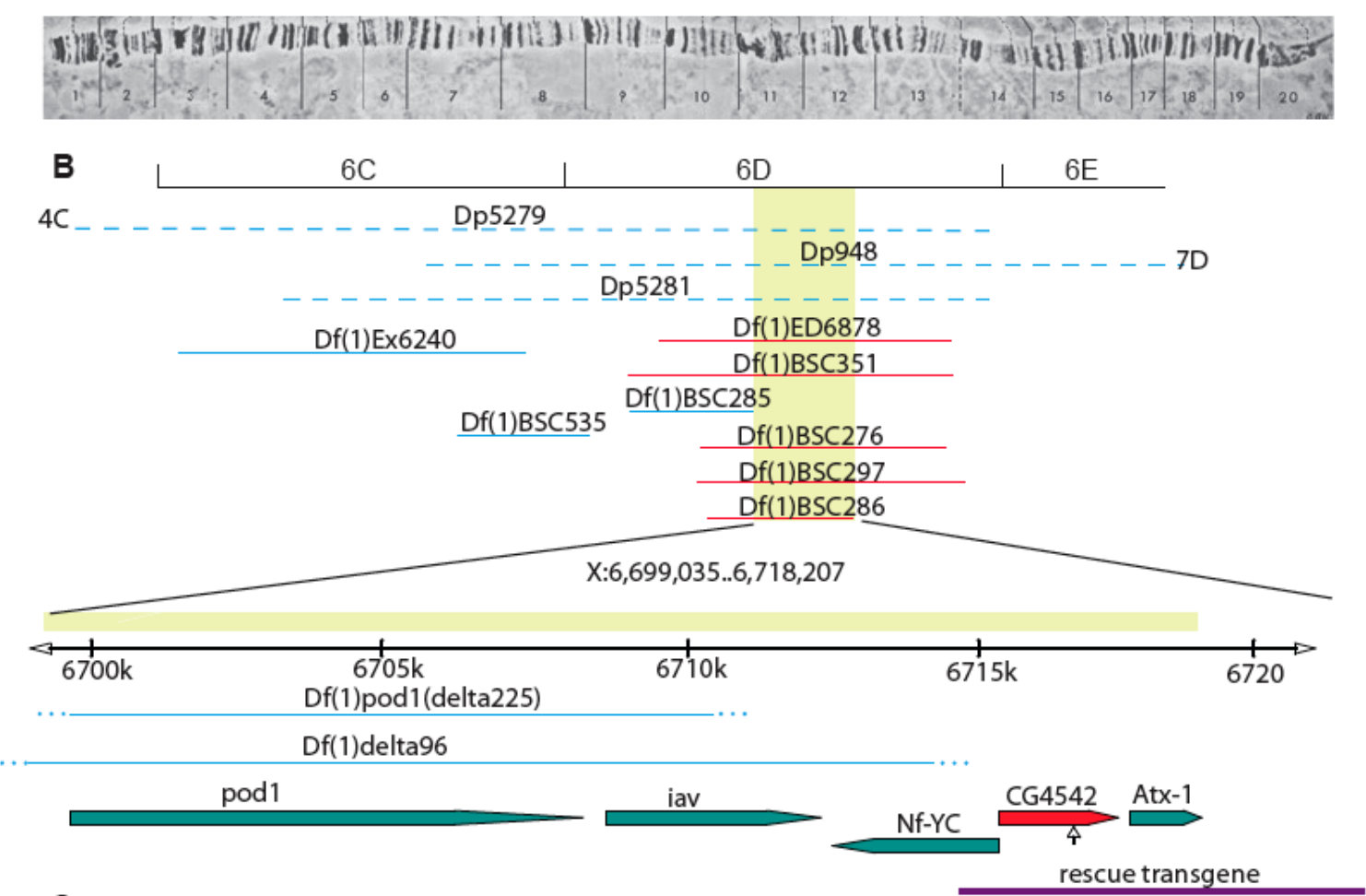

C

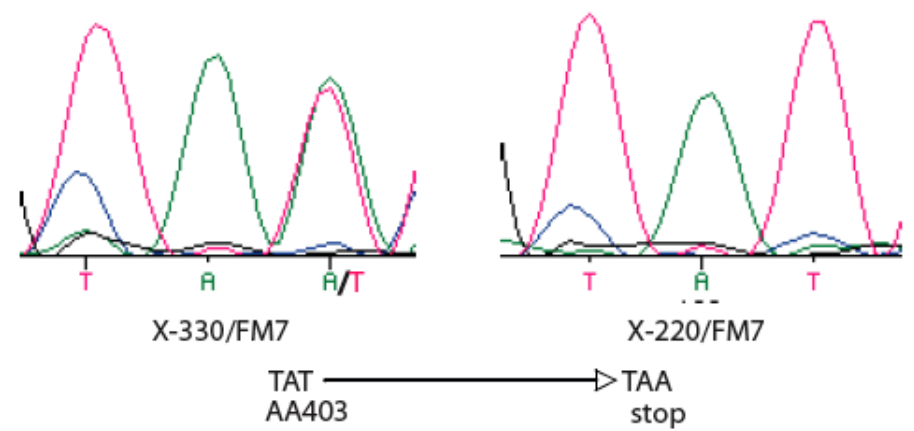

Figure 11. $X-330$ is a mutation in CG4542. A. The whole $X$ chromosome. B. The $6 \mathrm{C}-6 \mathrm{D}$ region in X chromosome includes 3 duplications (Dp5279, Dp948 and Dp5281) (blue dotted lines), which could rescue the phenotype of X-330. Their overlapping region contains five deficiencies (ED6878, BSC351, BSC276, BSC297 and BSC286) (red lines), which are not complimentary with the X-330 mutant, and three deficiencies (Ex6240 BSC285 and BSC535) (blue lines), which are complimentary with the X-330 mutant. By the overlapping region of deficiencies (yellow bar), five genes (pod1, iav, Nf-YC, CG4542 and Atx-1) are possible to be the mutant gene $\mathrm{X}-330$. The first three genes are ruled out from the candidates by another two deficiencies (pod1 (delta225) and delta96). The 3kb region was sequenced, which includes CG4542 and Atx-1. The point mutation was found in CG4542 coding region (arrow site). C. The PCR sequencing result of the X-330 mutant (left) and the wild type (right). The mutation site changed the 403 codon TAT to a stop codon TAA. 


\subsubsection{Genomic DNA of CG4542 could rescue X-330 lethality and its phenotype}

$7.1 \mathrm{~kb}$ genomic DNA, which covers CG4542 and Atx-1 gene, was used to make transgenic flies (Fig.11C). The transgenic construct was inserted into the third chromosome ( $86 \mathrm{Fb}$ site) and balanced by TM3/TM6B. The CG4542 transgene was put into X-330 maternal mutant background to test complementation, including lethality test and phenotype test at the gastrulation stage. With CG4542 transgene, $\mathrm{X}-330 / Y$ male flies could survive $(\mathrm{n}>50)$, which means $\mathrm{X}-330$ mutant lethality was rescued by CG4542. In the control group, X-330/Y male flies were lethal. The phenotype of X-330 mutant at the gastrulation stage was rescued, which was shown in DIC movies (Fig. 17A). Based on these results, we conclude that X-330 is a mutant in CG4542. However, we found that, in the rescued embryos, the nuclei were smaller and more than the wild type ones, indicating that an extra cell cycle may exist in the rescued embryos. To explain this, a shorter genomic DNA region was taken to make new transgenic flies. By this test, we could tell if the extra cell cycle is caused by over-expression effect of CG4542 or Atx-1.

\subsubsection{CG4542 protein is localized in ER}

Based on the information in the website of FlyBase (http://flybase.org/) and protein sequence blast, CG4542 was identified as a homologue of Alg8 in yeast and human (Shaik et al., 2011). CG4542 has $38.7 \%$ and $49 \%$ similarity with yeast and human Alg8 respectively (Fig. 12). It has $28 \%$ and $30.7 \%$ similarity with yeast and human Alg6 respectively. Alg6 and Alg8 both belong to CAZY family of glycosyltransferases GT57, which may have function redundancy with each other (Shaik et al., 2011). By phylogenetic analysis, CG4542 is the homologue of Alg8, while CG5091/Gny is the homologue of Alg6 (Fig. 13) (Shaik et al., 2011).

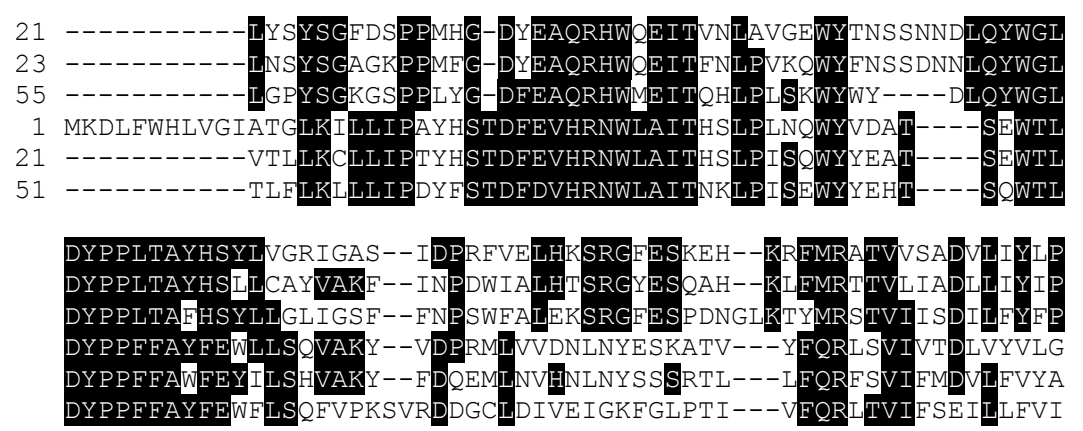




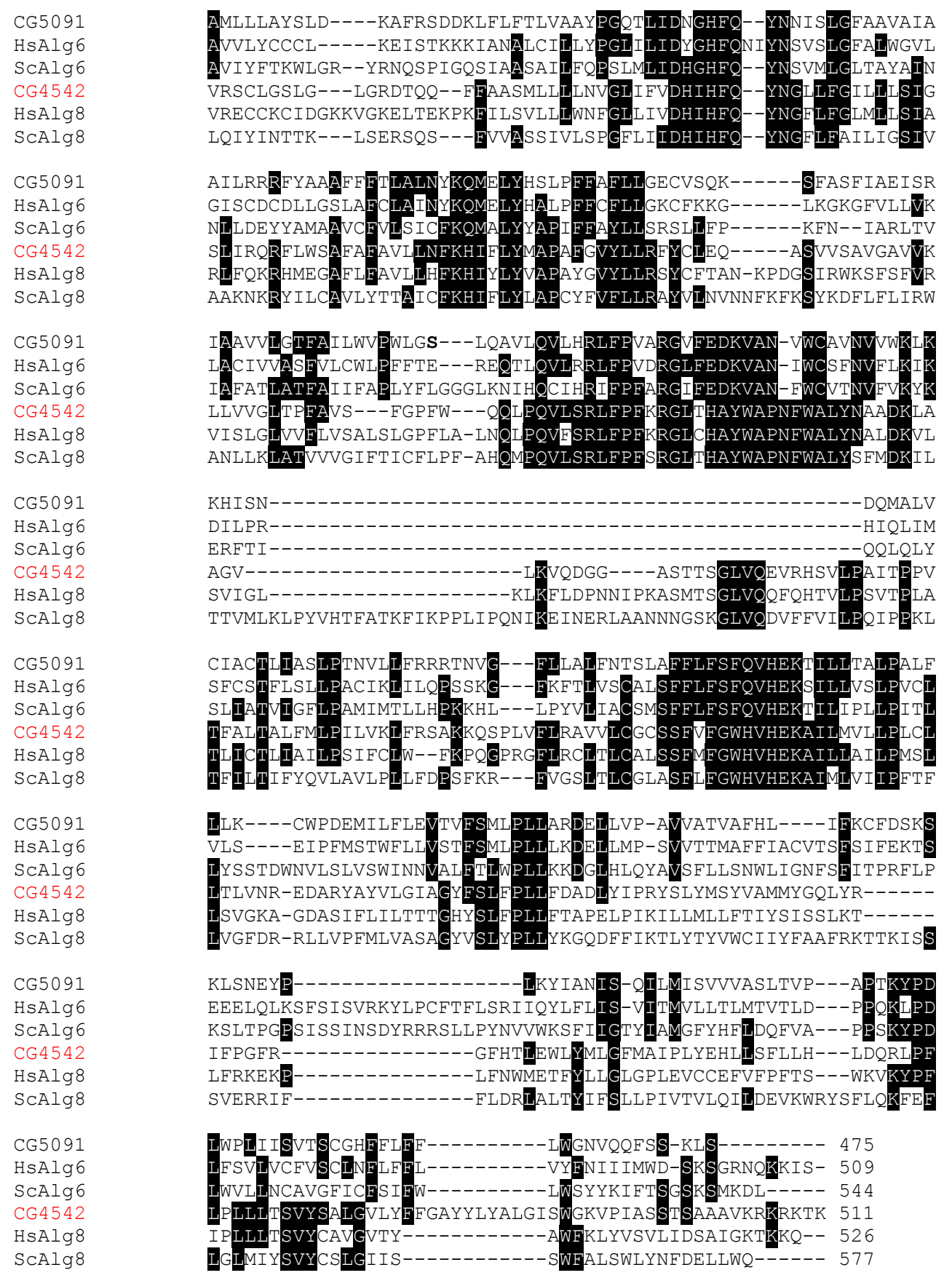

Figure 12. Alignment of human and yeast Alg6 and Alg8 with Drosophila proteins CG4542 and CG5091. Highlighted parts are amino acid sequence shared by more than 50\%. (Shaik et al., 2011) 


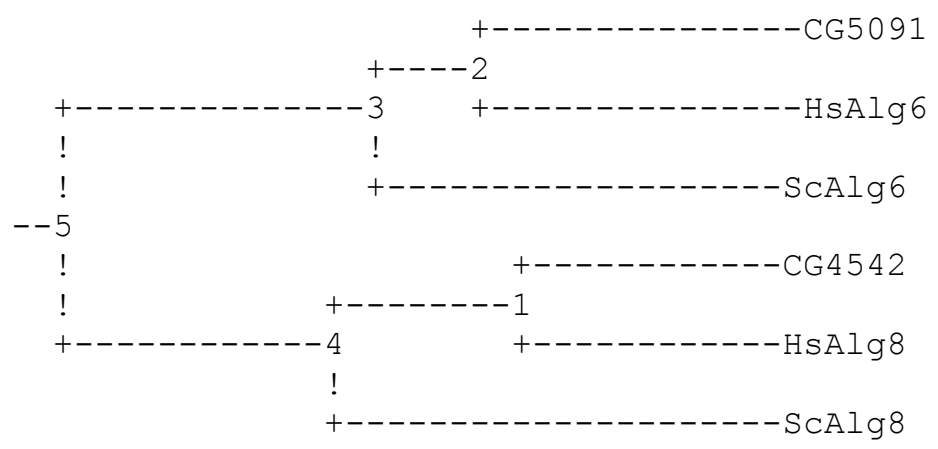

Figure 13. Phylogeny of CG4542 and CG5091 with their homologues Alg6 and Alg8 in yeast and human. (Shaik et al., 2011)

CG4542 protein was predicted to be a membrane protein (Fig.14) by online prediction in Simple Modular Architecture Research Tool (SMART) (http://smart.embl-heidelberg.de/). It has a 29aa signal peptide in N-terminus, predicting in SignalP 4.0 Server (http://www.cbs.dtu.dk/services/SignalP/). Based on previous studies, we knew some structural information about CG4542' s homologue Alg8 in yeast. It has a large hydrophilic region in the cytoplasm, which contain active sites. Alg8 was predicted to have two conserved domains: the Nterminal half (domain A) and the C-terminal half (domain B). From the known functions of the analyzed proteins, only the processive glycosyltransferases carry two domains $\mathrm{A}$ and $\mathrm{B}$, while those that add a single sugar residue carry only domain A (Saxena et al., 1995). It is verified that C-terminal transmembrane domain of Alg8 in yeast was critical for the polymerization reaction in vivo (Oglesby et al., 2008). In X-330 mutant, CG4542 enzyme was made without the C-terminal three transmembrane domains. This truncated glycosyltransferase may carry impaired domain B, which is important for its activity.

To make antibody, two fragments of CG4542 (67aa and 69aa) were cloned, which are 26aa $\cdots 93$ aa and 231 aa $\cdots 299$ aa (Fig.14 red lines). They were expressed in E.coli BL21 and purified (Fig.15). Mixture of the two fragments $(1 \mathrm{mg} / \mathrm{ml})$ was injected into a rabbit. We got the serum, which should contain the CG4542 antibody. 


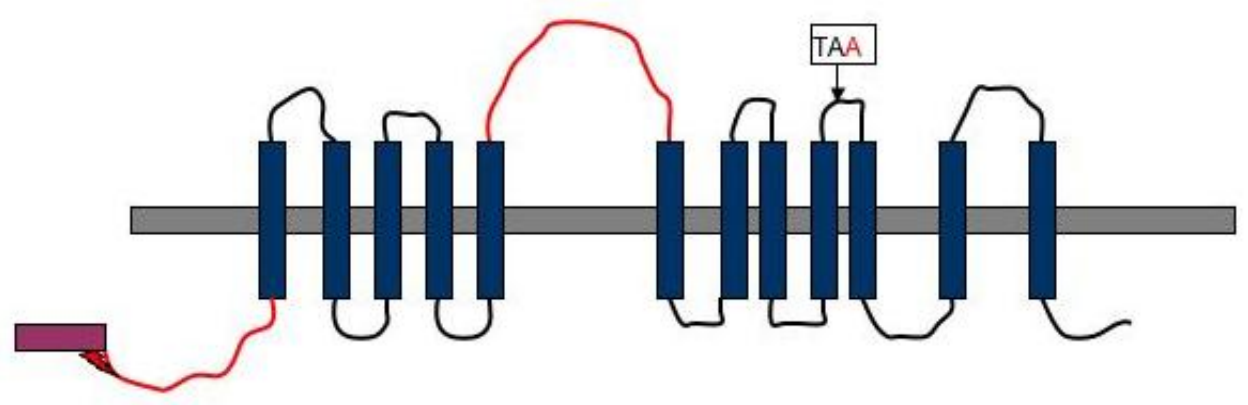

Figure 14. CG4542 is predicted to be an ER membrane protein. CG4542 protein has 12 transmembrane domains (blue bars). The grey bar represents the ER membrane. A typical signal peptide (purple bar) is in N-terminal, which should be cut off from the mature protein. The X330 mutation site is marked (TAA box). Two fragments of the protein (red lines) are designed to be expressed and purified for making the antibody.

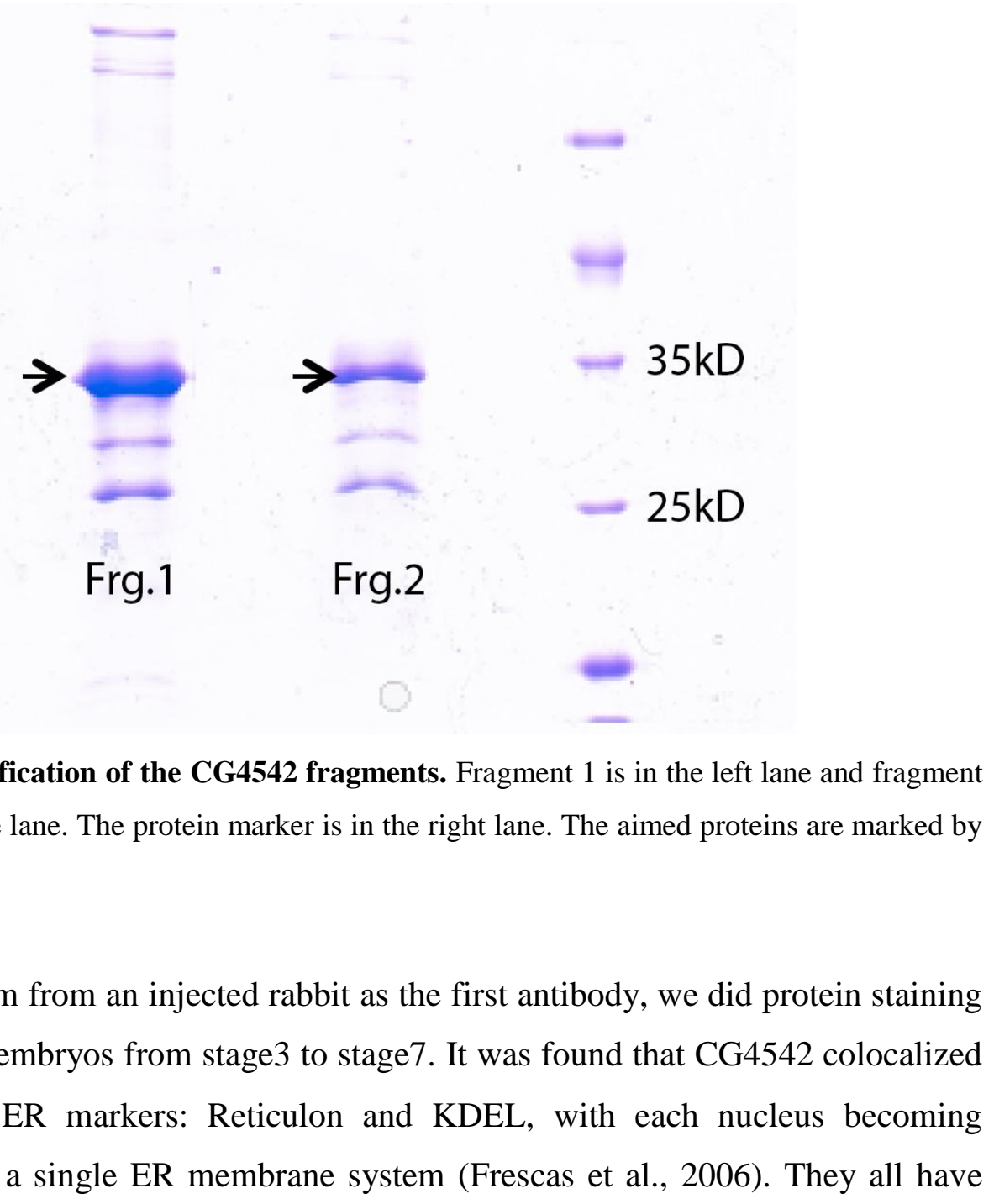

Figure 15. Purification of the CG4542 fragments. Fragment 1 is in the left lane and fragment 2 is in the middle lane. The protein marker is in the right lane. The aimed proteins are marked by arrows.

Using the serum from an injected rabbit as the first antibody, we did protein staining in Drosophila embryos from stage3 to stage7. It was found that CG4542 colocalized with the two ER markers: Reticulon and KDEL, with each nucleus becoming surrounded by a single ER membrane system (Frescas et al., 2006). They all have 
perinuclear localization, where should be the ER region (Fig.16). This result confirmed that CG4542 is an ER protein.

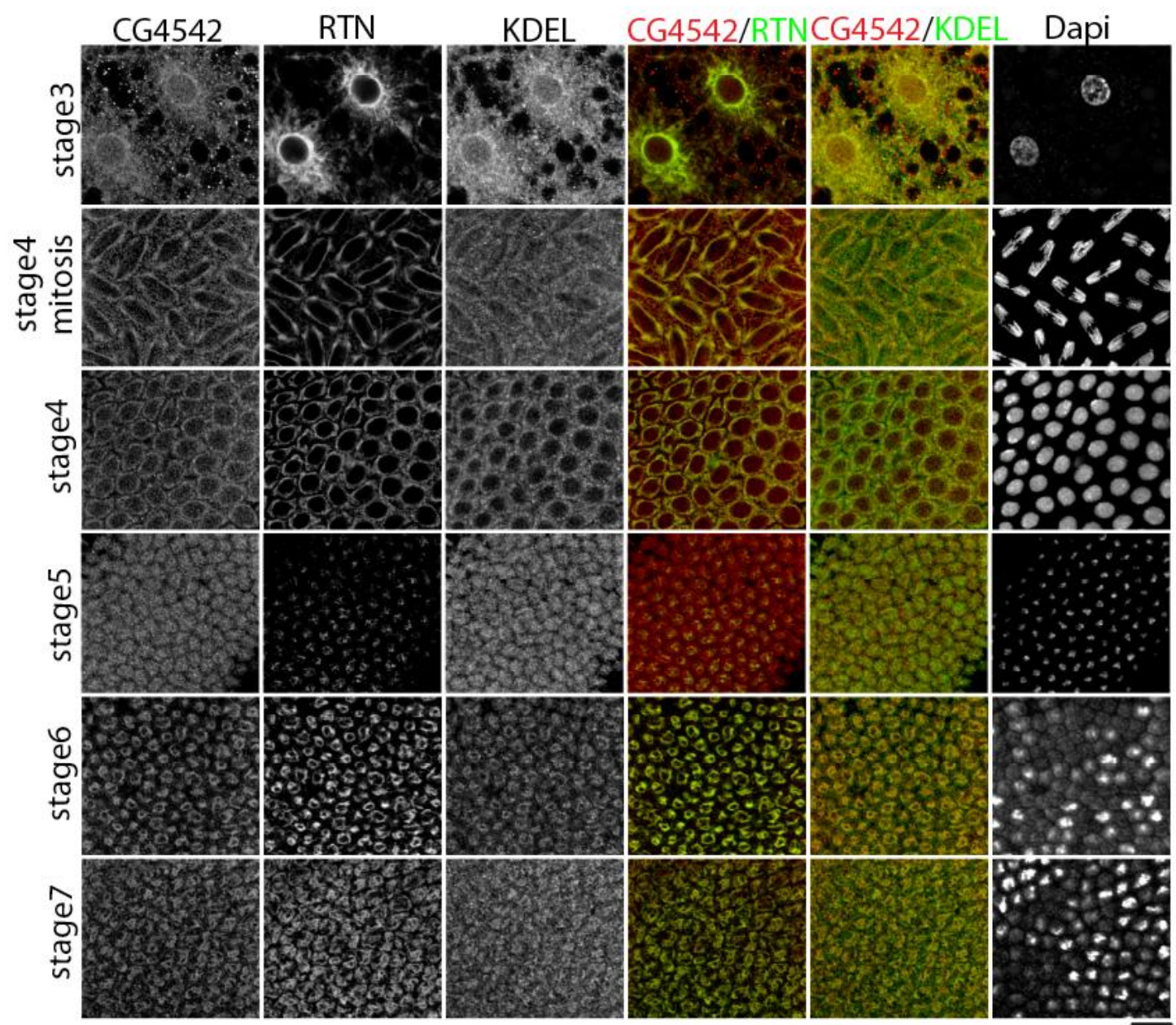

Figure 16. The CG4542 protein is localized in ER. The CG4542 protein is stained using the first antibody from rabbit. It is colocalized with the two ER markers: Reticulon (RTN) and KDEL from stage3 to stage7. Nuclei are marked by DAPI. The scale bar represents $10 \mu \mathrm{m}$.

\subsection{Germ band extension is abnormal in X-330 mutant}

In X-330 germline clones, more than half of the embryos collapsed. Only a few kept normal shapes. We took the uncollapsed ones to observe their development. Their cellularization process was normal, but the morphogenetic events in gastrulation stage were abnormal. The phenotype includes germ band extension defect, impaired ventral furrow formation and cephalic furrow formation defect. Our main interest is in the question that how does X-330 mutant affect cell intercalation during germ band extension. 


\subsubsection{Germ band extension is abnormal in the mutants of $X-330$, Wol or Gny}

During the 30 minutes at gastrulation stage, germ band extends along the AP axis. Its length increases for more than 2 folds in the wild type embryos (Fig.17A). Using DIC time-lapse images, we measured the distance between germ band moving frontier and the posterior end of the embryos in every two minutes and counted the ratio between the distance and the whole embryonic length. A chart was made to show the curves of ratio values (Fig.17B). In the wild type, germ band extended to about $53 \%$ of the whole length in 40 minutes (Fig.17B, blue line). In X-330 mutant, germ band extension started normally. However, it stopped in the midgut position (Fig.17A). In the curve chart, germ band extended to about $28 \%$ of the whole length (Fig.17B, red line).

To examine whether germ band extension defect is specific in X-330 mutant or it is the same situation in other N-glycosylation enzyme mutants, Wol, Gny and their double mutant were taken to do germline clones. In gastrulation stage, germ band extension was stopped in the midgut position in these mutants, which were very similar with the X-330 mutants (Fig.17A, B). This result indicates that ER Nglycosylation, at least the three glucosylation, is required for the germ band extension. The defect in Wol and Gny double mutant is not more severe than the single mutants, which suggests that the two genes Wol and Gny function in the same pathway. 

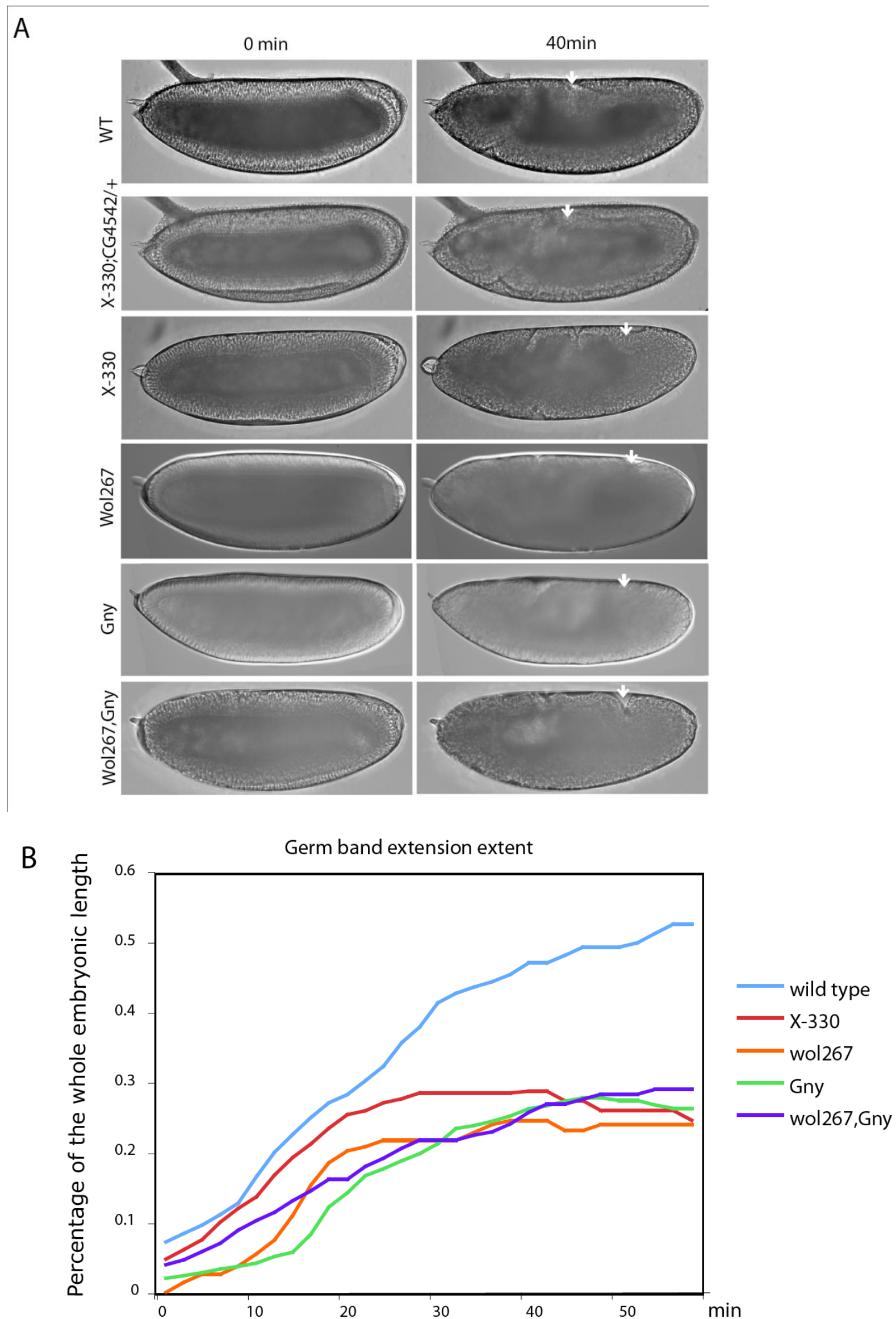
Figure 17. X-330, Wol or Gny mutant has similar germ band extension defect. In the wild type embryos, germ band extends to about two thirds of the whole embryo length (A, first row). In X-330 mutant, germ band extends to the midgut position (A, third row). The phenotype could be rescued by CG4542 transgene (A, second row). The similar phenotype was shown in Wol267 (A, fourth row), Gny (A, fifth row) and their double mutant (A, sixth row). In time-tracking curves for characterizing the germ band extension extent, the wild type germ band frontier extends to more than $50 \%$ position of the whole embryo length (B, blue line). In X-330 mutant (B, red line), Wol mutant (B, orange line), Gny mutant (B, green line) and the double mutant of Wol and Gny (purple line), germ band extension is blocked in the similar position, which is less than $30 \%$ of the whole length.

\subsubsection{Removing $\mathrm{N}$-glycans from proteins induces germ band extension defect}

Tunicamycin is a mixture of homologous nucleoside antibiotics, which inhibits the UDP-HexNAc: polyprenol-P HexNAc-1-P family of enzymes. In eukaryotes, GlcNAc phosphotransferase (GPT) belongs to these enzymes and functions in catalyzing the transference of $\mathrm{N}$-actelyglucosamine-1-phosphate from UDP-Nacetylglucosamine to dolichol phosphate in the first step of glycoprotein synthesis. Tunicamycin could inhibit synthesis of all the N-glycans and induce the unfolded protein response. It is a tool to study the glycoprotein synthesis in variety of biological systems, including embryonic development (Atienza-Samols et al., 1980). By microinjection of tunicamycin into embryos, all the proteins synthesized afterwards would have no $\mathrm{N}$-glycans. In our experiment, $1 \mathrm{mg} / \mathrm{ml}$ tunicamycin was injected into embryos, which were laid within one hour. Injected embryos could accomplish cellularization with no obvious defect. However, their germ band extension was blocked in midgut position, which was very similar with the phenotype of mutants mentioned above (Fig.18A). 117GFP embryos were injected for tracking the movement of cells. By marking several rows of cells, we found that cell intercalation is normal after tunicamycin injection (Fig.18B). However, cell division was obviously earlier than the wild type. From this result, we conclude that $\mathrm{N}$-glycosylation of some essential proteins is required for germ band extension, but may be not through affecting cell intercalation. 

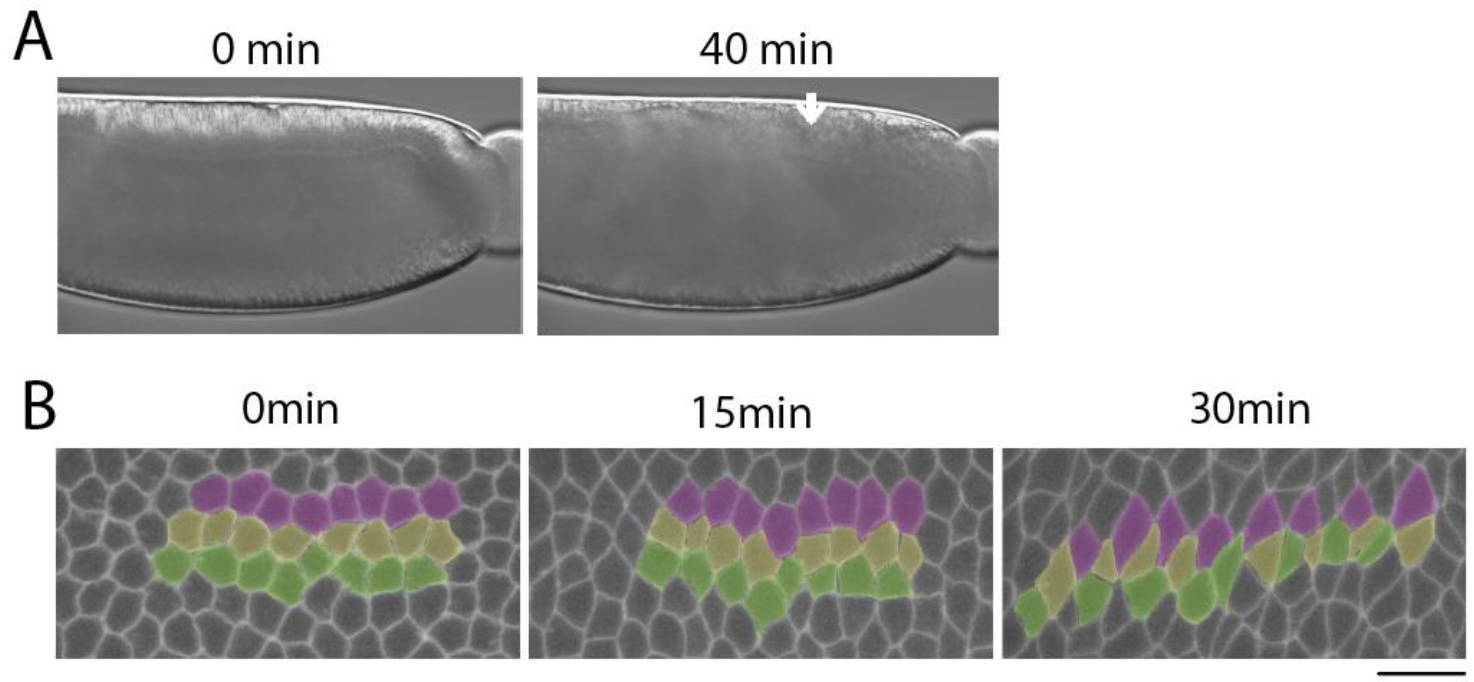

Figure 18. Tunicamycin injection induces germ band extension defect. A. After injection of tunicamycin $(1 \mathrm{mg} / \mathrm{ml})$, the germ band extension was tracked. 40 minutes after germ cells starting to move dorsally, germ band extension was blocked in midgut position (arrow). B. Cell borders were marked by $117 \mathrm{GFP}$. Several rows of cells were marked by different colors. 30min after the beginning of gastrulation, cell intercalation was normal as the wild type. The scale bar represents $10 \mu \mathrm{m}$.

\subsubsection{Not all the mutants of $\mathrm{N}$-glycosylation enzymes affect gastrulation}

To detect if all the ER N-glycosylation enzymes affect germ band extension in gastrulation stage, we took some of the ER enzymes' mutants ( $p$ element insertions) in the N-glycosylation pathway and used FLP-FRT system to make germline clones. CG4542 mutant (X-330), wol and gny have germ band extension defect as we showed above. Calnexin 99A mutants could produce no embryos, which indicates that the mutant affects oogenesis. In calreticulin mutants, the embryos were shorter in the AP axis than normal ones. In addition, they stopped development in the early stage before cellularization. CG8412 mutants developed normally. Their germ band extension was normal in gastrulation stage. Maybe other glycosylation enzymes have functional redundancy with CG8412 to rescue its mutant phenotype. OstStt3 is only one subunit of Ost enzyme complex. No obvious phenotype was observed in ostStt3 germline clone mutant. I list the genes, their homologue names in yeast and their maternal mutant phenotype in the following table. For other ER enzymes I list, their mutants haven't been studied. Their function in Drosophila embryogenesis remains unknown. 


\begin{tabular}{|c|c|c|}
\hline Gene & $\begin{array}{l}\text { Homologous gene } \\
\text { in yeast }\end{array}$ & Mutant phenotype \\
\hline CG4542 & Alg8 & gastrulation \\
\hline Wol/CG7870 & Alg5 & $\begin{array}{l}\text { Embryo patterning, cuticle formation, germ } \\
\text { band extension } \\
\text { (Haecker et al., 2008; Shaik et al., 2011) }\end{array}$ \\
\hline Gny/CG5091 & Alg6 & $\begin{array}{l}\text { Gastrulation, } \\
\text { epidermal differentiation (Shaik et al., 2011) }\end{array}$ \\
\hline CG8412 & Alg12 & $\begin{array}{l}\text { Normal } \\
\text { PBac }\{\text { WH }\} C G 8412 f 07214 / T M 6 B\end{array}$ \\
\hline calreticulin & calreticulin & $\begin{array}{l}\text { Early embryogenesis } \\
\mathrm{P}\{\text { lacW }\} \text { CrcS114307/TM3 }\end{array}$ \\
\hline calnexin 99A & calnexin & $\begin{array}{l}\text { Oogenesis } \\
\mathrm{P}\{\mathrm{EP}\} \mathrm{Cnx} 99 \mathrm{AEP} 3522 / \mathrm{TM} 6 \mathrm{~B}\end{array}$ \\
\hline ost Stt3 & ost subunit & $\begin{array}{l}\text { Normal } \\
\mathrm{P}\{\text { lacW }\} \text { OstStt3j2D9/TM3 }\end{array}$ \\
\hline Alg10/CG32076 & Alg10 & $?$ \\
\hline CG11851 & Alg9 & $?$ \\
\hline CG11306 & Alg11 & $?$ \\
\hline CG18012 & Alg1 & $?$ \\
\hline CG1597 & Glucosidase I & $?$ \\
\hline CG6850 & $\begin{array}{l}\text { Glucosyltransferase } \\
\text { UGT }\end{array}$ & $?$ \\
\hline CG3810 & $\begin{array}{l}\text { ER Mannosidase } \\
\text { Edem } 1\end{array}$ & $?$ \\
\hline
\end{tabular}

\subsection{Cell intercalation is abnormal during germ band extension in X-330 mutant}

\subsubsection{Cell intercalation is decreased in X-330 mutant}

It is already known that germ band extension is caused by cell intercalation (Bertet et al., 2004; Irvine and Wieschaus, 1994; Zallen and Wieschaus, 2004). During this process, cells move ventrally and intercalate each other along the dorsal-ventral axis. 
The length of the germ band is prolonged along the AP axis. We tracked cell movement by $117 \mathrm{GFP}$, which marks the cell borders. The extent of cell intercalation was compared among the wild type, Bicoid Nanos Torso-like (BNT) mutant and X330 mutant. In the wild type, several rows of cells were marked by different colors (Fig.19). After 30 minutes, the colors were mixed, which means cells intercalated strongly. In BNT mutant, the embryo had no AP polarity. The cells remained relatively still within 30 minutes. In X-330 mutant, the germ band cells' intercalation was much weaker than the wild type one (Fig.19). This result suggests that X-330 mutant affects germ band extension by decreasing cell intercalation.

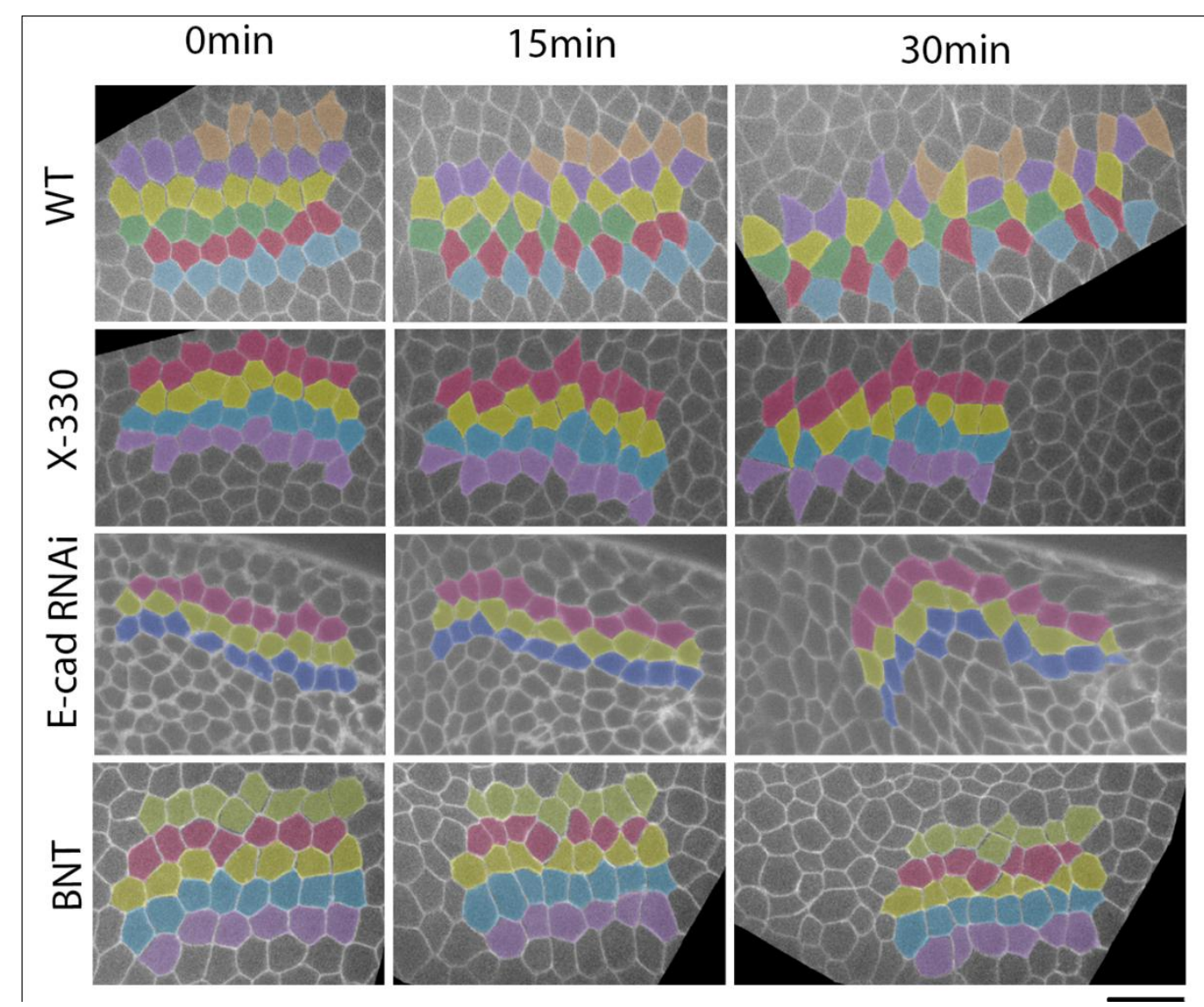

Figure 19. Cell intercalation is abnormal in X-330 mutant. In the beginning of gastrulation, several rows of germ band cells are marked using different colors. 30 minutes later, the different lines of cells intercalate into each other in the wild type embryos (first row). Cells' intercalation is much weaker in X-330 mutants (second row). In E-cadherin RNAi embryos, cell intercalation is much weaker than the wild type (third row). Different rows of cells remain relatively still in BNT mutants (fourth row). 


\subsubsection{T1 process is affected in $\mathrm{X}-330$ mutant}

During cell intercalation, relative position of four adjacent cells changes: the old neighbor cells along the AP axis separate, while the DV cells get closer to form new contacts. In this process, an intermediate state is the four cells contact in a single point or 4-fold vertex. The forming and dissolving process of the 4-fold vertex is named T1 process, in which the vertical border (type I) transfers to the 4-fold vertex (type II) and finally to the horizontal border (type III) (Fig.20A) (Zallen and Blankenship, 2008). About 50 type I borders were randomly picked and tracked from the beginning of gastrulation (0min). In the wild type cases, the borders of three different types were about the equal number after 15 minutes. In 30 minutes, most of them transferred to type III and finished the typical T1 process (Fig.20B, C). In the BNT mutant, most type I borders were still type I after 30 minutes (Fig.20E). In X-330 mutant, the T1 process was delayed: After 15 minutes, type I borders were still the most ones. After 30 minutes, the three types were the equal number (Fig.20D).
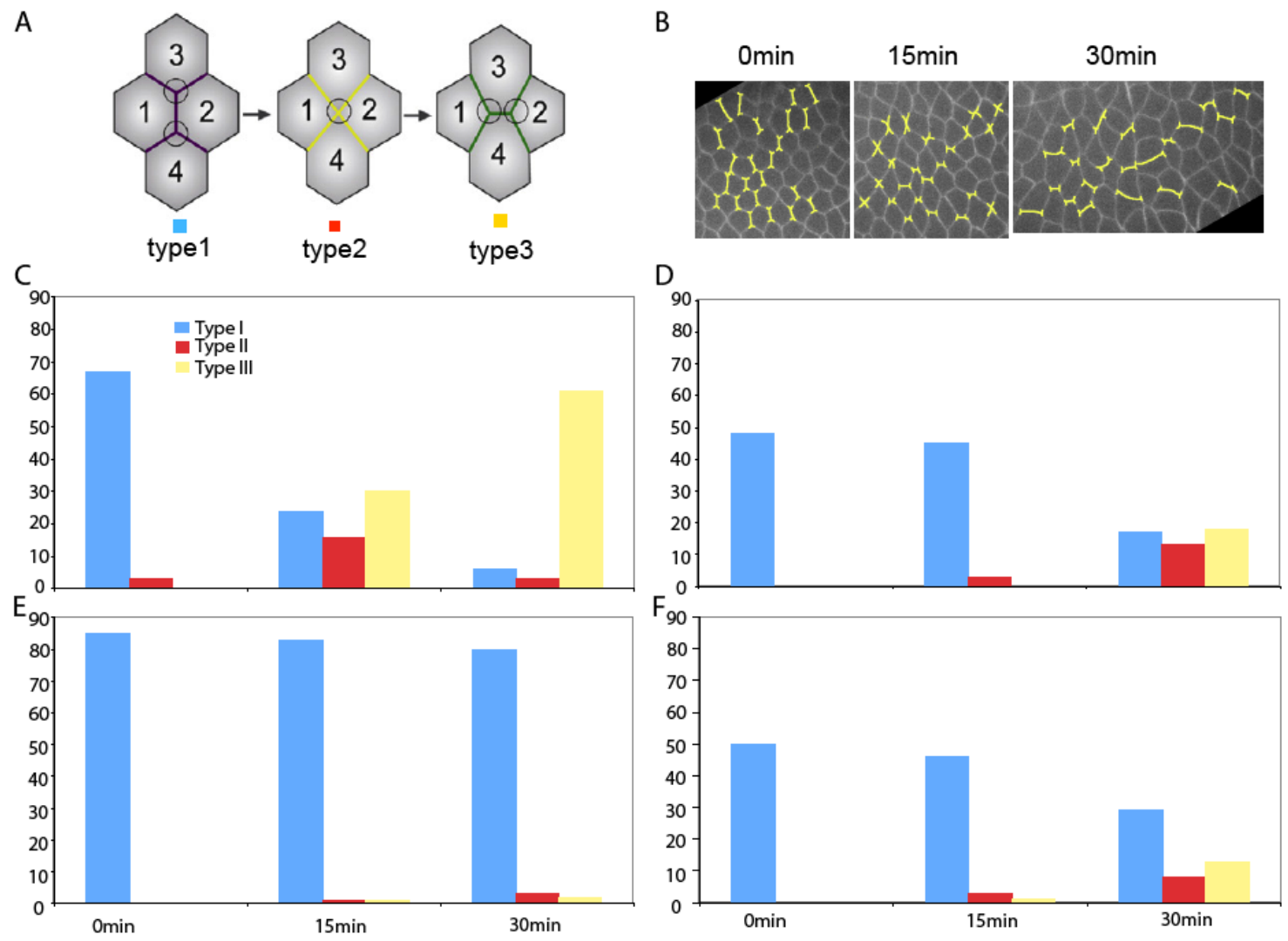
Figure 20. T1 process is delayed in $\mathrm{X}-330$ mutant. A. T1 process model: During cell intercalation, vertical borders (type I) transfer to 4-fold vertexes (type II) and then to horizontal borders (type III). B. T1 process is shown in a wild type embryo. C-F. About 50 cases were picked and tracked in different embryos. In the wild type, three border types were similar numbers after 15 minutes. Most cases transferred to type III after 30 minutes (C). In X-330 mutant, this transformation is delayed. 30 minutes later, three types were equal number (D). In BNT mutant, most type I cases kept still from 0 minute to 30 minutes (E). In E-cadherin RNAi embryos, the transformation from type I to type II and type III was much delayed, compared with the wild type, which was similar with the X-330 mutant (F).

\subsection{Anterior-posterior polarity and planar cell polarity has no obvious defect in X-330 mutant}

Segmental subdivision along AP axis is essential for germ band extension and its associated cell intercalation (Irvine and Wieschaus, 1994). Planar polarized junctions and cytoskeleton proteins are likely to drive the T1 process (Bertet et al., 2004; Blankenship et al., 2006; Zallen and Wieschaus, 2004). To find out the mechanism of how X-330 mutation affects cell intercalation, we examined the embryonic polarity and planar cell polarity in the mutant.

\subsubsection{AP polarity is not obviously affected in X-330 mutant}

Even-skipped (Eve) protein is a transcriptional repressor, which functions in the primary segmentation. It is known that mutations affect AP patterning decrease germ band extension and cell intercalation (Irvine and Wieschaus, 1994). Eve protein was used as an AP segmentation marker to examine if AP patterning is affected in X-330 mutants. In the wild type embryos, Eve protein formed a symmetrical seven-striped pattern in cellularization stage (Fig.21A). Similarly, Eve expressed in seven-stripped pattern in X-330 mutants (Fig.21B). This result suggests AP segmentation is normal in X-330 mutants. 

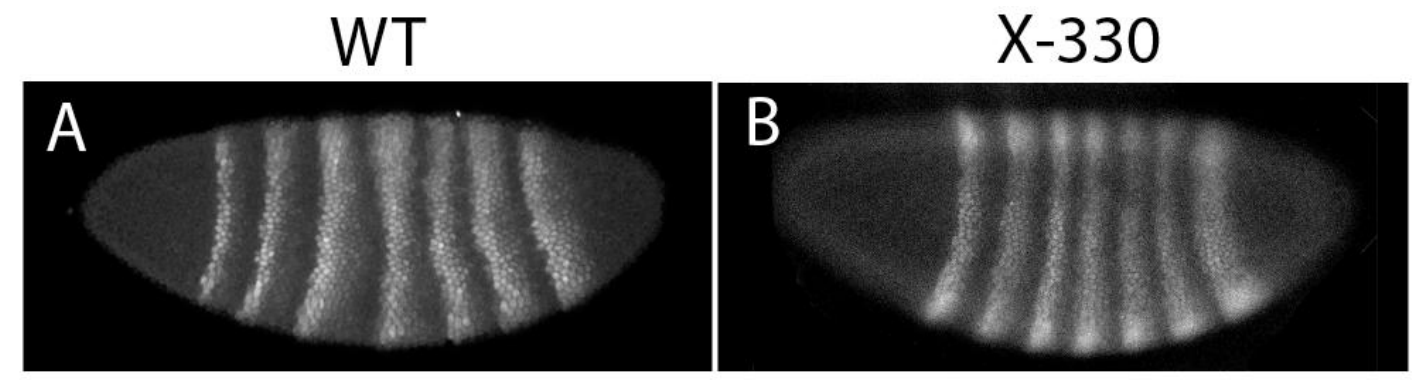

Figure 21. Eve patterning is not affected in $\mathbf{X - 3 3 0}$ mutants. In the wild type embryos, Eve protein expresses in seven-striped pattern in cellularization stage (A). In X-330 mutants, the seven-striped pattern is normal (B).

\subsubsection{Planar cell polarity is normal in $\mathrm{X}-330$ mutant}

Germ band extension is accompanied by the planar polarity of junction proteins and cytoskeletal proteins, which is the downstream response of stripped patterns of gene expression, like Eve (Bertet et al., 2004; Blankenship et al., 2006; Zallen and Wieschaus, 2004). Adherens junction protein E-cadherin and its associated proteins Armadillo and Bazooka are concentrated in the horizontal borders, while cytoskeletal proteins actin and myosin-II are enriched in the vertical borders (Zallen and Blankenship, 2008). Baz and Actin were used as markers of planar cell polarity in our protein staining experiments. In X-330 mutant, Actin was more enriched in vertical borders than horizontal borders (Fig.22B, E). This planar polarity was similar with the wild type situation (Fig.22A, E). However, Actin was ectopically localized in cytoplasm much more than the wild type (Fig.22A, B). The localization of Bazooka was complement with Actin and more localized in horizontal borders both in the wild type and X-330 mutant embryos (Fig.22C, D, F). These results indicate that planar cell polarity is not obviously affected in X-330 mutant. 


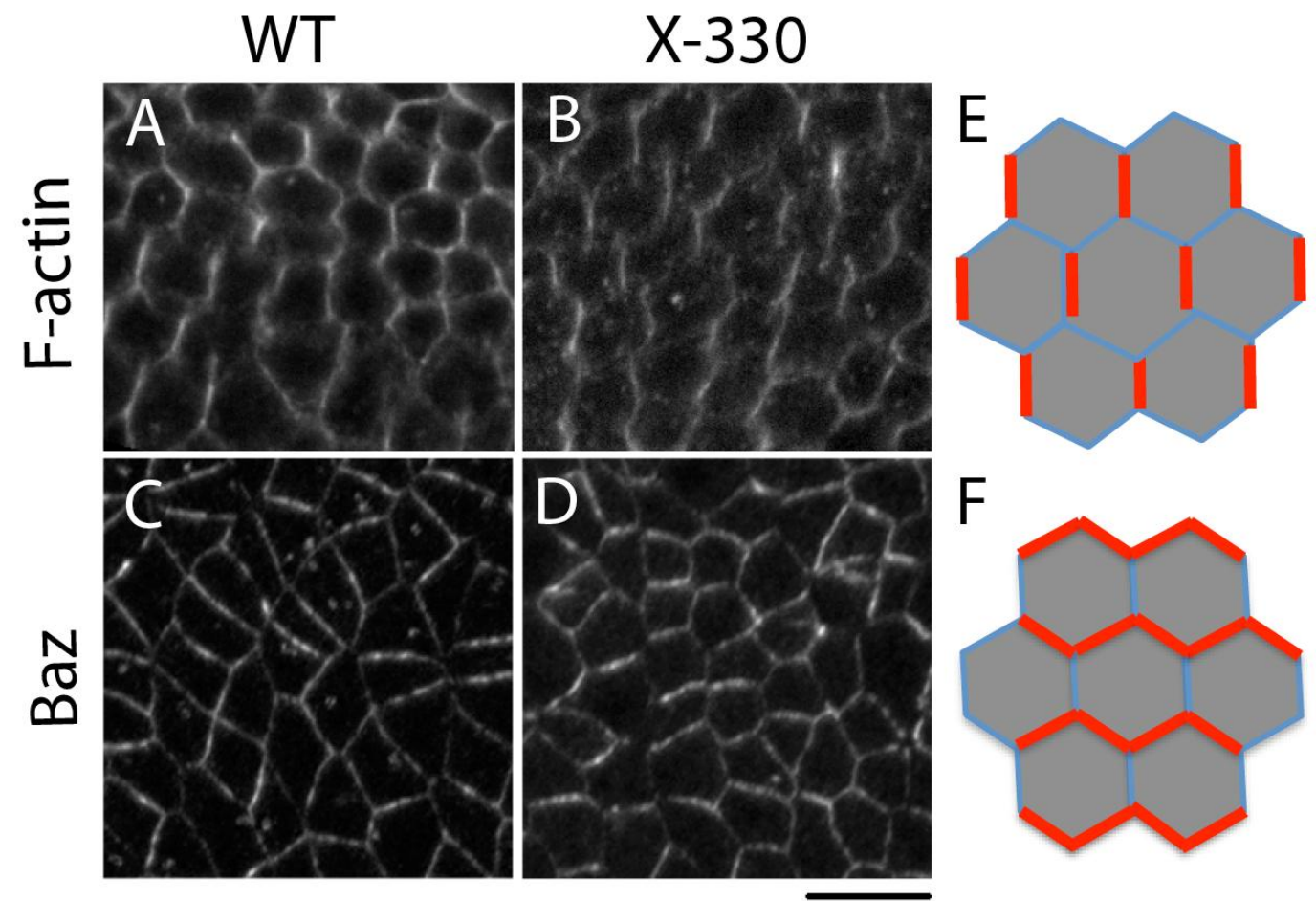

Figure 22. Planar cell polarity exists in $\mathbf{X - 3 3 0}$ mutant. By protein staining, Actin is shown enriched in vertical borders. Its localization has planar polarity both in the wild type (A) and in X-330 mutant (B). The red lines in the model show that F-actin attached to the vertical membranes (E). Bazooka protein is enriched in the horizontal borders both in the wild type (C) and in X-330 mutant (D). Red lines in the model show Bazooka is localized in the horizontal borders (F). Scale bar represents $10 \mu \mathrm{m}$.

\subsection{E-cadherin is a target of $\mathrm{X}-330$ mutant}

On one hand, half of the proteins are synthesized in ER, most of which are glycoproteins. Glycoproteins should be universally affected in X-330 mutant. On the other hand, X-330 mutant shows quite specific phenotype in gastrulation stage. It suggests that glycoproteins, which are required for cell survival, are not so much affected in the mutant, while some others, which function in cell behavior, are abnormal. E-cadherin is both a glycoprotein and a critical component in cell adherens junctions. It is a promising main downstream target, by which X-330 mutation affects cell movement. Drosophila E-cadherin has five cadherin-specific repeats (E1-E5), one EGF domain, one laminin domain and one transmembrane domain in mature proteins. Eight N-glycosylation sites were predicted in NetNGlyc 1.0 Server (Fig. 23) (http://www.cbs.dtu.dk/services/NetNGlyc/). 


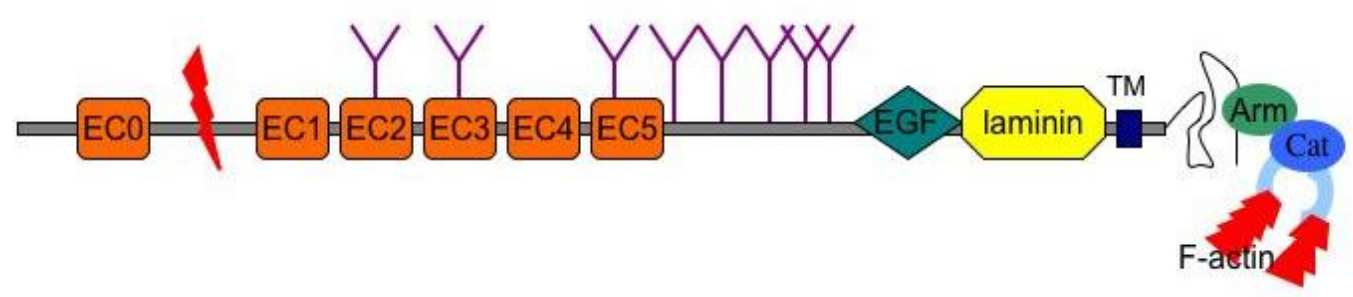

Figure 23. Schematic structure of Drosophila E-cadherin. In extracellular part, Drosophila Ecadherin has six cadherin-specific repeats (EC0-EC5). It is predicted that EC0 is cleaved off during maturation. In addition, it has one epidermal growth factor-like domain (EGF) and a LamininA globular repeat (laminin). Eight predicted N-glycosylation sites are marked (purple lines). It has a single transmembrane domain (blue bar). Drosophila E-cadherin intracellular part has high similarity with other vertebrate cadherins. E-cadherin interacts with F-actin via Armadillo and $\alpha$-catenin.

\subsubsection{E-cadherin protein is reduced in adherens junctions in X-330 mutant}

E-cadherin antibody (DCAD2) was used to do protein staining. In the wild type embryos, E-cadherin localized in adherens junctions and formed very sharp dots or lines (Fig.24A). However, in X-330 mutant, expression of E-cadherin was quite weak (Fig.24B). In E-cadherin-GFP ${ }^{\text {ubiquitin }}$ (E-cadGFP) transgenic flies, E-cadGFP protein was localized in adherens junctions (Fig.24C). However, when the transgene was recombined with X-330 mutant, E-cadGFP expression was much decreased (Fig.24D). These two results suggest that E-cadherin localization in adherens junctions is much reduced in X-330 mutant. E-cadherin western blot result further confirmed this conclusion (Fig.25A). 


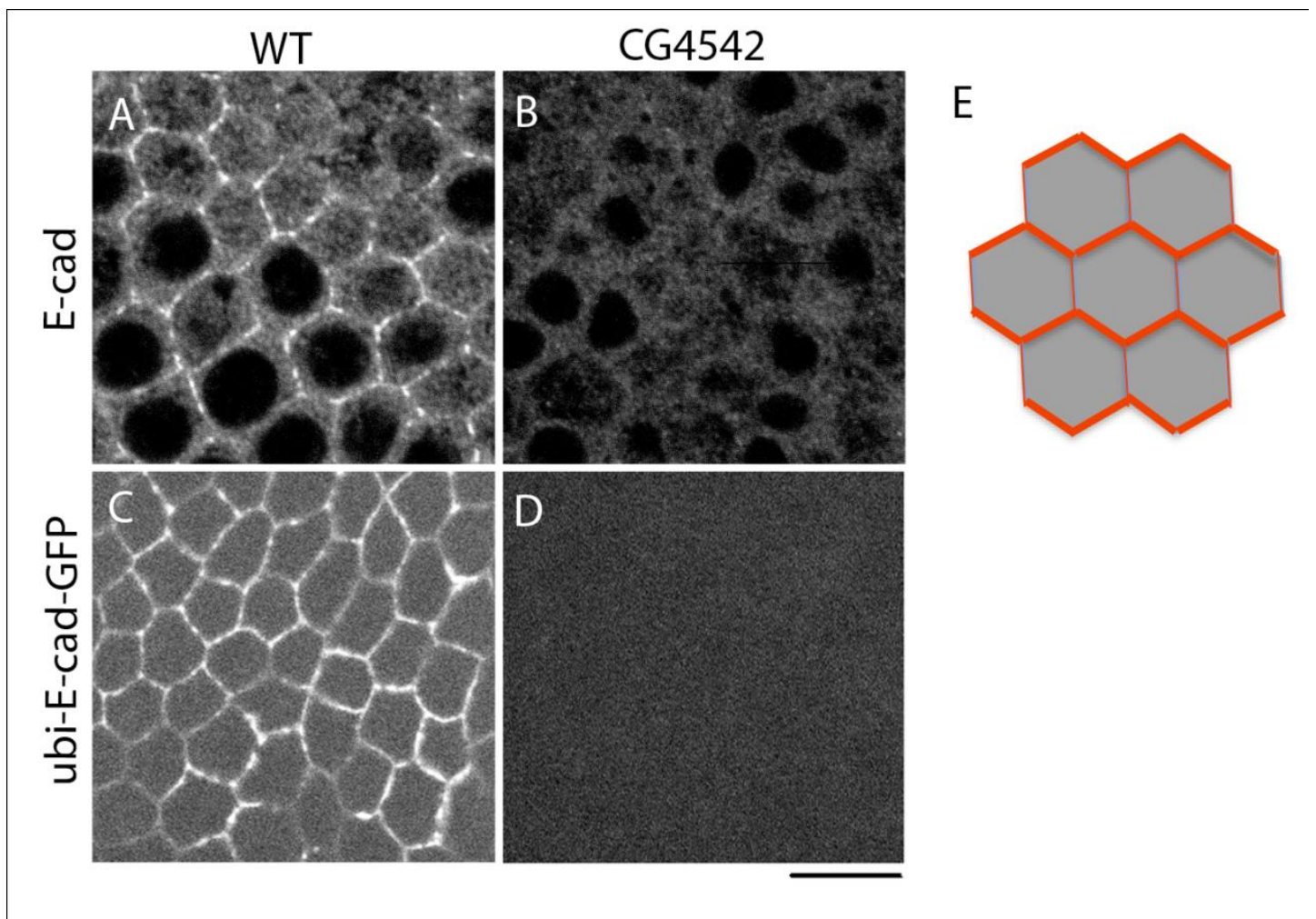

Figure 24. E-cadherin is reduced in adherens junctions in X-330 mutant. In protein staining, E-cadherin is localized in adherens junctions. The fluorescence signal is concentrated in sharp lines in the wild type embryos, stage7 (A). E-cadherin signal is very weak in X-330 mutant. No sharp lines are seen in junction position (B). E-cadGFP is localized in adherens junctions in the wild type background (C). In X-330 mutant background, E-cadGFP could hardly be seen (D). In the model, E-cadherin should be localized in adherens junctions and more enriched in the horizontal borders (E).

\subsubsection{E-cadherin is partially glycosylated in X-330 mutant}

In Western blot, E-cadherin was reduced in X-330 mutant (Fig.25A). $\alpha$-Tubulin was used as a control for protein loading amount. Interestingly, E-cadherin protein size was decreased in X-330 mutant, compared to the wild type one (Fig.25A). It indicates the glycosylation state of E-cadherin is affected. To further detect its $\mathrm{N}$ glycosylation, we used N-Glycosidase F (GaseF) to treat the protein samples, which could remove all the $\mathrm{N}$-glycans from proteins. Western blot was used to test protein size of different samples. After GaseF treatment, E-cadherin band shifted to the same position both in the wild type and X-330 mutant (Fig.25B). It suggests that Ecadherin protein without $\mathrm{N}$-glycans is the normal size in X-330 mutant. However, in X-330 mutant, E-cadherin band was in the middle position between the wild type 
band and the enzyme treated one (Fig.25B). It suggests that E-cadherin does not completely lose N-glycans in X-330 mutant. Instead, N-glycans are partially reduced.

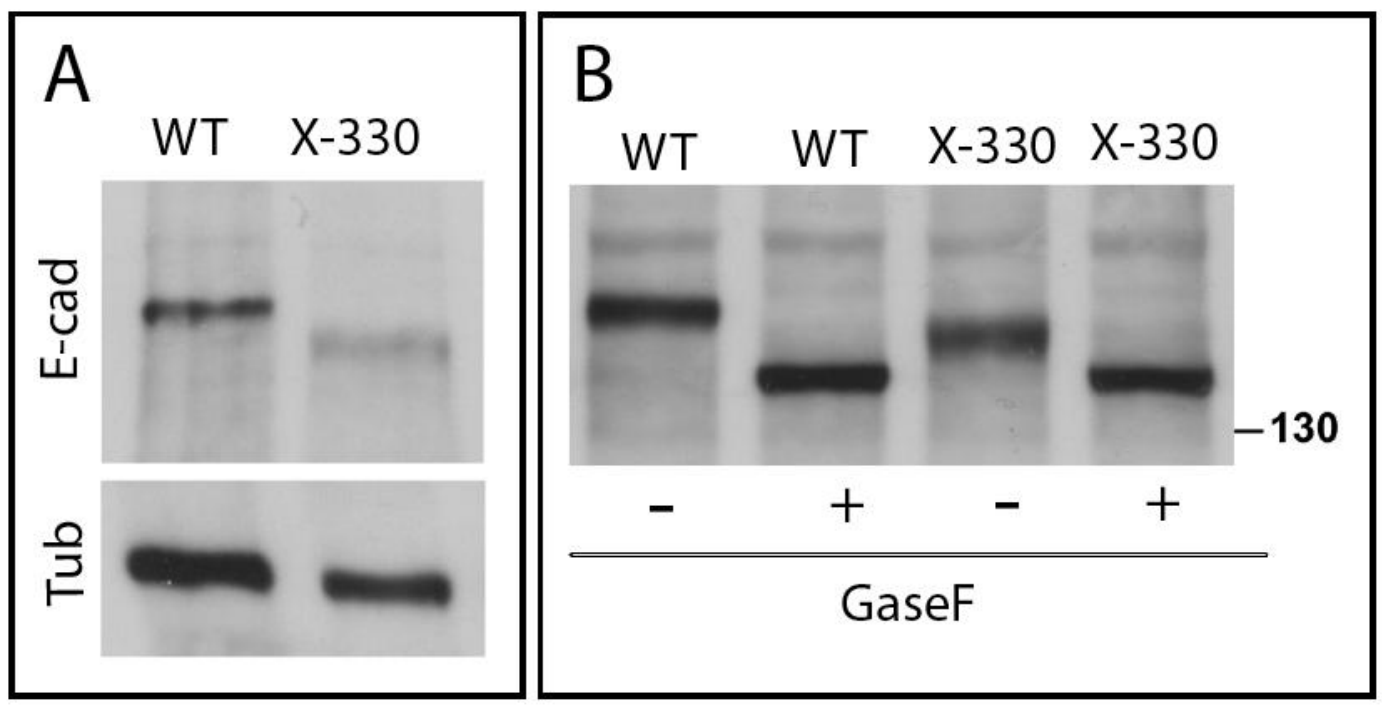

Figure 25. E-cadherin protein amount is reduced and its N-glycosylation is affected in X330 mutant. E-cadherin protein size is about $150 \mathrm{~kb}$. In western blot, E-cadherin band in X-330 mutant is much weaker than the wild type (A up layer). $\alpha$-Tubulin (Tub) is used to show that the loading amount of protein is comparable between the wild type and the mutant (A down layer). After GaseF treatment, E-cadherin bands in the wild type and the mutant are both in the same position (B, second and forth lane). The size of E-cadherin in X-330 mutant is between the wild type band and the enzyme treated one (B, third lane), which indicates its $\mathrm{N}$-glycosylation is partially impaired.

$\mathrm{N}$-glycosylation firstly synthesized the core pentasaccharide in ER, Man3GlcNAc2 (Fig.5). The glycoprotein was transferred to Golgi for further processing modification, producing three main classes of N-linked glycan classes: Highmannose, Hybrid and complex. The High-mannose glycans contain 5 to 9 mannose. To examine whether Golgi apparatus modification function is affected or not, EndoH was used to treat the protein extraction from the wild type and mutant embryos. EndoH only cleaves within the chitobiose core of high mannose and some hybrid oligosaccharides from N-linked glycoproteins. It means, only with Golgi modification, glycan could be cleaved by EndoH. The western blot result showed that E-cadherin bands in the two mutants without enzyme treatment were localized between the wild type one and the EndoH treated one. They shifted to the common lower position after EndoH treatment in the wild type, X-330 mutant and Wol267 
mutant (Fig.26). This result indicates that function of Golgi apparatus is not obviously affected by X-330 or Wol267 mutant.

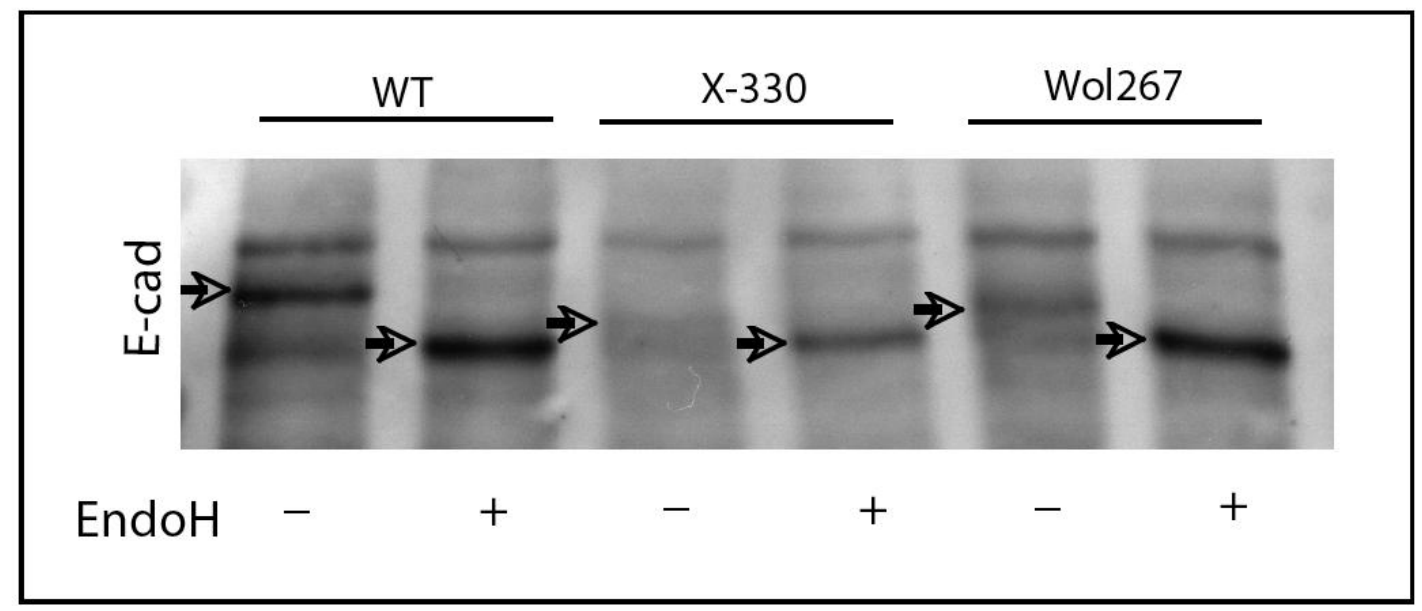

Figure 26. Modification of E-cadherin protein in Golgi may not be affected in the mutants. E-cadherin band was marked by arrow in every lane. After EndoH treatment (+), the band shifted to the same position in the wild type (WT) and the mutants (X-330 and Wol267).

\subsubsection{Expression and localization of some ER synthesized membrane proteins are normal, while the others are abnormal in X-330 mutant}

Since the reduction of E-cadherin protein is detected in X-330 mutant, our question is whether the other membrane proteins are affected or not. We examined another three membrane proteins: 117GFP (CG8668), Neurotactin and Crumbs (Hortsch et al., 1990; Tepass et al., 2001). 117GFP transgenic fly was made by GFP inserted into the membrane protein CG8668 site (inverse PCR sequence is provided by Dr. Alain Debec). In the wild type embryos, 117GFP was localized in cell junctions and formed sharp fluorescent lines (Fig.27A). In X-330 mutant, its localization and intensity was both normal (Fig.27B). Neurotactin is another membrane protein, which expresses in cellularization stage. Protein staining result showed that Neurotactin was localized in cytoplasm membrane both in the wild type and X-330 mutant (Fig.27C, D). 


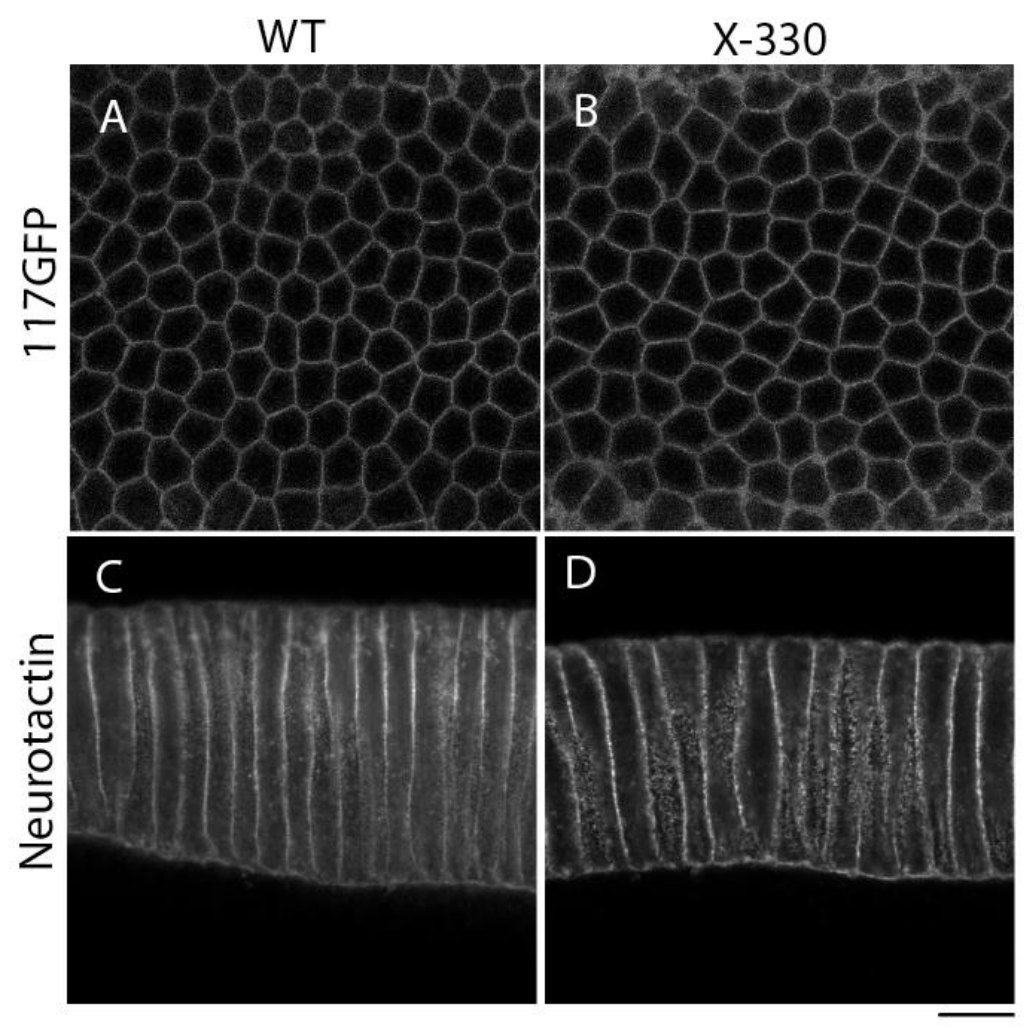

Figure 27. 117GFP and Neurotactin are normally localized in the cytoplasm membrane. 117GFP protein is localized in cell junctions both in the wild type (A) and X-330 mutant (B). Neurotactin is localized in the plasma membrane in the wild type (C) and X-330 mutant (D). A and $B$ are the surface view. C and D are the side view. Scale bar represents $10 \mu \mathrm{m}$.

Crumbs is another transmambrane protein, which is essential for maintaining the apicobasal polarity (Tepass et al., 2001). We extracted embryonic total proteins as a sample for western blot to examine Crumbs amount. Crumbs proteins contain three isoforms. In western blot result, a group of bands around $270 \mathrm{kDa}$ showed in the wild type sample (Fig.28). The bands, especially the biggest band, were weaker in X-330 mutant or Wol267 mutant, which indicates Crumbs proteins were reduced in the mutants (Fig.28). Taken together, we conclude that the defect of ER N-glycosylation makes some proteins not obviously affected, like 117GFP and Neurotactin, while some ones reduced, like E-cadherin and Crumbs. 


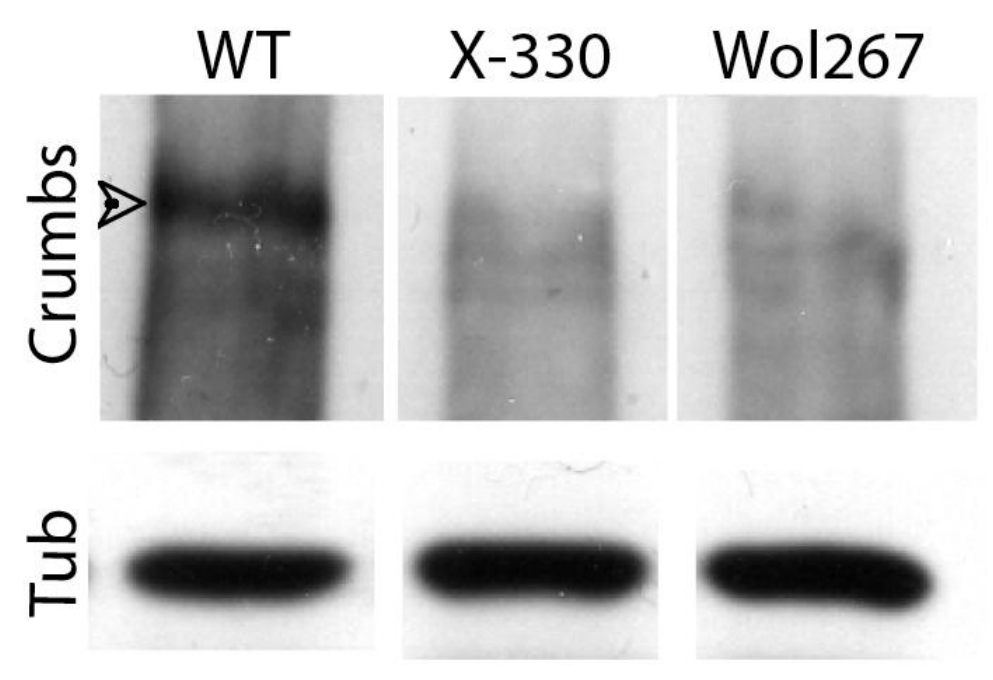

Figure 28. Crumbs is reduced in X-330 mutant and Wol267 mutant. In western blot, Crumbs show a group of bands around 270kDa: a stronger one (arrowhead) and two weaker ones. The bands in the mutants are in the same position, but weaker than the wild type. $\alpha$-Tubulin (Tub) is used as a loading control.

\subsubsection{Adherens junctions are normally localized in X-330 mutant}

Reduction of E-cadherin in X-330 mutant may affect adherens junctions' formation. To detect whether adherens junctions are affected or not, some other junction proteins were examined in stage7. Result showed that $\alpha$-Catenin (cat), Armadillo (arm) and Bazooka (baz) were all localized in adherens junctions (Fig.29A) (Tepass et al., 2001). Their expression was not apparently different from the wild type situation. Western blot was used to further examine the amount of proteins. Armadillo is about $105-110 \mathrm{kDa}$ (Peifer, 1993). $\alpha$-Catenin is 102kDa. In X-330 mutant, Armadillo was slightly reduced, while $\alpha$-Catenin was normal (Fig.29B). In Wol267 mutant, the protein amount of Armadillo and $\alpha$-Catenin were all in the same level with the wild type (Fig29B). These results indicate that the adherens junctions' formation and localization are not obviously affected in X-330 mutant or Wol267 mutant. 


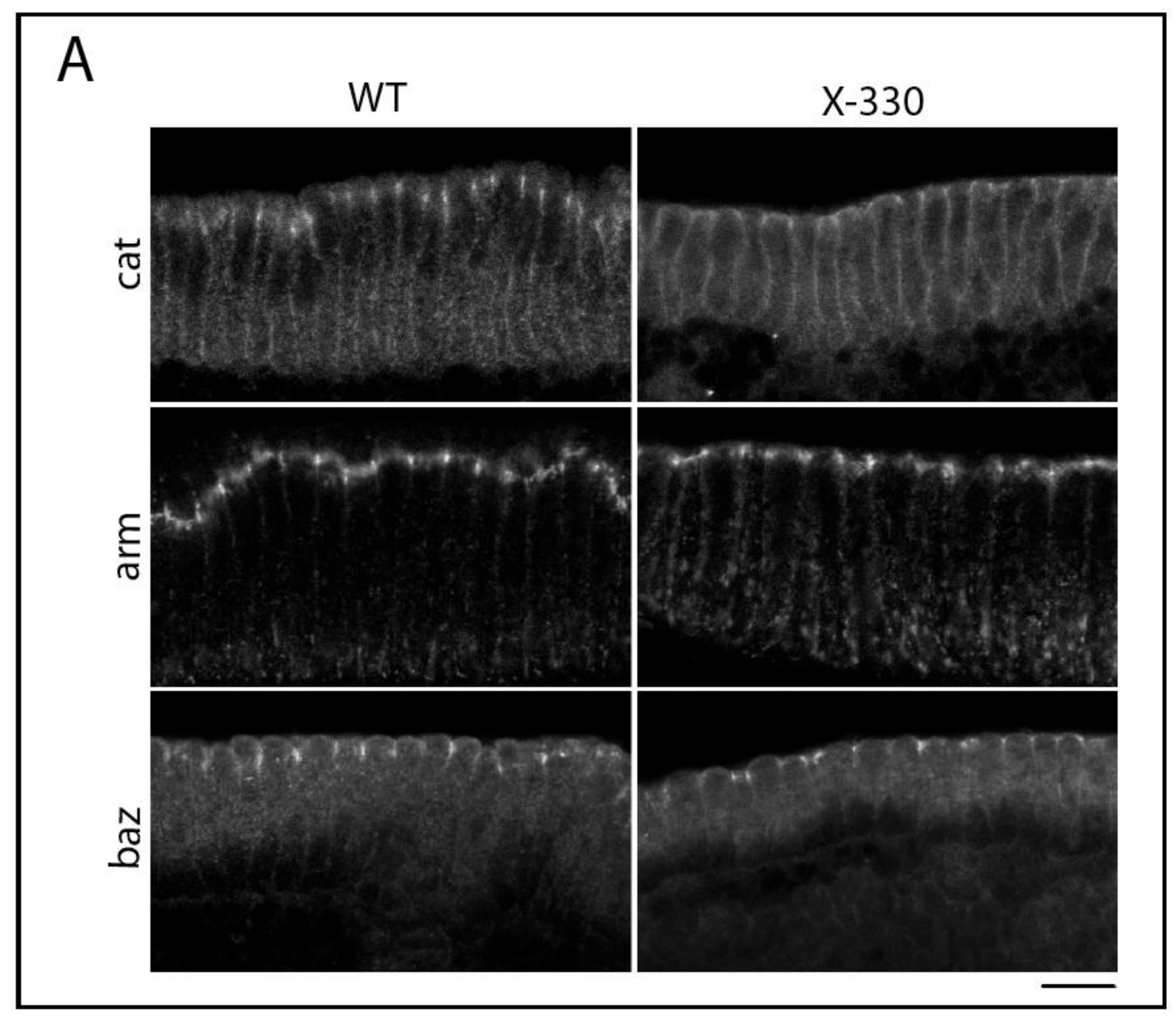

B

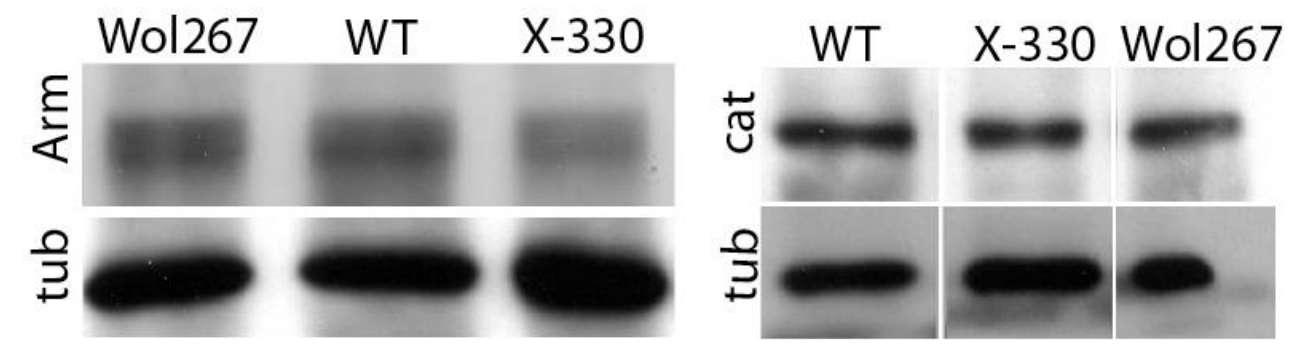

Figure 29. Adherens junctions are normally localized in X-330 mutant. In the wild type embryos of stage7, $\alpha$-Catenin (cat), Armadillo (arm) and Bazooka (baz) are all localized in junctional sites. In X-330 mutant, the three proteins' localization and their amount are similar with the wild type (A). In western blot, Armadillo is a group of bands in 110kDa. The bands in the wild type and Wol267 mutant are similar, while the bands in X-330 mutant are slightly weaker (B, left image). For $\alpha$-Catenin, it is a band in $102 \mathrm{kDa}$. The band position and intensity are all similar in the wild type and the mutants (B, right image). 


\subsubsection{Knockdown of E-cadherin induces cell intercalation defect during germ band extension}

In germ band extension, cells change their neighbors and set up new adherens junctions without breaking down the integrity of the cell sheet. However, the mechanism involved is not clear until now. E-cadherin, as the main component of adherens junctions, should function in this process. Therefore, reduction of Ecadherin may be the direct reason why X-330 mutant has cell intercalation defect during germ band extension. E-cadherin may be the downstream target of CG4542 and other $\mathrm{N}$-glycosylation enzymes, through which the mutants cause the specific phenotype in gastrulation. To examine our hypothesis, we did E-cadherin RNAi to knockdown E-cadherin in early stage embryos (within one hour after laying) and observed their development. After E-cadherin dsRNA injection, we picked the embryos, which could develop to cellularization stage normally, and took DIC movies. In about $68 \%$ embryos $(n=25)$, germ band extension stopped in the midgut position, which was quite similar with the phenotype of X-330 mutant, Wol mutant and Gny mutant (Fig.30, Fig.17A). It suggests that E-cadherin is the target of $\mathrm{N}$ glycosylation enzymes, by which the mutants affect cell intercalation during germ band extension.

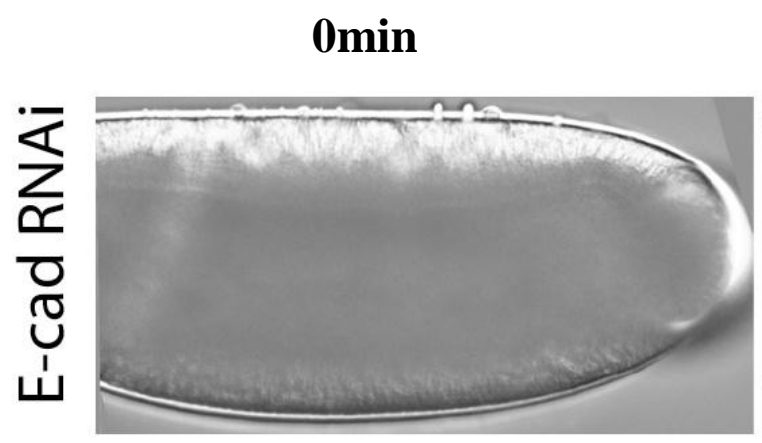

40min

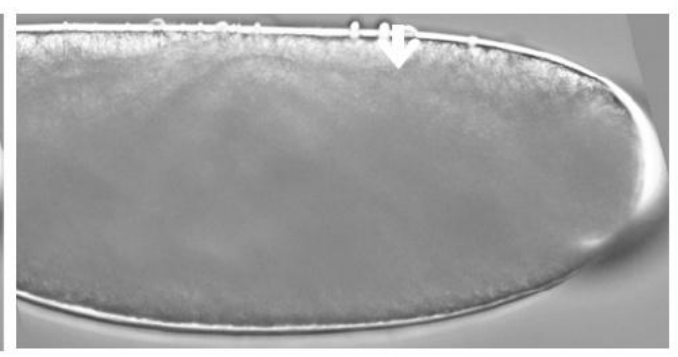

Figure 30. E-cadherin RNAi induces germ band extension defect. After injection of Ecadherin dsRNA in the wild type embryos, germ band extension was blocked in the midgut position (arrow). 0 min represents the germ cells start to move dorsally.

To characterize the $\mathrm{T} 1$ process in the E-cadherin knockdown embryos, we did Ecadherin RNAi in the 117GFP embryos, in which cells were marked and their movement could be tracked. We quantified borders of three types as mentioned before and found the $\mathrm{T} 1$ process was delayed like in X-330 mutant (Fig.20F). Most 
Type I could not transform to Type II or Type III within 30 minutes. This result indicates that E-cadherin is the downstream substrate of X-330 to induce the cell intercalation defect during germ band extension.

In addition, we tried to rescue the phenotype by overexpression of E-cadherin in X330 mutant background, using X-330/FM7; Cad::Cherry ${ }^{\mathrm{UAS}} / \mathrm{Cyo}$ and OvoX, Frt/C(1)/Y; mat67Gal4/Cyo. However, the germline clones were quite weak. It was very hard to get the embryos, which were not collapsed. Only a few $(n=6)$ could develop and all of them showed the germ band extension defect. It suggests that Ecadherin overexpression could not rescue the phenotype of X-330 mutant.

\subsection{New horizontal borders are formed by pulsed manner and stabilized by E-cadherin}

During cell intercalation, the T1 process involves two steps: vertical border constriction and new horizontal border extension. It is already known that the recruitment of medial myosin to junctional site causes the shrinkage of vertical borders (Rauzi et al., 2010). However, it is still remained unclear how the horizontal borders extend. Our result shows that E-cadherin is required for cell intercalation. It is possible that E-cadherin functions in horizontal border extension and new adherens junctions' formation. To examine this hypothesis, we tracked and analyzed the formation of new borders and E-cadherin dynamics.

\subsubsection{New horizontal borders extend by pulsed behavior}

Using 117GFP transgenic Drosophila, we recorded the cell intercalation during germ band extension by time-lapse images in the confocal microscope. We manually picked $30 \mathrm{~T} 1$ process cases in the wild type and X-330 mutant separately and measured their border length in every 30 seconds using ImageJ. Vertical border constriction and horizontal border extension were separated and made charts (Fig.31, 40). As for the new border extension, it was very efficient in the wild type cases. $90 \%$ of them extended to more than $1.1 \mu \mathrm{m}$ within 10 minutes (Fig.31B). However, in X330 mutant, the new formed borders could not extend fast, but always extended a little bit and shrank back to the 4-fold vertex. Sometimes, they even jumped back to vertical borders. 10 minutes after the border extension starts, only $30 \%$ cases were 
more than $1.1 \mu \mathrm{m}$ in $\mathrm{X}-330$ mutant (Fig.31A, B). It suggests that the new border extension is abnormal in X-330 mutant.

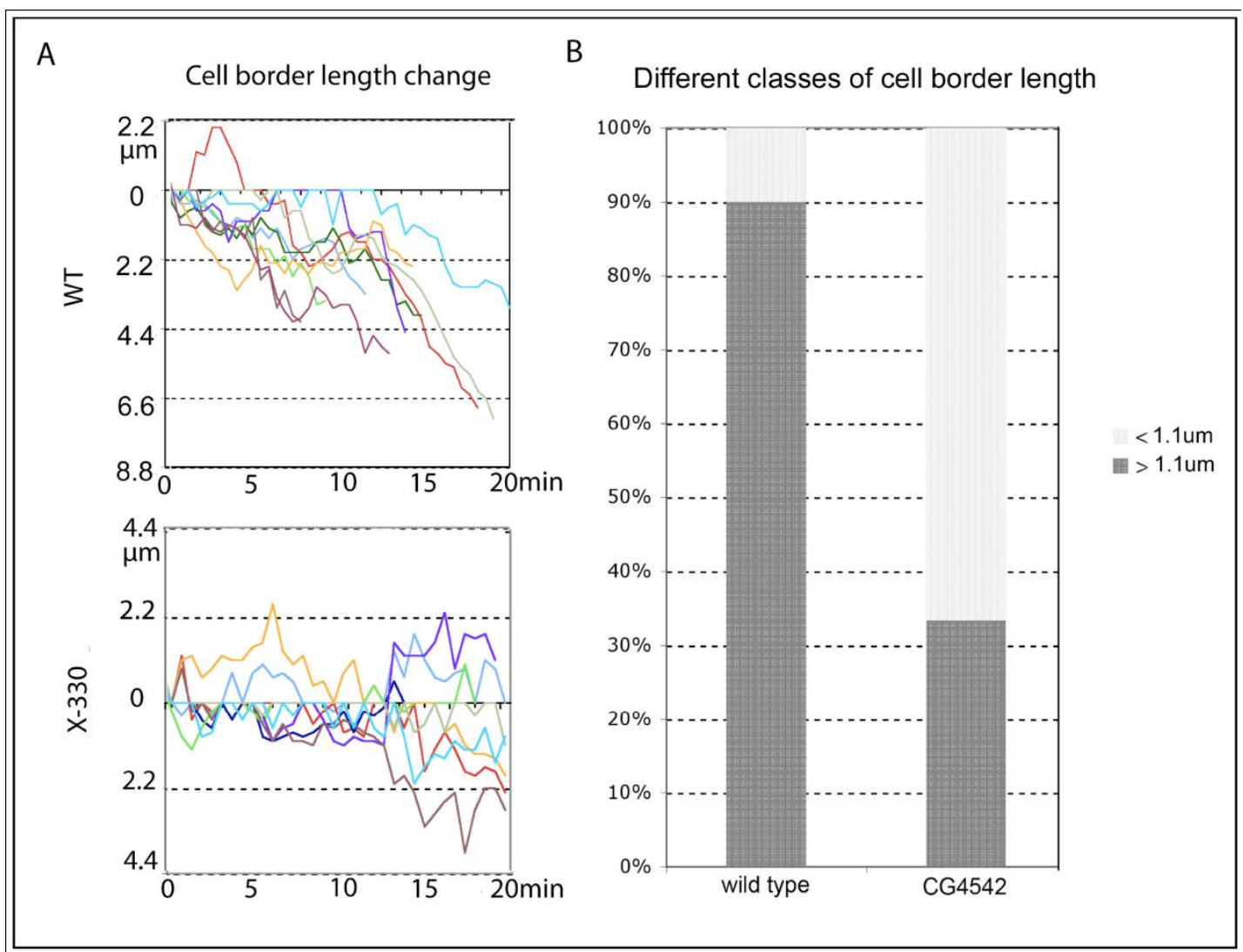

Figure 31. Comparison of the new border formation between the wild type and X-330 mutant.

A. In manually picked 30 cases, the border length is measured every 30 seconds. For new border extension, they fastly extend in horizontal direction in the wild type embryos (up one). In X-330 mutants, they are more stick to the 0 value (down one). B. 10 minutes after the new border extension, $90 \%$ of the border length is more than $1.1 \mu \mathrm{m}$ in the wild type (left). Only about $30 \%$ of the border length is more than $1.1 \mu \mathrm{m}$ in X-330 mutant (right).

In addition, we used EDGE program to make cell segmentation in 117GFP movies (Fig.32). The segmentation model was used by MATLAB to analyze the border length, cell area, cell shape and other relative parameters. For this analysis, we collaborated with Prof. Dr. Fred Wolf and Dr. Lars Reichl from Max Plank Institute for Dynamics and Self-Organization. We picked $30 \mathrm{~T} 1$ process cases in the wild type, X-330 mutant and E-cadherin RNAi separately. We did cell segmentation and cell border length measurement in MATLAB. In the result, two types of T1 process are shown here, while more data are shown in the Appendix (Spp.Fig.4). In some T1 
process, 4-fold vertexes lived very short and resolved into the new horizontal borders quite fast and efficient (Fig.33A, Fig.34A). While in other cases, the 4-fold vertexes lived relatively long. They extended slightly and shrank back to the 4-fold vertex until the last time, in which it extended and never came back again (Fig.33B, Fig34A). In all of the wild type cases we picked, the life times of 4-fold vertexes were within 5 minutes (Fig. 34A). The pulsed behavior during extension is quite interesting. The newly extended borders could not keep its length steadily in a short time, but always constrict a little bit. It seems there are two forces keeping balance during this process. Cells need the persistent extension to resist the tendency of constricting.

However, the situation in X-330 mutant is different from the wild type. The extension of the new borders was not efficient and always inclined to returning 4fold vertex or even the old vertical border state. After a long time, a new border extended into a horizontal border (Fig.33C) or still kept struggling against the 4vertex state (Fig.33D). Every curve is different, two of them are shown here (Fig33C, D). More data are in the Appendix (App.Fig.5). In the life time chart of 4-fold vertexes in X-330 mutant, some 4-fold vertexes extended instantly, while some ones remain its 4-fold vertex state for 1 to 11 minutes, even 20 minutes (Fig.34B). It suggests that the beginning of the new border extension is normal in X-330 mutant. However, the abnormality is in the increase of extension. Based on this result, we propose such a hypothesis: there are two forces in the new border extension. The first one takes charge of extending the new border. The second one is to stabilize the extended state. If the second force has defect, the new border could form, but always jump back to the original state.
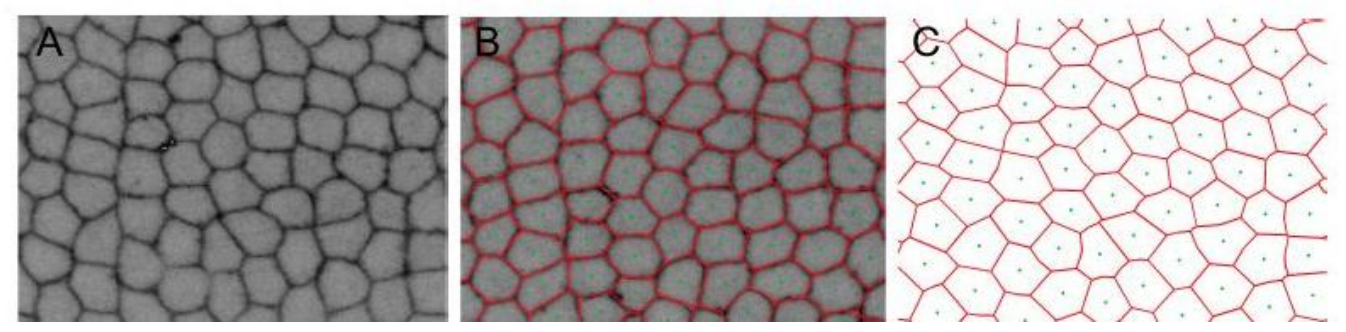

Figure 32. Cell segmentation by EDGE program. A. The original image of $117 \mathrm{GFP}$, taken by the confocal microscope. B. Cell's shape is recognized by EDGE program in MATLAB software. C. The recognized cell shape is made a model for analyzing the information included. 
A

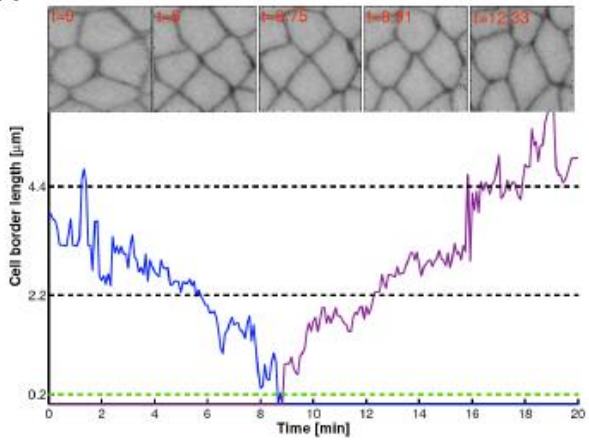

C

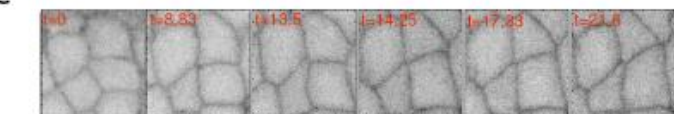

돌

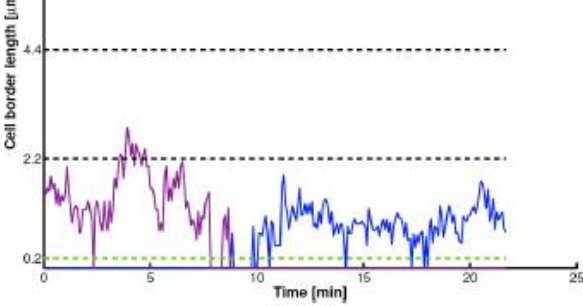

E

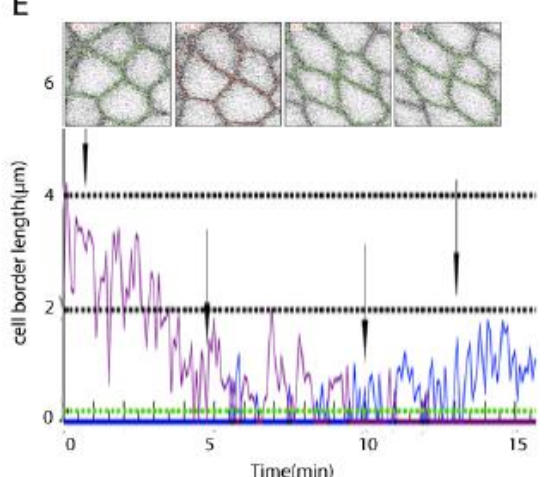

B

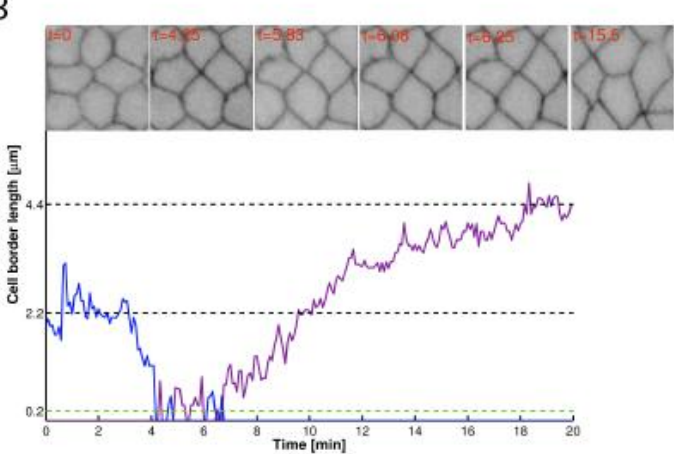

D

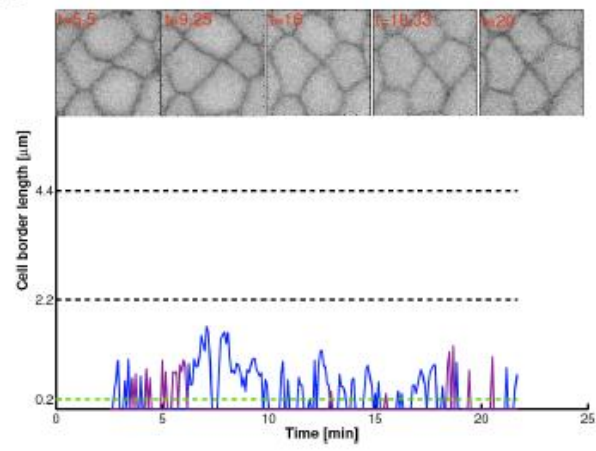

$\mathrm{F}$

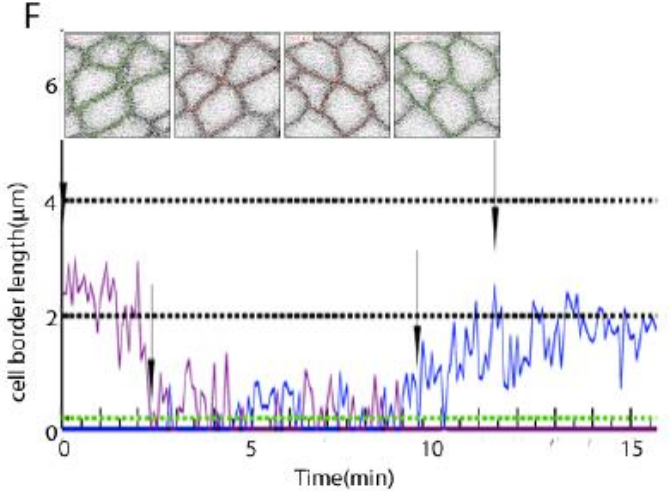

Figure 33. The length change of cell borders in the T1 process. EDGE program in MATLAB was used to do segmentation for 117GFP marked cell images. The border length was measured in every 5 seconds. In the wild type movies, new borders extend instantly or shortly after the 4-fold vertex formed (A, B). The extension is in a kind of pulsed behavior. In X-330 mutant, the pulsed behavior is more obvious. The new border extension is not as stable as the wild type, but always goes back to the 4-fold vertex or even to the vertical borer state $(C, D)$. In E-cadherin RNAi embryos, the new border extension is similar with X-330 mutant (E, F). 

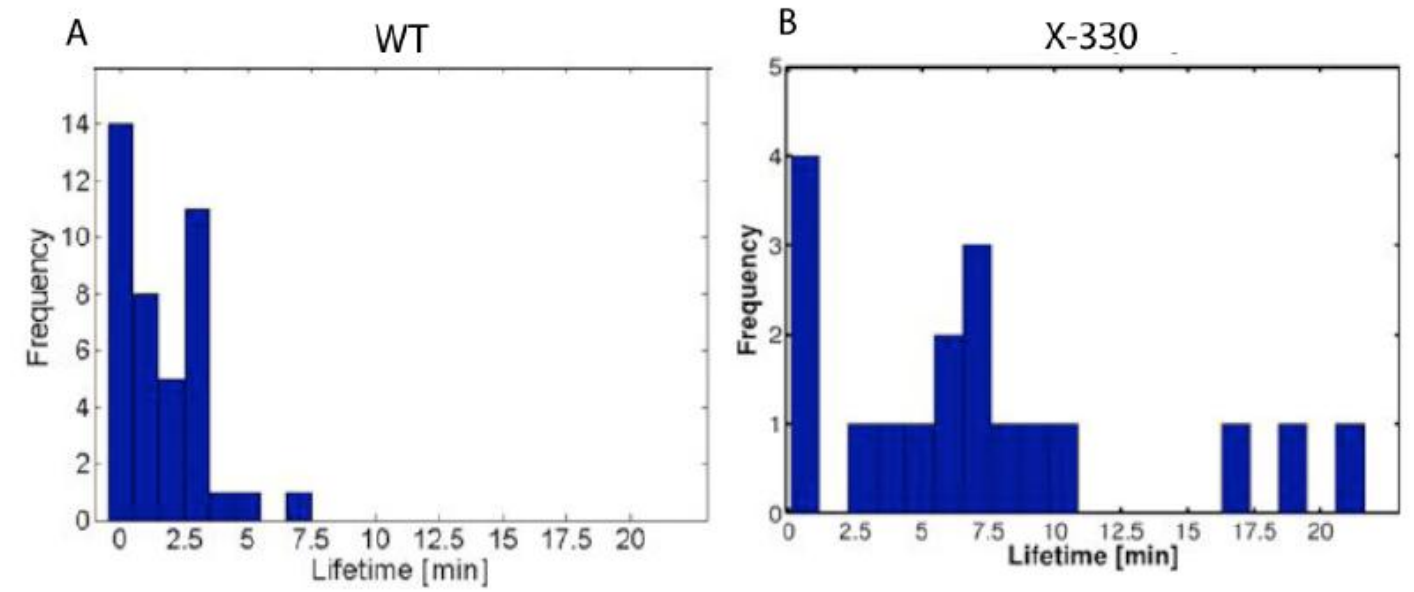

Figure 34. The Life time of 4-fold vertex in the T1 process of the wild type and X-330 mutant. In the wild type embryo, some 4-fold vertexes live shorter than 1 minute, while others live from 1 minute to 5 minutes (A). In X-330 mutant, the 4-fold vertexes live longer than the wild type ones. A few of them live less than 1 minute, similar with the wild type ones. Most others are scattered from 2.5 minutes to 20 minutes (B).

Knockdown of E-cadherin leads to the cell intercalation defect. To further characterize this phenotype, the cell border length was tracked during the T1 process (Fig. 33E, F and Spp.Fig.6). The curves in E-cadherin RNAi showed the length of the new borders was inclined to stick to 0 value or jump back to the vertical borders again. It indicates that the extension force is not enough to resist the constricting tendency. These curves are more like X-330 mutant ones, which indicates they may have the same defect during the $\mathrm{T} 1$ process. This result further suggests that $\mathrm{E}$ cadherin is required for the $\mathrm{T} 1$ process and the new border extension. Its function may be for stabilizing the extended new borders.

\subsubsection{E-cadherin is gradually accumulated in the new adherens junctions during the new border formation}

E-cadherin is important for the T1 process. However, how it is involved in this process is unknown. There are two possibilities: One is that E-cadherin actively contributes to new border extension. Its accumulation in the new borders provides force to stick the new neighbor cells together. The other possibility is that E-cadherin is passively accumulated after the new borders' formation. It does not provide force for the new border extension. To examine which possibility is true, we tracked E- 
cadherin dynamics during $\mathrm{T} 1$ process. In the Cad::GFP ${ }^{\text {cadherin }}$ transgenic fly, Cadherin::GFP was knocked into the original E-cadherin gene position, which means the Cad::GFP amount should be the same with E-cadherin in the wild type embryos. We recorded time-lapse images of Cad::GFP ${ }^{\text {cadherin }}$ in stage7 and measured the green fluorescence intensity during the new horizontal border extension. In 20 cases randomly picked, about 50\% showed that GFP intensity obviously increased during the new border extension (Fig.35A, B). In the beginning of the 4-fold vertexes extending to the short horizontal borders, the GFP intensity suddenly decreased, gradually recovered and got stronger and stronger (Fig.35A). 10 cases in one movie were collected to show that the GFP intensity increased about 2 folds in 5 minutes (Fig.35B). This result indicates that E-cadherin could not provide the force for cell border extension. Instead, it is involved in forming the new adherens junctions, which may facilitate stabilizing the extended new borders.

Fluorescence recovery after photo bleaching (FRAP) was used to further examine the dynamics of E-cadherin. Laser bleaching decreased the E-cadGFP fluorescence to about $20 \%$ of the original intensity (Fig.36). Within 2 minutes, the signal recovered to about $50 \%$ of the original intensity both in the vertical borders and the horizontal borders. It indicates that the dynamic turnover of E-cadherin protein is very fast, which means it has the ability to accumulate in the new adherens junctions rapidly. However, the real case is that E-cadherin is first diluted by the length extension and accumulates later. This result further suggests that E-cadherin is not required for the new border extension, but may function in stabilizing the extended borders. 
A
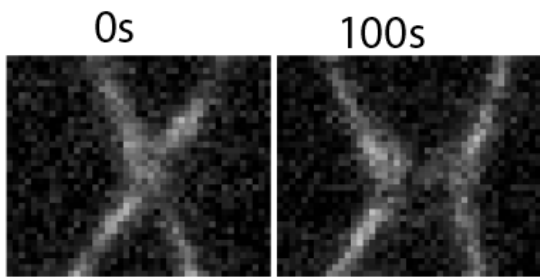
200 s

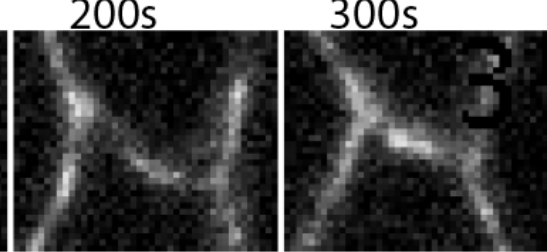

10um

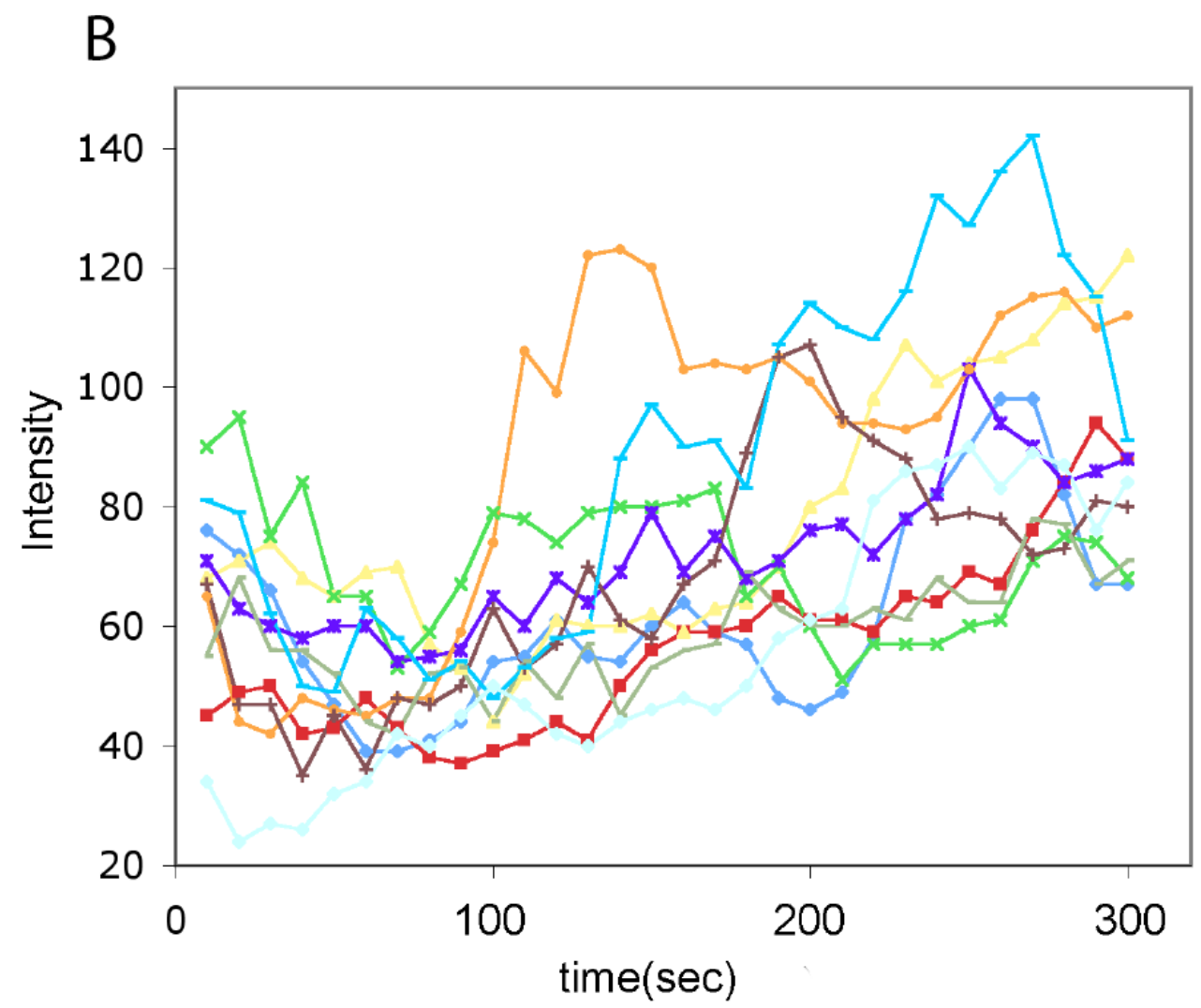

Figure 35. E-cadherin is accumulated gradually in the new formed junctions. E-cad::GFP represents the in vivo E-cadherin expression without any does effect. Time-lapse images were taken to track the dynamics of E-cad::GFP during the new cell border formation. E-cad::GFP was quite weak in the beginning of the new border extension. Within 5 minutes, it is accumulated and get stronger and stronger (A). 10 cases were collected to make a chart for the E-cad::GFP signal intensity during 5 minutes. E-cad::GFP increased about 2 folds in 5 minutes (B). 


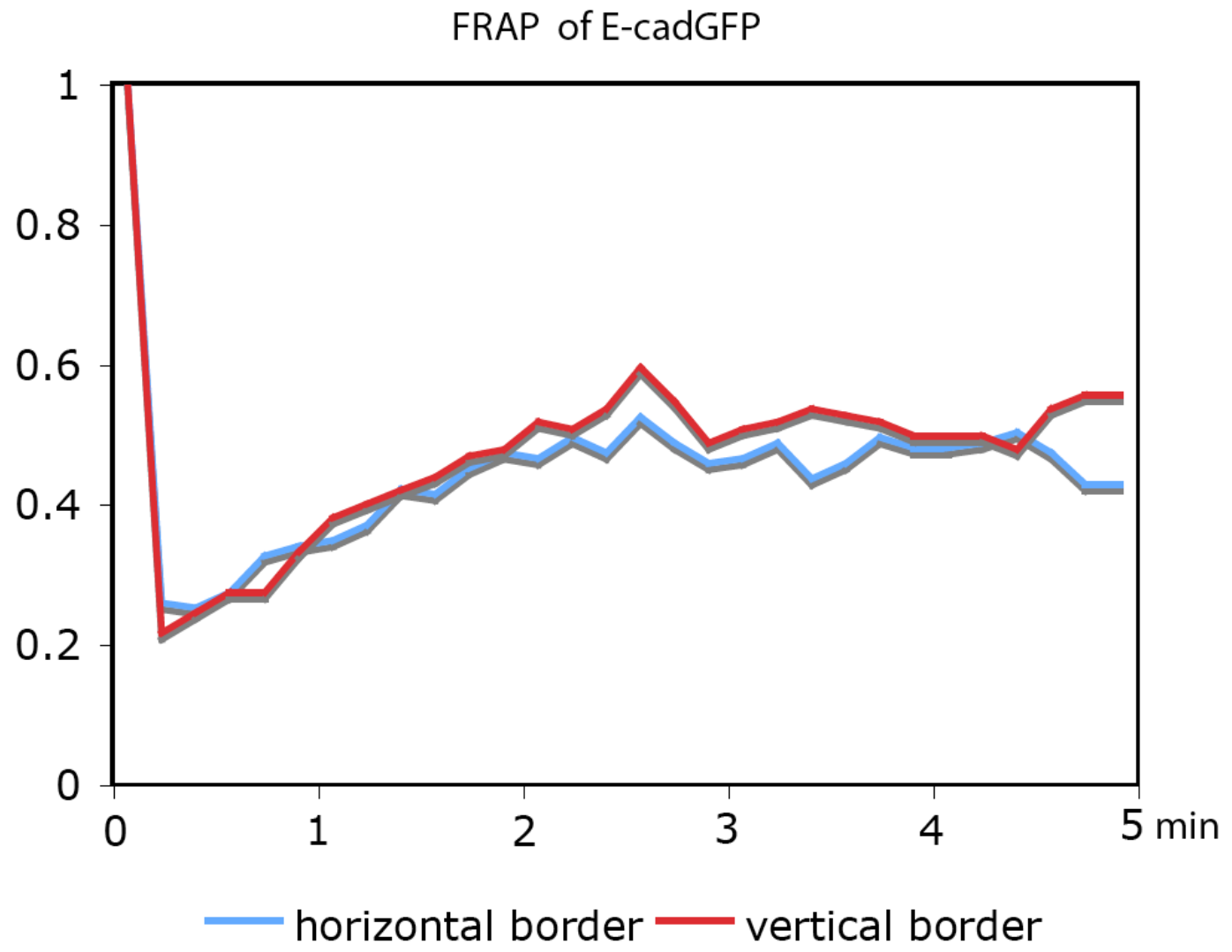

Figure 36. E-cadherin recovers quite fast after photo bleaching. In FRAP experiment, the fluorescence decreased to about $20 \%$ of the original intensity by laser bleach. It recovered to about $50 \%$ in 2 minutes. Blue line represents a horizontal border. Red line represents a vertical border.

To further study the correlation between E-cadherin amount and the length of newly formed cell borders, we picked 32 cases from 3 single movies and measured both the GFP intensity and the new border length. With the help of our collaborator, we made curves to show their correlation (Fig.37 up row, Spp.Fig.3). Interestingly, the anticorrelation was found between the two curves. To make the result more clear, we also made the detrended curves, in which the linear trend was subtracted from the original curves (Fig.37 low row, Spp.Fig.3). Almost all of the $\mathrm{C}$ values were negative, which means the two curves are anticorrelation (Fig.37, 38A). We also made a heat chart to show the anticorrelation of GFP intensity and the length of newly formed borders, using red color to represent high value and blue color to represent low value (Fig.38B). This result further confirmed that the new border extension is earlier than E-cadherin accumulation. Cell border extension makes E-cadherin diluted. More E- 
cadherin protein is accumulated afterwards, possibly functioning in stabilizing new borders.
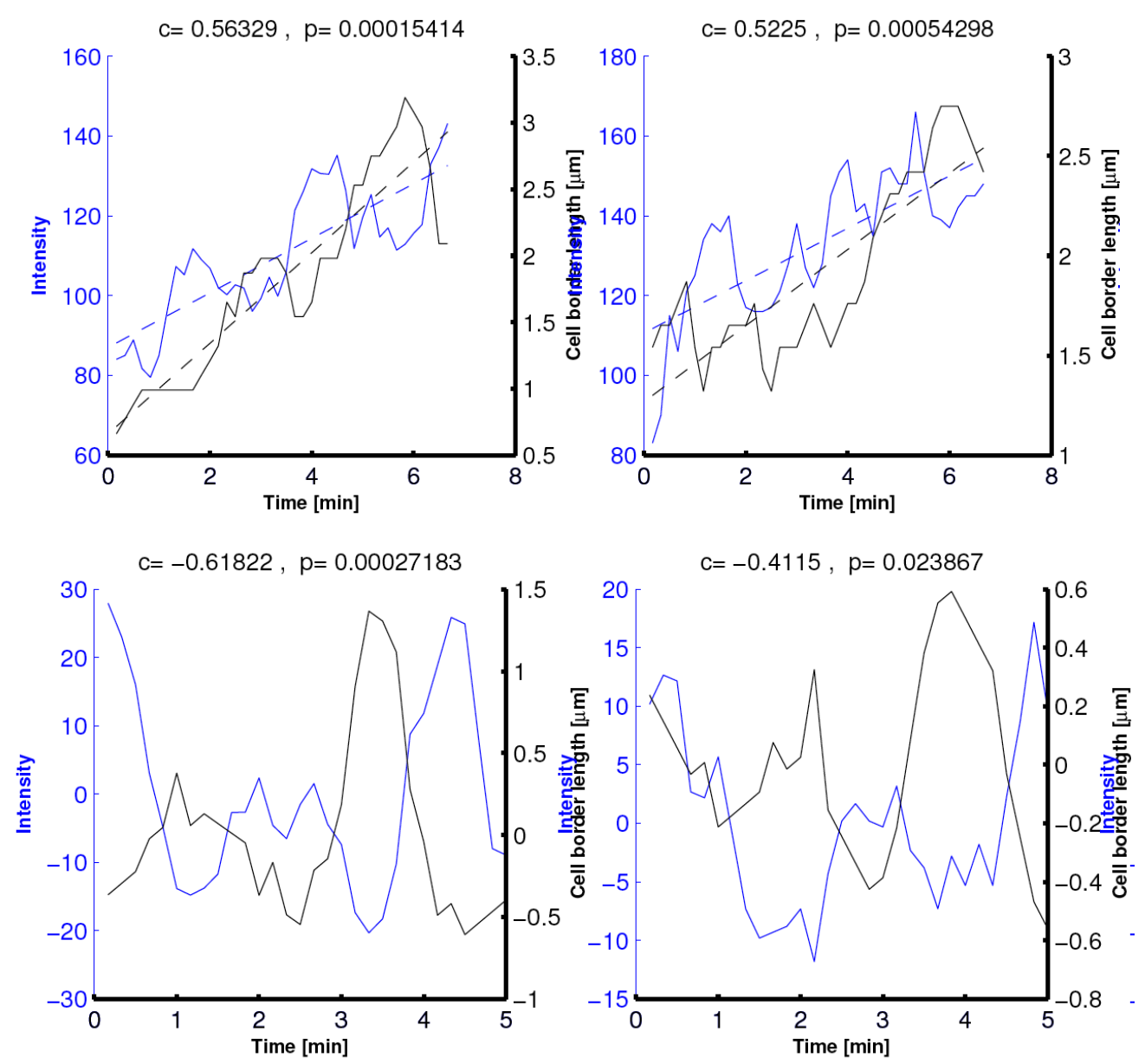

Figure 37. E-cadherin protein amount and the new border length are anticorrelated. Ecad::GFP's fluorescence intensity and the new cell border length are in the same chart. They two curves have anticorrelation (up row for two cases). In each chart, Y axis of GFP intensity (Grey value from 0 to 255) is in the left side, while $\mathrm{Y}$ axis of cell border length is in the right side. $\mathrm{X}$ axis shows the time scale. The blue curves represent E-cadherin intensity. The black curves represent the border length. Detrended curves are made to clearly show the anticorrelation (low row for the upper cases). 
A

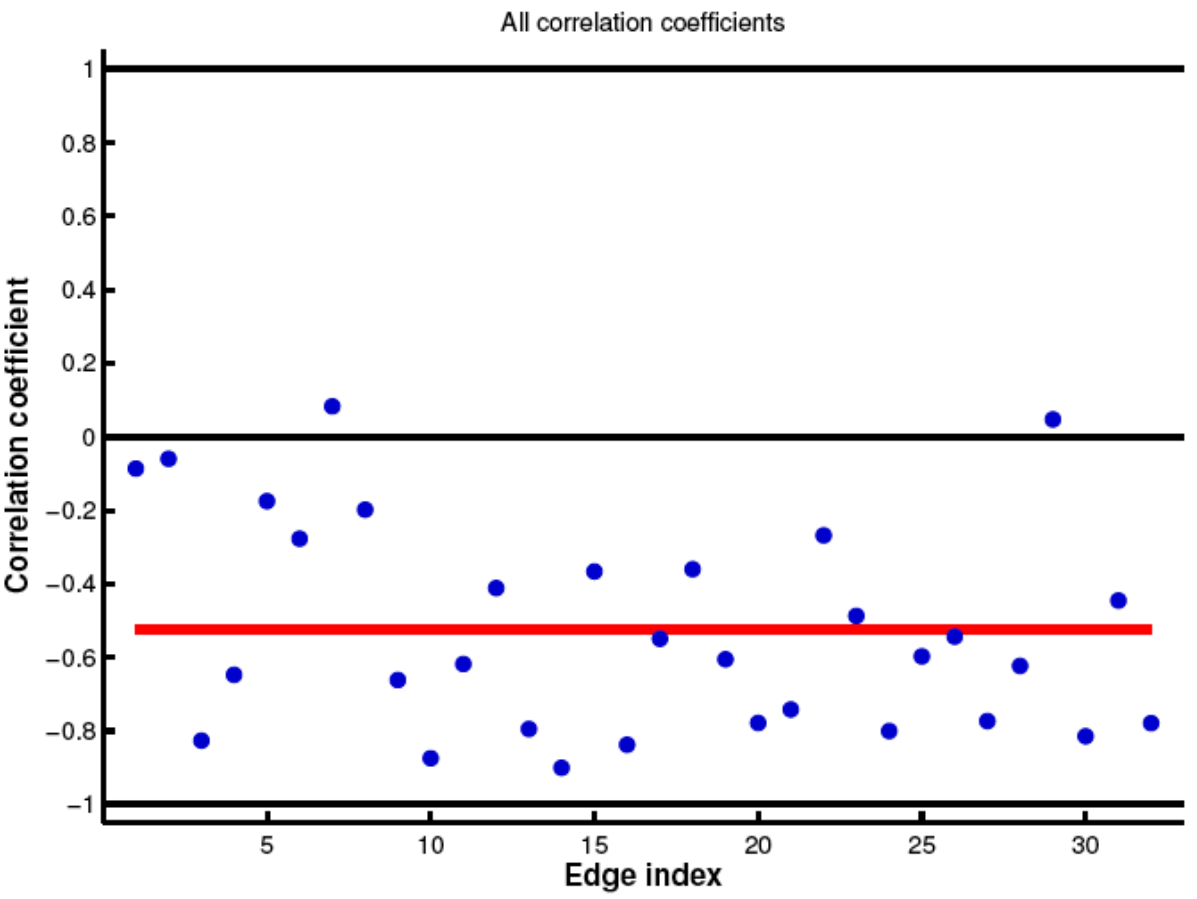

B

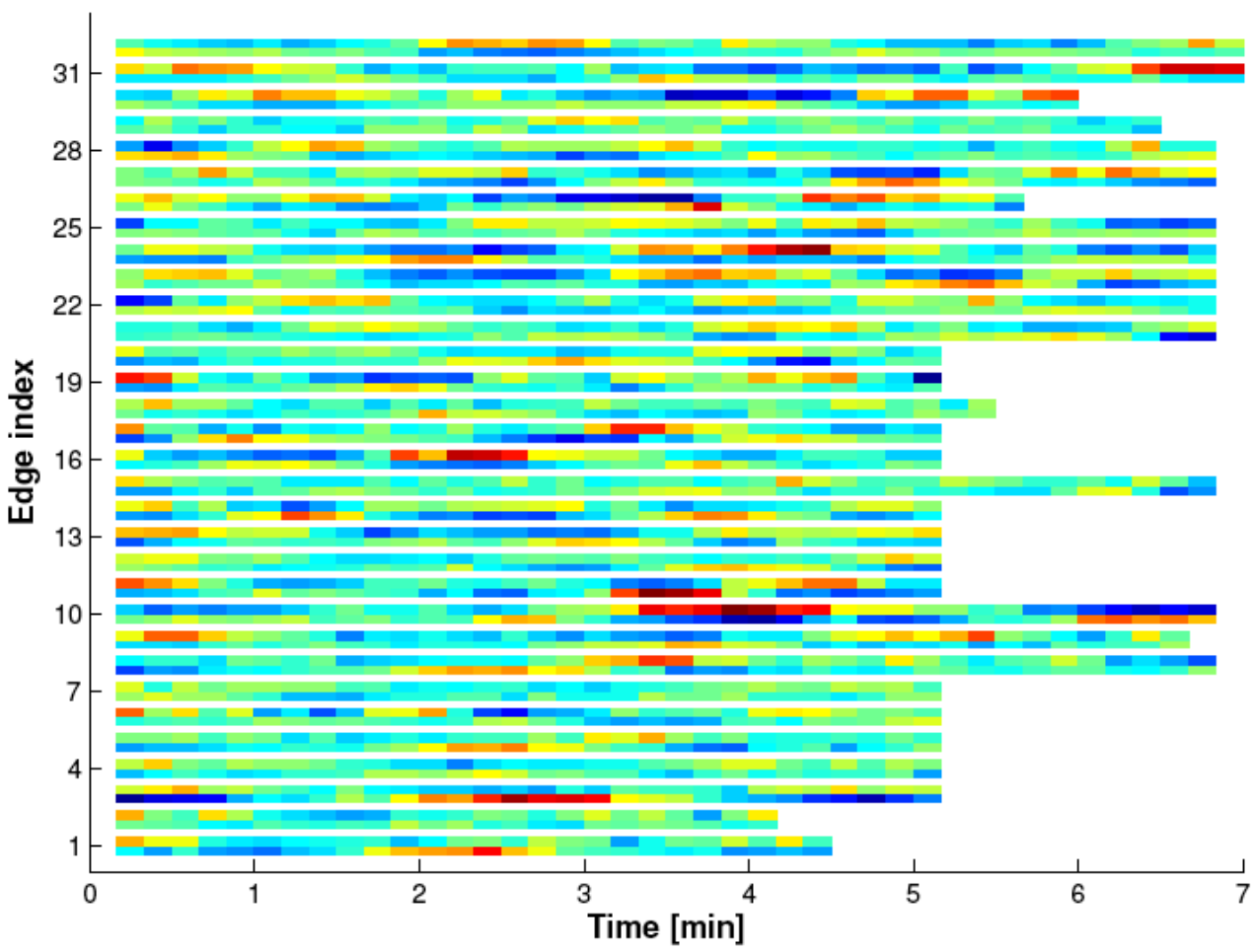

Figure 38. E-cadherin protein amount and the new border length are anticorrelated. A. C value of thirty cases is almost all negative values, only with two exceptions. B. Different colors are used to represent the different values in heat bars. From blue to red, the values increase. For every two color bars, the upper one shows E-cadherin intensity, while the lower one shows the new border length. The colors between the two bars are complementary to each other, indicating that they are anticorrelated. 


\subsubsection{Myosin enrichment in vertical junctions is delayed in X-330 mutant}

Myosin-II flows from the medial region to the vertical junctions drive the vertical border shrinkage (Martin et al., 2009; Rauzi et al., 2010). The shortening of border length is stabilized by junctional myosin (Fernandez-Gonzalez et al., 2009; Rauzi et al., 2008). To examine whether the localization of myosin in X-330 mutant is normal or not, Myosin::Cherry ${ }^{\text {ubiquitin }}$ transgenic flies were used to track the myosin dynamics. In stage 7, shortly after the ventral furrow formation, myosin appeared in the germ band region (Fig.39A). Its signal was weak and random. 10 minutes later, myosin was enriched in the junctional sites with stronger localization in the vertical borders (Fig.39C). In 20 minutes, myosin signal was very strong and sharp in the vertical borders (Fig.39D). Myosin's weak signal appeared in the normal time in X-330 mutants (Fig.39E, I). However, it could not accumulate in the junction sites within 10 minutes (Fig.39G, K). In 20 minutes, the medial myosin was still randomly localized in X-330 mutant (Fig.39H, L). In some embryos, junctional myosin could not be detected, only medial myosin tethered near the cell borders (Fig.39H). While in other ones, the localization of junctional myosin could be weakly detected with planar polarity (Fig.39L). It suggests that the recruitment of medial myosin to junctional sites is blocked in X-330 mutant. In addition, vertical border constriction was tracked by measuring the randomly picked 30 cases. In the wild type, most cases finished the constriction within 10 minutes (Fig.40A). The times were concentrated in about 5 minutes (Fig.40B). In X-330 mutant, vertical border constriction was delayed. They could accomplish shrinkage within 20 minutes (Fig.40A). The times were more scattered than the wild type ones (Fig.40B). The delayed vertical border constriction could be explained by the defect of medial myosin's recruitment to junctional sites in X-330 mutant. 

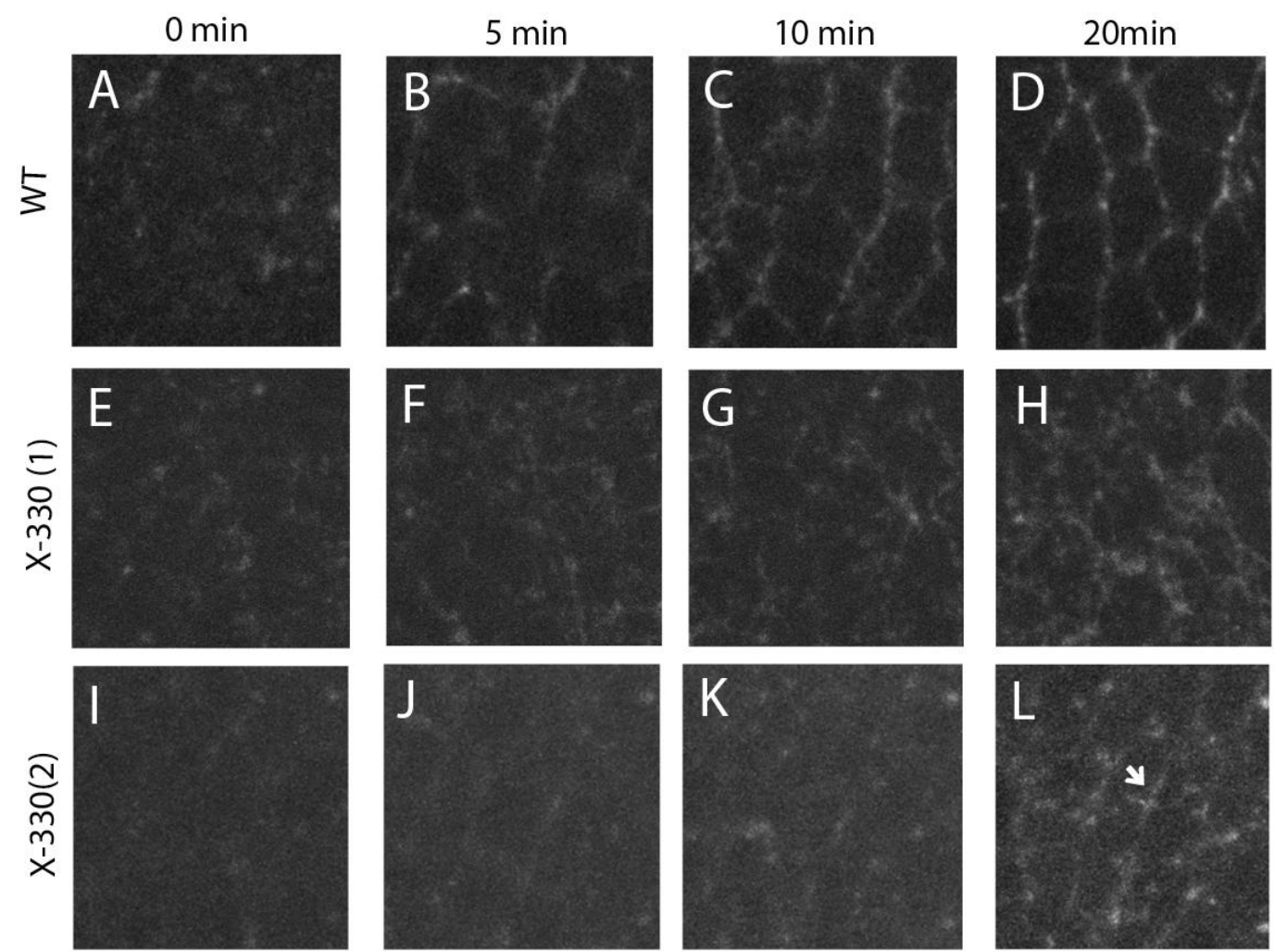

Figure 39. Medial myosin's recruitment to junctions is inhibited and delayed in X-330 mutant. In the wild type embryos, medial myosin is gradually increased and recruited to junctions (A-D). For two cases of X-330 mutant: X-330 (1) and X-330 (2), their myosin accumulation is both delayed. The medial myosin in the mutant is stronger than the wild type one (E-H, I-L). For X-330 (1), junctional myosin is not detectable (H). For X-330 (2), junctional myosin is weak (arrow) with the planar polarity (L).

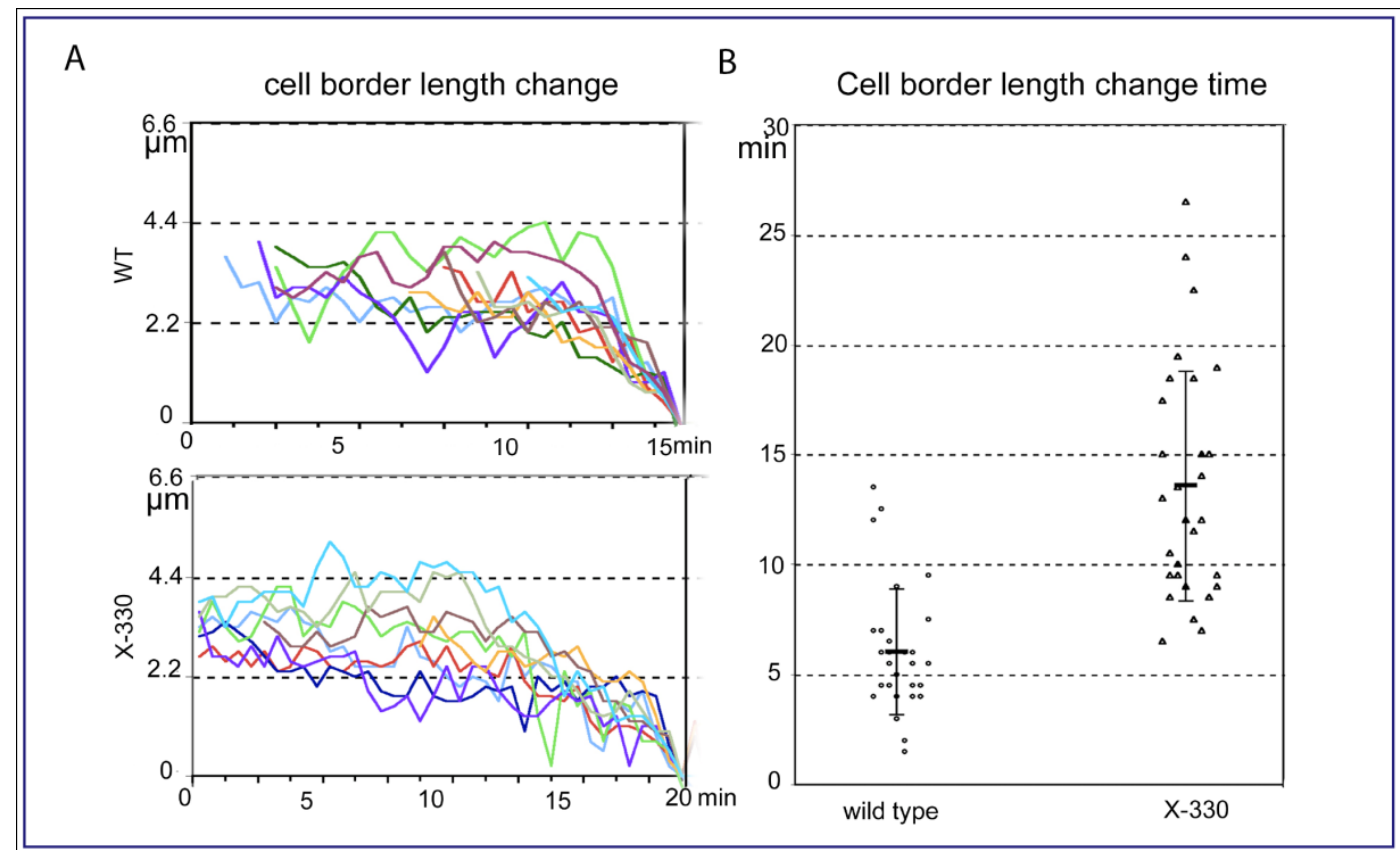


Figure 40. The constriction of vertical borders is delayed in X-330 mutant. A. In manually picked 30 cases, the border length is measured every 30 seconds. Based on the curves of border length change, vertical border constriction is mostly within 10 minutes in the wild type embryos (up one). In X-330 mutant, the constriction time is prolonged to 15 to 20 minutes (down one). B. In this chart, every point represents the time of each vertical border constriction. The times are concentrated to about 6 minutes in the wild type (left). In X-330 mutant, the average time is about 13 minutes (right). The times are more scattered than the wild type ones.

\subsection{Other phenotypes in $\mathrm{X}-330$ mutant}

\subsubsection{Ventral furrow could not form normally in X-330 mutant}

In 117GFP transgenic flies, cell borders are marked, which makes the cell movement and cell shape change tractable. We recorded the time-lapse images of ventral furrow formation (Fig.41A). In the wild type embryos, the presumptive mesoderm invaginated, caused by the cell' s apical constriction. 10 minutes after the apical constriction starts, internalization of the mesodermal precursors formed the ventral furrow. Within 30 minutes, ventral furrow closed completely. The mesoderm and the ectoderm were separated (Fig.41A, up row). In X-330 mutant, apical constriction of ventral cells could start normally. However, the mesodermal precursors ' invagination and the ventral furrow' s closure were inhibited (Fig.41A, down row). We measured the single cells' area in the ventral side in every 2.5 minutes. It was shown that the apical constriction of presumptive mesoderm cells in X-330 mutant was delayed, especially in 7.5 to 10 minutes (Fig.41B). 
A
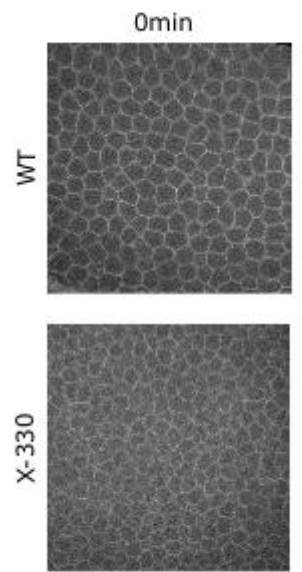

B

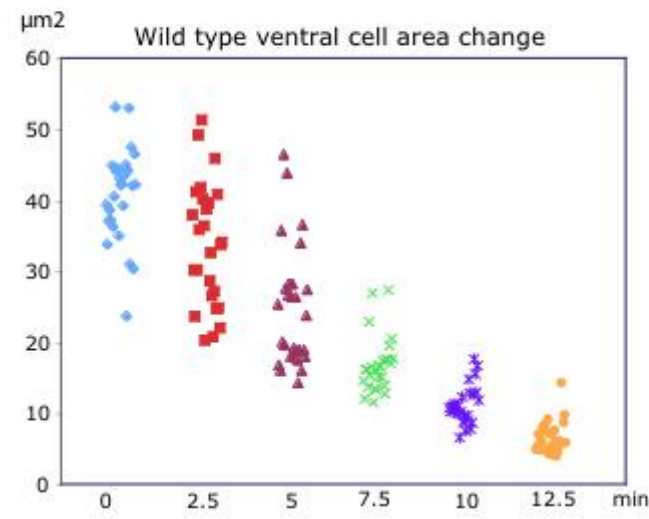

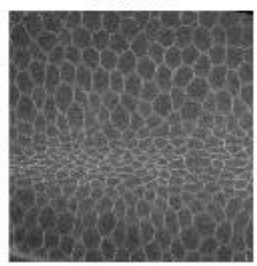

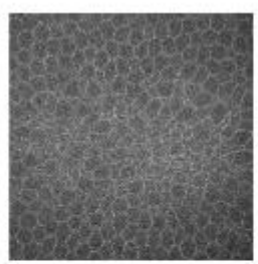

$20 \mathrm{~min}$

$30 \mathrm{~min}$
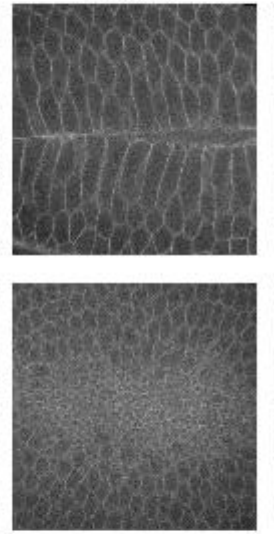
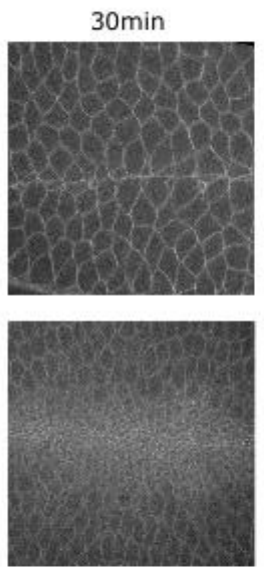

$\mathrm{X}-330$ mutant ventral cell area change

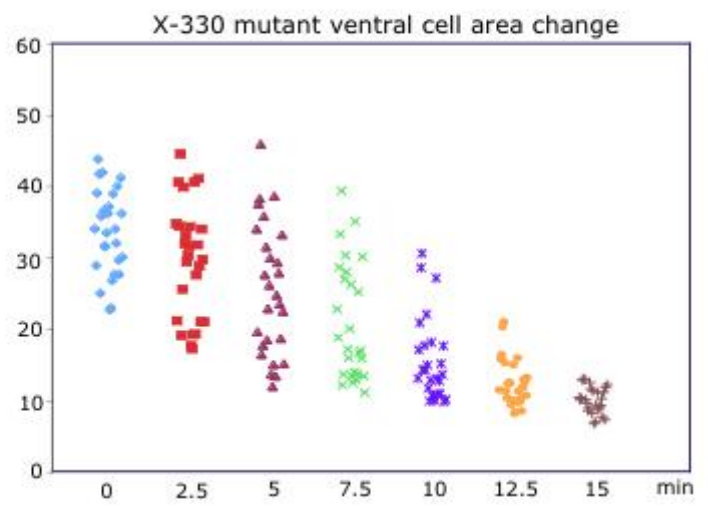

Figure 41. Ventral furrow formation is abnormal in $\mathbf{X}-\mathbf{3 3 0}$ mutant. In the wild type embryos, the apical constriction of the ventral cells finished within 10 minutes. The ventral furrow formed and closed in 30 minutes (A, up row). In X-330 mutants, the apical constriction starts normally, but the ventral furrow could not close even after 40 minutes (A, down row). In the wild type embryos, area of the ventral cells decreased very fast (B, left chart). In X-330 mutant, apical constriction was delayed and scattered (B, right chart).

\subsubsection{Dorsal-Ventral polarity is abnormal in $\mathrm{X}-330$ mutant}

Rhomboid (Rho) is a dorsal-ventral patterning marker, which is expressed in two ventrolateral bands in the downstream of Dorsal during cellularization (Stathopoulos and Levine, 2002). It is expressed in the dorsal cells shortly before gastrulation, activated by Dpp signal (Fig.42A-C). In X-330 mutant, Rho expresses in two bands in ventral side, which is normal, in cellularization stage (Fig.42D). However, the two bands remain still very strong in late cellularization stage, even in gastrulation stage, which is abnormal. Its expression in dorsal side only concentrates to a strong point in the anterior part (Fig.42E, F). This result indicates that X-330 mutant affects dorsal- 
ventral patterning upstream of Dpp. It is consistent with the result that Rho has the similar expression pattern in Wol284 mutant (Haecker et al., 2008). We conclude that $\mathrm{N}$-glycosylation affects the DV patterning.
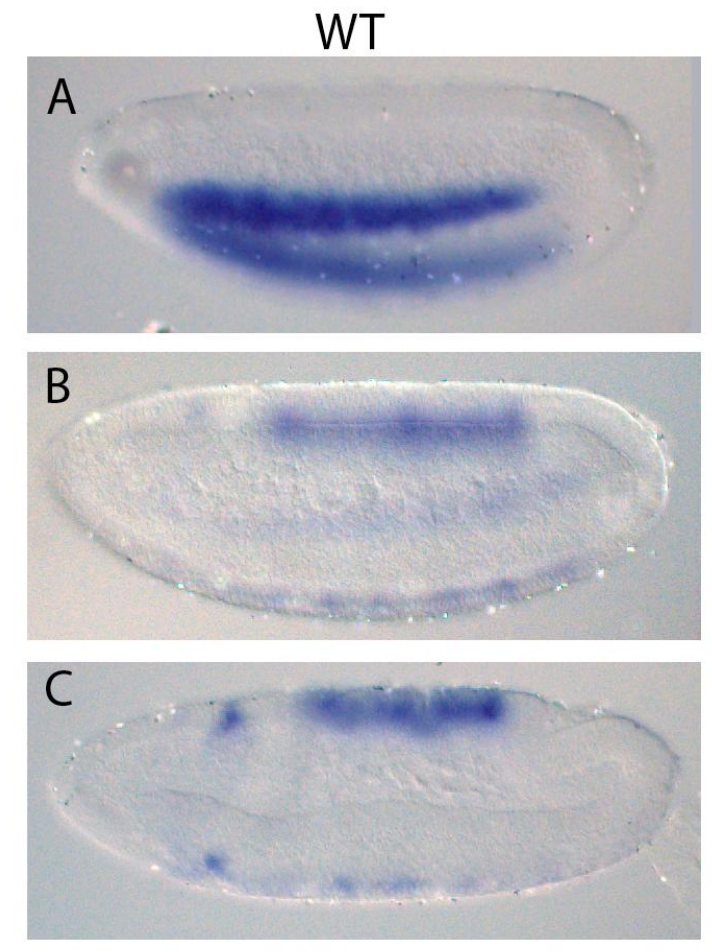
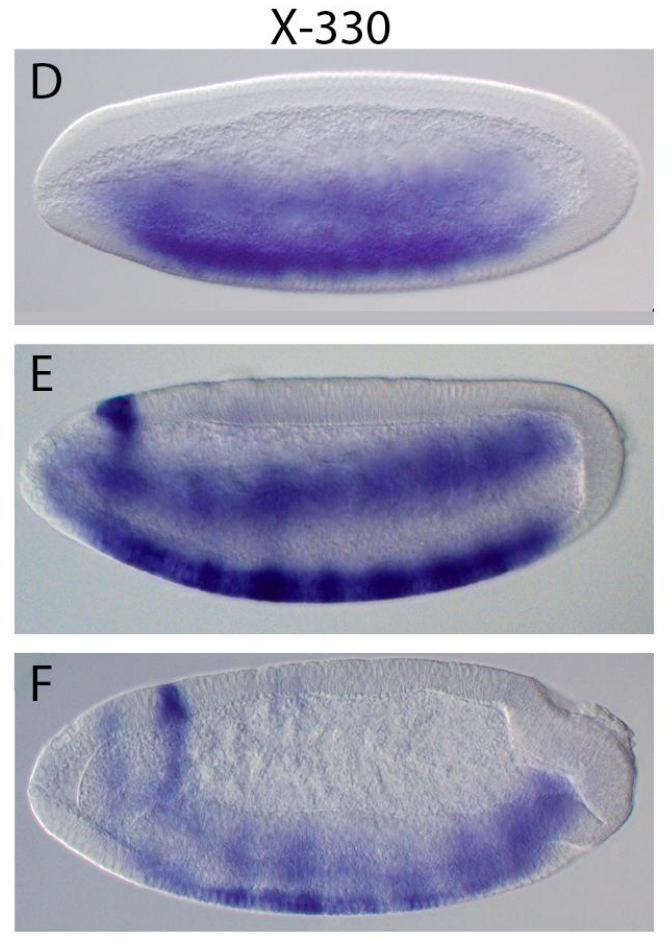

Figure 42. Dorsal-ventral patterning is abnormal in X-330 mutant. A-C. In the wild type embryos, Rho expressed in two ventrolateral bands in cellularization stage (A). In the beginning of gastrulation, it is expressed in one band in the middle of the dorsal side (B). This dorsal expression is stronger in stage7 (C). D-F. In X-330 mutant, Rho expressed in two ventral bands, which is normal (D). In the beginning of gastrulation stage, the ventral expression is still quite strong with one strong point expression in the anterior-dorsal part (E). In stage7, the ventral expression is still abnormal (F).

\subsubsection{Mesoderm patterning is normal in X-330 mutant}

Since ventral furrow formation is impaired in X-330 mutant, the question is proposed that whether the mesoderm specification is affected or not. Twist is a ventral mesoderm marker, which is expressed in about 20 rows of nuclei in the ventral cells in cellularization stage (Fig.43A) (Leptin and Grunewald, 1990; Thisse et al., 1988). In X-330 mutant, Twist expression in the ventral cells is normal (Fig.43B). It indicates that the mesoderm specification may be normal in X-330 mutant. 

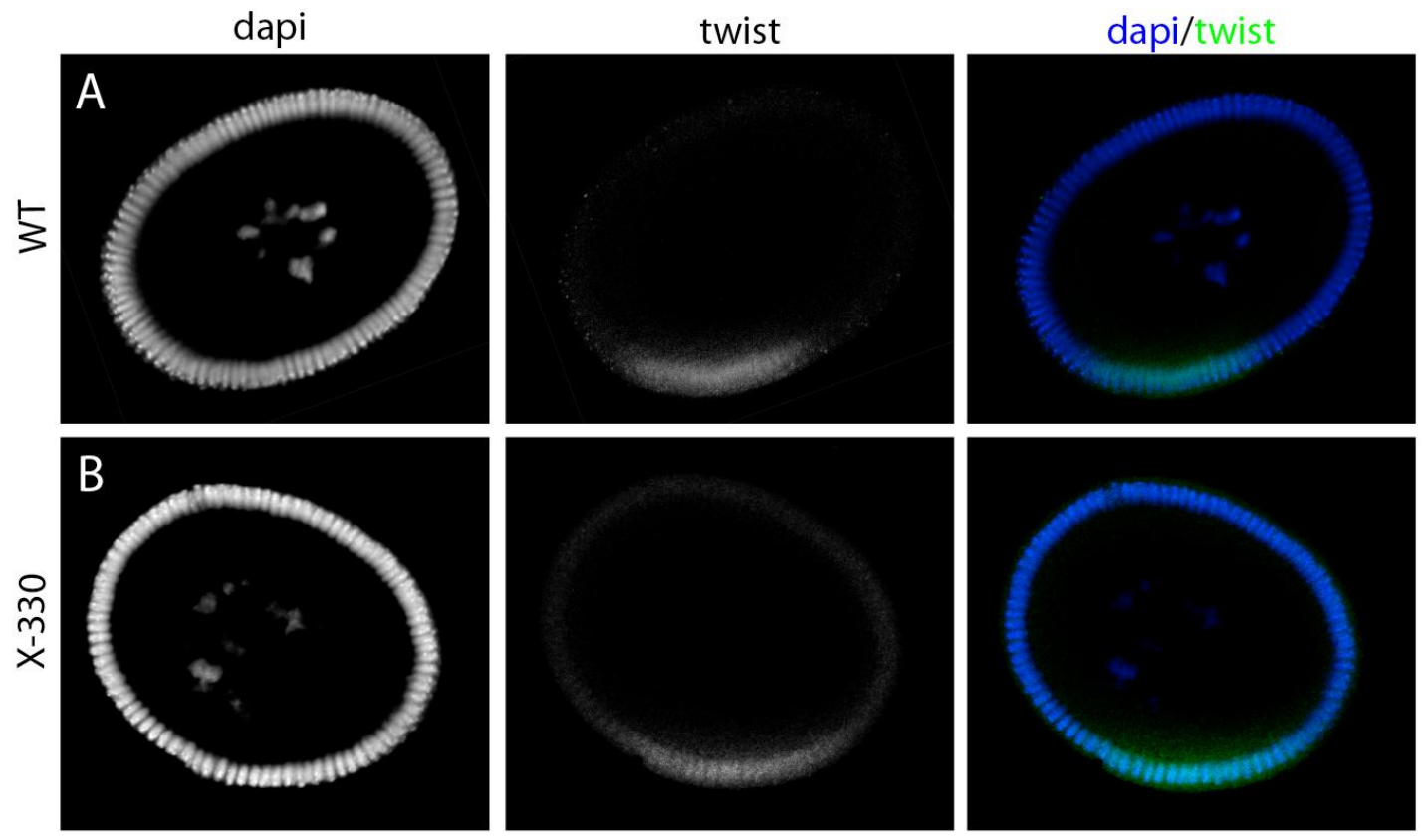

Figure 43. Twist protein is normally expressed in X-330 mutant. DAPI is blue fluorescence. Twist is green fluorescence. In the wild type, twist protein localizes in about 20 rows of ventral cell's nuclei in cellularization stage (A). In X-330 mutant, this expression pattern is normal (B).

\subsubsection{No obvious defect is shown in X-330 mutant follicle cell clones}

It is mentioned previously that many germline clones of X-330 mutant collapsed especially after long-time heat shocks $(2 \times 1 \mathrm{~h})$. This indicates that the phenotype may be related with the size of the follicle cell clones. To examine if there is some abnormality in X-330 mutant follicle cell clones, we did protein staining to test the expression and localization of adherens junctions and cytoskeleton molecules. In the follicle cells, X-330 homozygous mutant clones have no green fluorescence, while $\mathrm{X}-330 / \mathrm{GFP}$ heterozygous clones and GFP homozygous clones have green fluorescence, based on which we could distinguish different genotypes. The egg chambers in stage10 of oogenesis were used. Dlg is a lateral membrane marker. Armadillo and Bazooka are adherens junctions' markers. Actin is a cytoskeleton marker. In X-330 mutant clones, protein expression and the localization of all the markers were normal as the wild type clones (Fig.44). This result further confirmed that X-330 mutant does not affect cell adherens junctions' formation and cell polarity. We conclude that epithelium formation has no obvious defect in X-330 mutant in 
early oogenesis stage. The defect that leads to collapsed embryos may appear in later stage.
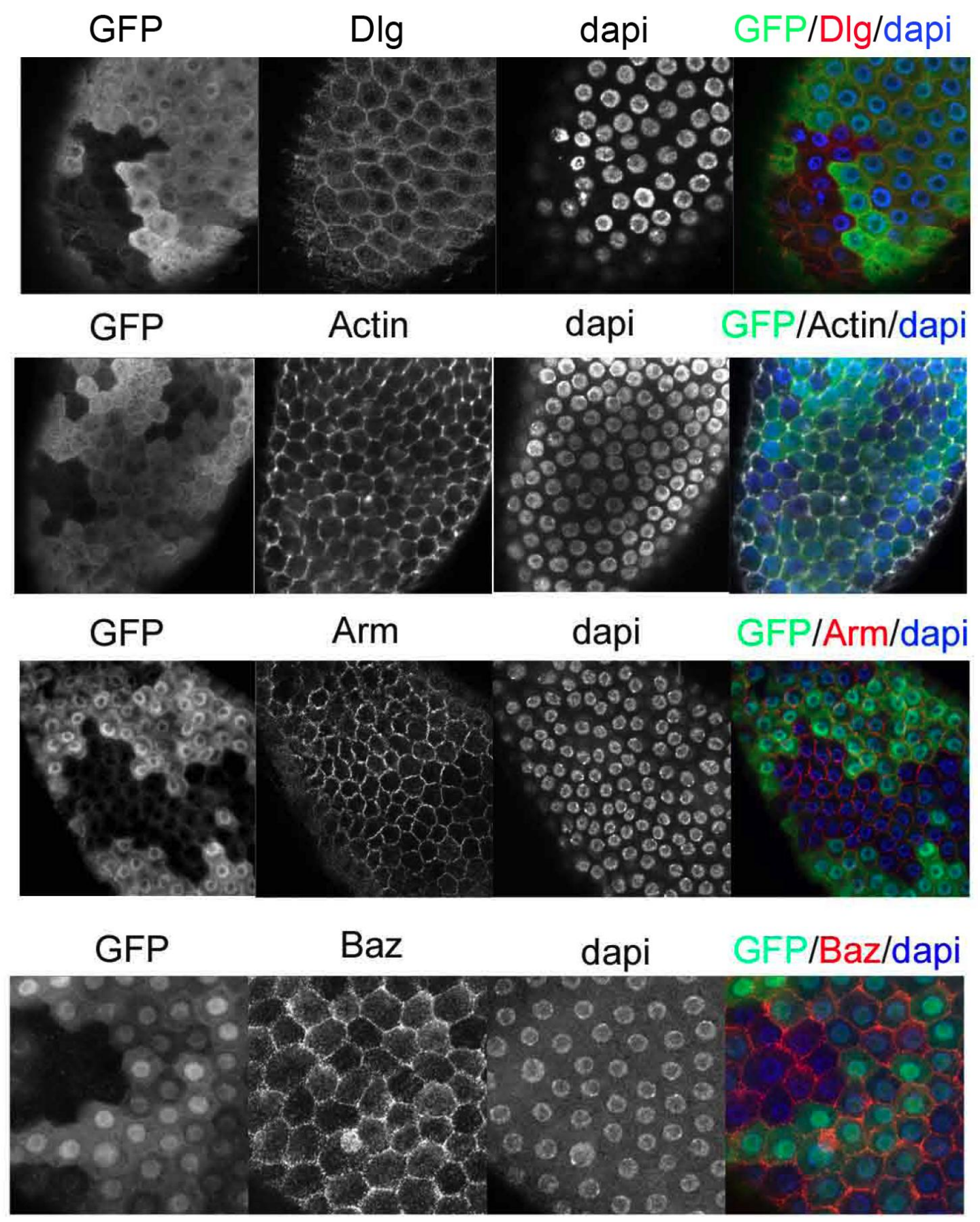

Figure 44. Adherens junctions and cytoskeleton have no obvious defect in the follicle clones of X-330 mutant. In follicle cells, X-330 homozygous mutant clones have no green fluorescence, while X-330/GFP heterozygous clones have weak green fluorescence. GFP homozygous clones have strong green fluorescence. Dlg is used as a lateral membrane marker, which is red. Armadillo and Bazooka are adherens junctions' markers, which are both red. Actin is a 
cytoskeleton marker, which is white. The egg chambers we stained are in stage10. In X-330 mutant clones, all the markers' expression is similar with the other clones. 


\section{Chapter4. Discussion}

\subsection{Different functions of E-cadherin in Drosophila embryogenesis}

In germline clones of shotgun alleles, no egg is discovered or the eggs only produce small patches of cuticle, suggesting that maternal E-cadherin is essential for oogenesis and embryogenesis (Tepass et al., 1996). By dominant negative Ecadherin construct, which uses maternally active driver lines, maternal E-cadherin is knocked down. It leads to germ layers forming irregular double or triple layers of rounded cells that lack zonula adherens in blastoderm stage and cell mitosis being abnormal (Wang et al., 2004). These results indicate that E-cadherin functions in formation and maintenance of the epithelial cell structure.

In shotgun zygotic mutant, the appearance of defects and morphogenetic movements has the correlation in time and place. Epithelial integrity is lost where and when the tissues undergo dramatic morphogenesis, like the neurectoderm, malpighian tubules and the midgut epithelium. In contrast, the tissues less active are more stable. Using the genetic manipulation to reduce the morphogenetic activity of different tissues, shotgun mutant phenotype is substantially reduced. In addition, the malfunction of these organs could be rescued by overexpression of E-cadherin cDNA under a heat shock promoter (Uemura et al., 1996). It is proposed that zygotic expression of Ecadherin is required during cell rearrangement in morphogenetic active epithelia (Tepass et al., 1996).

In Tepass' model, zygotic E-cadherin is required for forming new cell-cell contacts in active cells, while maternal E-cadherin is enough to maintain tissue integrity in less active cells. In our result, knockdown of E-cadherin by RNAi leads to cell intercalation defect, which gives further evidence for this model.

However, how E-cadherin functions in cell intercalation still remains an open question. There are three possibilities: First, it functions by affecting adherens junctions' formation. Second, it affects the intracellular actin-myosin network. Third, it could stabilize the newly formed cell-cell contacts. The three functions are not mutually exclusive. 
Our results give clues to the three possibilities. First, protein expression and localization of Armadillo and Bazooka is normal in X-330 mutant embryos and follicle cell clones, which indicates adherens junctions' formation is not affected. Second, medial myosin's recruitment to junction part is inhibited in X-330 mutant. In addition, part of actin filaments is mislocalized in cytoplasm. These results indicate that actin-myosin network is affected in X-330 mutant. It is known that planar polarity of E-cadherin is required to orient actomyosin flows to vertical junctions (Rauzi et al., 2010). Therefore, it is possible that E-cadherin expression defect induces actin-myosin recruitment inhibition in the mutant. Third, the extension of new borders could not be stabilized in X-330 mutant. Instead, they always shrink to 4-fold vertexes or vertical borders. We propose that E-cadherin may function in stabilizing newly formed borders.

\subsection{N-glycosylation of E-cadherin affects adherens junctions}

Tunicamycin was used as an N-glycosylation inhibitor to incubate with teratocarcinoma cells. The result showed that adherens junctions still exist, which indicates that $\mathrm{N}$-glycans are not the adhesive structures (Helenius and Aebi, 2004; Shirayoshi et al., 1986). However, N-glycosylation could regulate E-cadherin's adhesive function. In the yeast Saccharomyces cerevisiae, attenuation of protein Nglycosylation causes increased cell aggregation effect (Kukuruzinska and Lennon, 1995). GPT (ALG7) is the enzyme which initiates the synthesis of lipid-linked oligosaccharide precursor in ER. In mouse submandibular glands or hamster embryos, when GPT's expression is high, E-cadherin is in unstable cell-cell contacts. When GPT is down-regulated, E-cadherin forms stable adherens junctions (Fernandes et al., 1999; Menko et al., 2002). In MDCK cells, sparse cells produce Ecadherin modified with complex $\mathrm{N}$-glycans and form unstable adherens junctions. In dense cells, E-cadherin is scarcely modified with $\mathrm{N}$-glycan and forms stable adherens junctions (Liwosz et al., 2006). In CHO cells, removal of $\mathrm{N}$-glycan from EC4 could increase interaction of E-cadherin-catenin complex with vinculin and the actin cytoskeleton. This effect was enhanced by deletion of N-glycan of site3 in EC5. It is proposed that $\mathrm{N}$-glycosylation destabilize adherens junctions by affecting their molecular organization (Liwosz et al., 2006). Not every potential N-glycan site is 
modified. Frequently, variants exist in numbers of actual N-glycan sites and their composition. By modification of N-glycosylation, cells' state is regulated. Our result shows N-glycosylation of E-cadherin is decreased in X-330 mutant, which may affect cell intercalation behavior. To study the correlation of cell intercalation and $\mathrm{N}$ glycosylation of E-cadherin, we need to do more work to answer this question.

\subsection{E-cadherin accumulation is not the cause of new contacts formation}

It still remains unclear how does the DV cells form a new contact. One possibility is the enrichment of E-cadherin could cause new contacts formation. Using time-lapse imaging, we observed the new contacts formed before E-cadherin accumulation. It is consistent with the report that Bazooka is not detectable until several minutes after the new border forms in Drosophila embryos (Blankenship et al., 2006). These results indicate that E-cadherin is not the force that promotes new contacts' formation. However, when E-cadherin is knocked down in E-cadRNAi or X-330 mutant, the new formed borders could not stabilize its length and always shrink to 4-fold vertexes or even go back to vertical borders between AP cells. This result suggests that E-cadherin may function in stabilizing the length of new extended borders and inhibiting shrinkage once they form.

As for how does E-cadherin accumulate in new junctions, there are three possible mechanisms. E-cadherin may come from de novo synthesis or transferred within membrane or endocytosis recycling. To distinguish the first and the latter two possibilities, we could use the photoswitchable GFP to mark all the existing Ecadherin and test if the E-cadherin on new borders is with or without the marker. By marking the E-cadherin in cytoplasm and following its dynamics, we could tell if the E-cadherin on the new borders is from recycling or transferring within the membrane.

\subsection{Pull and stick model}

We try to give a model for new border extension. In the wild type, some force, which may be provided by actin-myosin network, drives the 4-fold vertexes extending to 
the horizontal borders (Fig.45A). It is not clear whether this force is provided by the pulling force from the AP cells (Fig.45, red arrow) or the pushing force from the DV cells (Fig.45, blue arrow). We observed the pulsed behavior of new borders' formation both in the wild type and X-330 mutant, which indicates that the newly extended borders have the tendency to shrink. With some stabilizing factor, the wild type new borders could steadily increase the length. However, new borders in X-330 mutant are lack of the stabilizing factor and could not steadily increase the length. Ecadherin may provide such stabilizing function by its gradual accumulation in the new borders (Fig.45A, green bar). With low amount of E-cadherin, the extended borders could not be stabilized in X-330 mutant and E-cadherin RNAi embryos (Fig.45B). They keep extending and shrinking movement. The length of them could not increase steadily. Because another force separates the AP cells apart and Ecadherin sticks the new neighbor cells together, we call this model "pull and stick model".

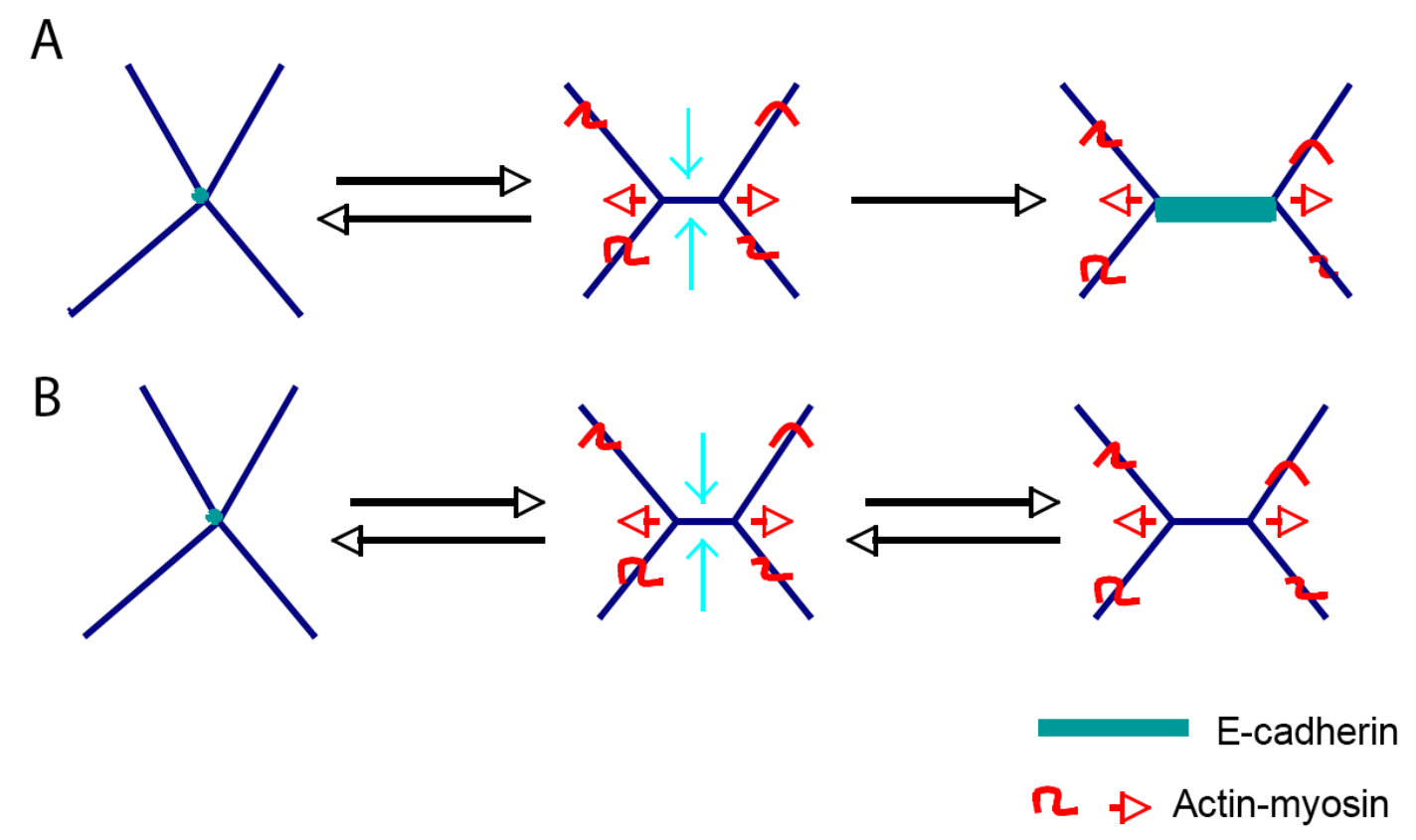

Figure 45. Model of the new border formation. A. In the wild type, certain force along AP axis (red arrows) or along DV axis (blue arrows) drives the new horizontal border extension. The extended border has tendency to shrink. With the increase of E-cadherin, the newly formed border is steadily extended. B. In X-330 mutant and E-cadherin RNAi situation, a kind of force 
could drive the new border extension. However, the length of the new borders could not increase steadily because of lacking the sticky force of E-cadherin.

\subsection{Membrane proteins are affected differently by $\mathrm{N}$ - glycosylation defect}

Our results indicate that $\mathrm{N}$-glycan is not equally important for different protein folding and secretion. Defect of $\mathrm{N}$-glycosylation makes some protein folded inefficiently and functioning abnormally, while many others proteins are not affected. It means the importance of $\mathrm{N}$-glycan is different to different proteins. Generally, the more $\mathrm{N}$-glycan sites a protein has, the more important role the $\mathrm{N}$-glycan plays for the protein. In our result, E-cadherin and Crumbs carry many $\mathrm{N}$-glycosylation sites (Fig.46). Their expression is decreased in X-330 mutant. For Neurotactin and CG8668, their glycosylation sites are less. Their expression and localization are not obviously affected by X-330 mutant.

Although it is still not clear how N-glycosylaion affect protein expression. Here, we propose some possibilities: First, OST enzyme may have problem to recognize the incomplete $\mathrm{N}$-glycans, which could not be transferred from dolichol to nascent proteins. Second, proteins may not be folded correctly or efficiently without the complete glycans. Third, proteins may not pass through the ER quality control and finally be degraded. This is quite possible in X-330 mutant, because western blot result showed that E-cadherin and Crumbs are both reduced. Forth, modification of glycans in Golgi apparatus may be affected. Fifth, proteins function abnormally. To examine these possibilities, more work should be done to give evidences. We could distinguish if the protein folding process is affected or the protein functions abnormally by testing protein expression. If the folding processing has problem, the protein would be degraded and its expression level is reduced, like E-cadherin and Crumbs in X-330 mutant. Otherwise, the protein activity maybe affected even it could localize in the normal position. 


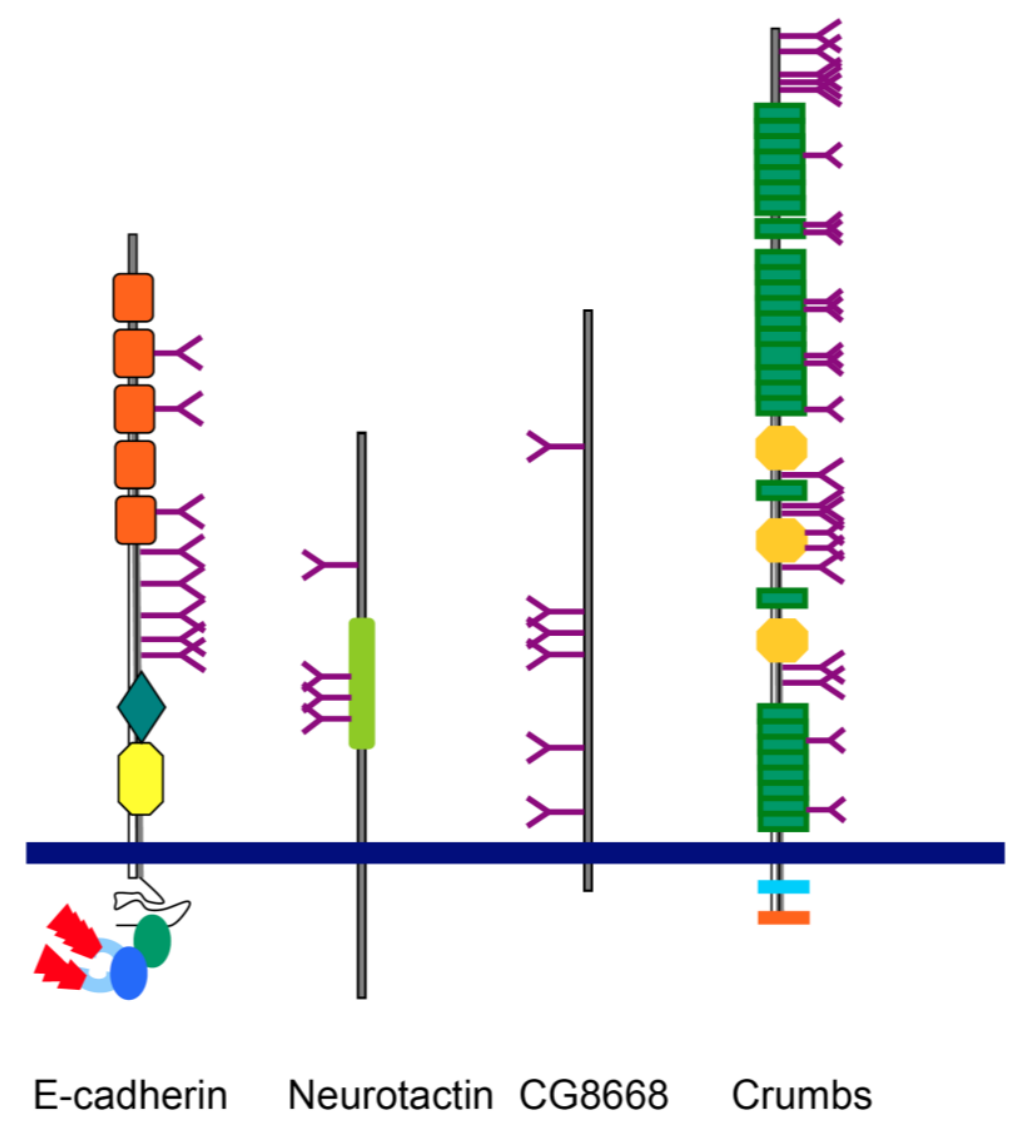

Figure 46. Schematic image of membrane proteins. E-cadherin has 8 possible $\mathrm{N}$-glycosylation sites, Crumbs have 23 sites. Neurotactin has 4 sites. CG8668 has 6 sites.

\subsection{Some glycoproteins, which are essential for ventral furrow formation, are affected by $\mathrm{N}$-glycosylation defect}

In X-330 mutant, ventral furrow formation is defective, which may be caused by the impaired N-glycosylation of some secreted factors or membrane proteins which function in this process. Based on the phenotype, we propose that folded gastrulation (fog) and T48 are the candidate factors. Fog gene is a known target of the patterning gene twist. The secreted Fog protein is apically localized and ultimately drives myosin to the apical side of the cell (Costa et al., 1994; Dawes-Hoang et al., 2005; Morize et al., 1998). In the process of driving myosin localization, RhoGEF2 and the downstream effectors Rho kinase are involved. Once the myosin-actin network localized apically, it provides continuous contraction force and causes the apical constriction of the cell shape. Fog is the very beginning apical polarized signal. The 
$\mathrm{N}$-glycosylation defect of fog or the unknown fog receptor may lead to the impairment of ventral furrow formation. Another candidate for X-330 mutant downstream target is T48, which is a transmembrane protein and a downstream target of twist. Together with $G$ protein signaling, T48 recruits adherens junctions and the cytoskeleton regulator RhoGEF2 to the apical constriction sites, which lead to the apical constriction and cell shape change (Kolsch et al., 2007). As a transmembrane protein, T48 should be synthesized in ER. The N-glycosylation defect may affect the normal function of T48. 


\section{Appendix}

\section{List of DNA oligos}

YZ19: 5'-GCTAACTGGCTACTTCCAAG-3'

YZ24: 5'-ACAGTAGTGAGGATAGACTG-3'

YZ25: 5'-AGCTACTTTAAACTTTATTTCAG-3'

YZ20: 5'-CACAATCGACAATCGCATTC-3'

YZ21: 5'-CATACTGCTCCTGAGCATC-3'

YZ22: 5'-GAAGGAATCCTACTAACAGG-3'

YZ23: 5'-TCCGATCGGCACAATGGAC-3'

YZ26: 5'-TGTAAATGCGTGGCGTACTC-3'

YZ27: 5'-GGGCCATGGGAACGGATTTCGAAGTCCATCG-3'

YZ28: 5'-GGGAGATCTGGTGGCCTTGGACTCGTAATTC-3'

YZ29: 5'-GGGCCATGGGATCTTTCGGACCCTTCTGGC-3'

YZ30: 5'- GGGAGATCTCAGCACCGAGTGCCTGACC-3'

E-cad-T7-F:

TAATACGACTCACTATAGGGAGACCACGAGTCTCTTTGATAATGGCGAG $\mathrm{C}$

E-cad-T7-R:

TAATACGACTCACTATAGGGAGACCACGGTTTCCATCGTTCTGGTGAATC $\alpha$-Cat-T7-F:

TAATACGACTCACTATAGGGCACAATGTCAGTTGAAAAAACACTTG $\alpha$-Cat-T7-R:

TAATACGACTCACTATAGGGGTTGGGATGACTTTCCTTGG 


\section{Plasmid maps}

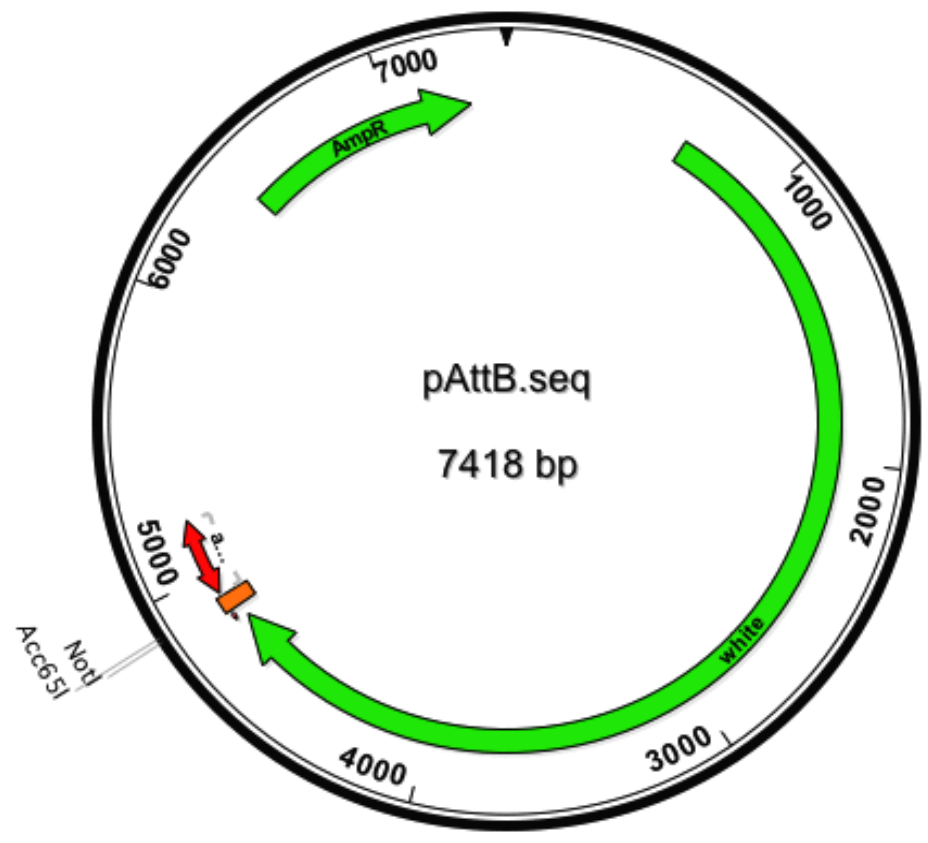

Supplemental figure 1. pAttB plasmid for making the transgenic construct.

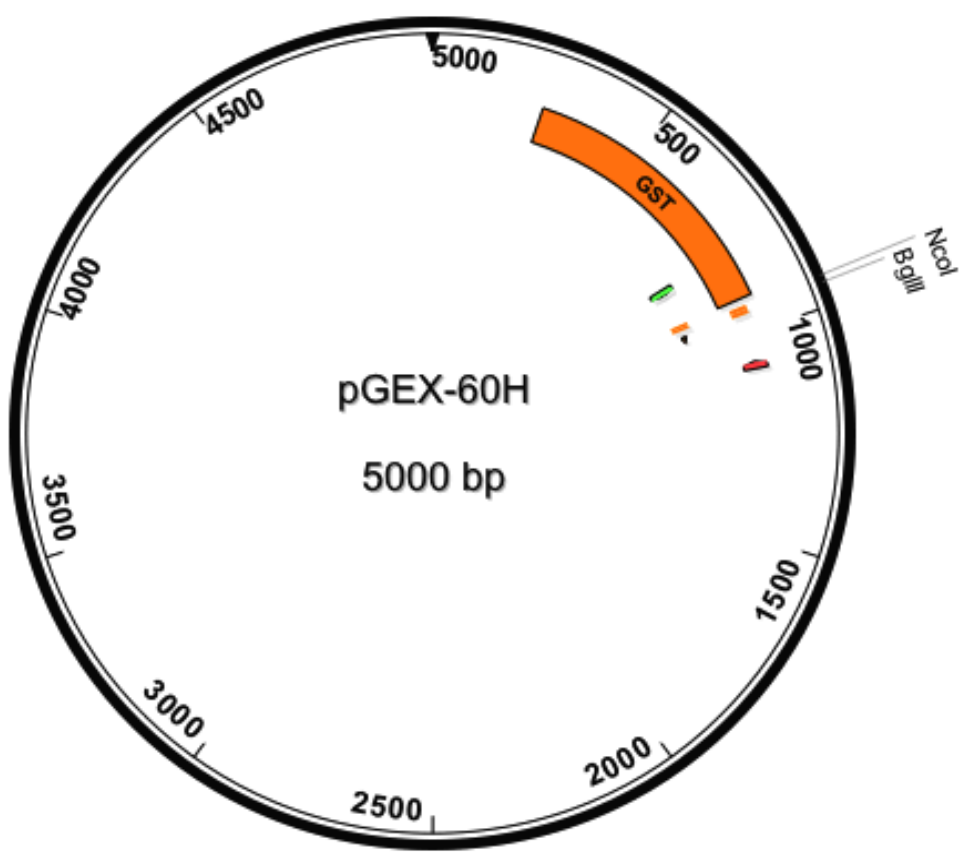

Supplemental figure 2. pGEX-60H plasmid for expression of the target protein 


\section{Complete data}
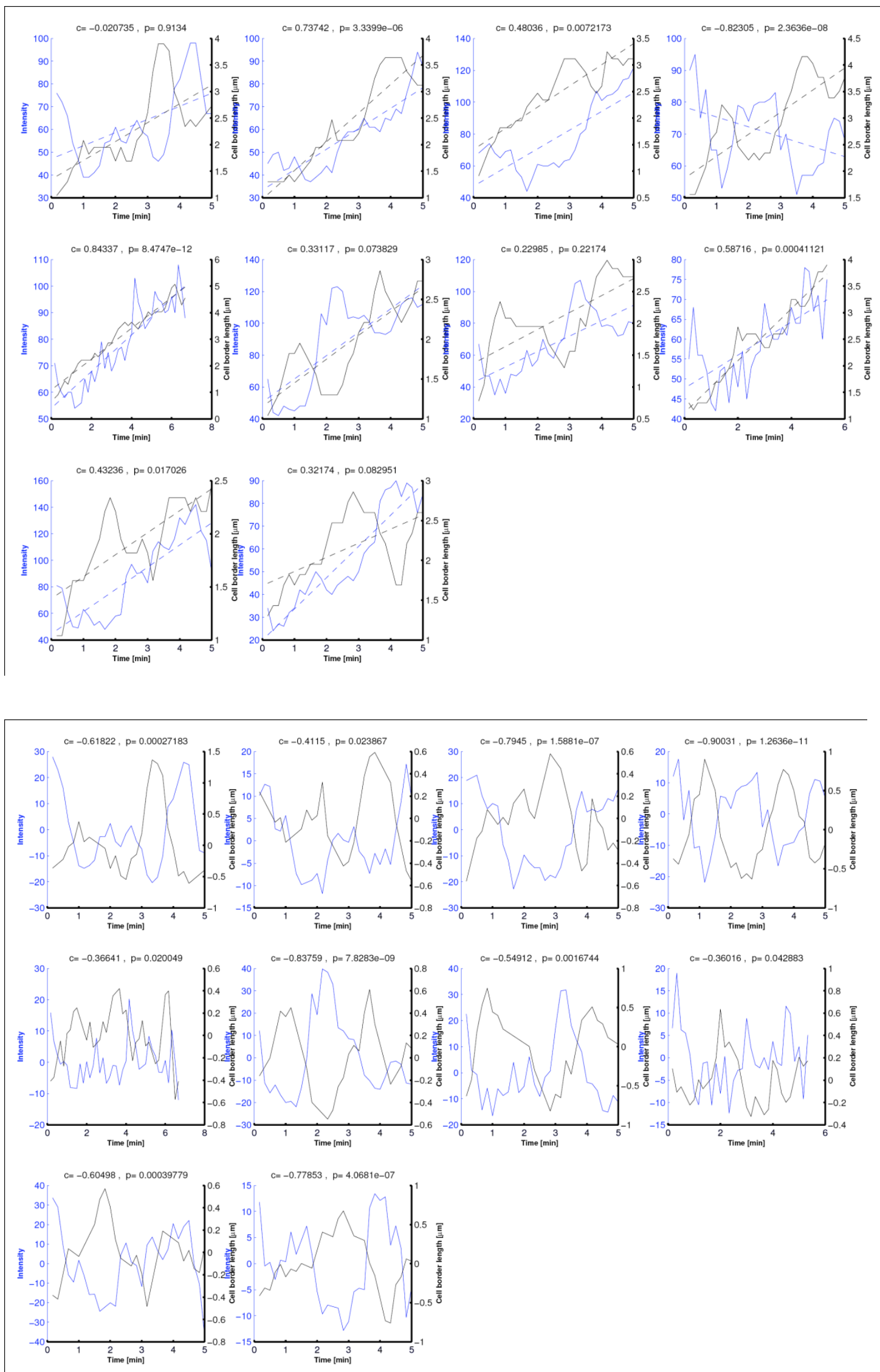

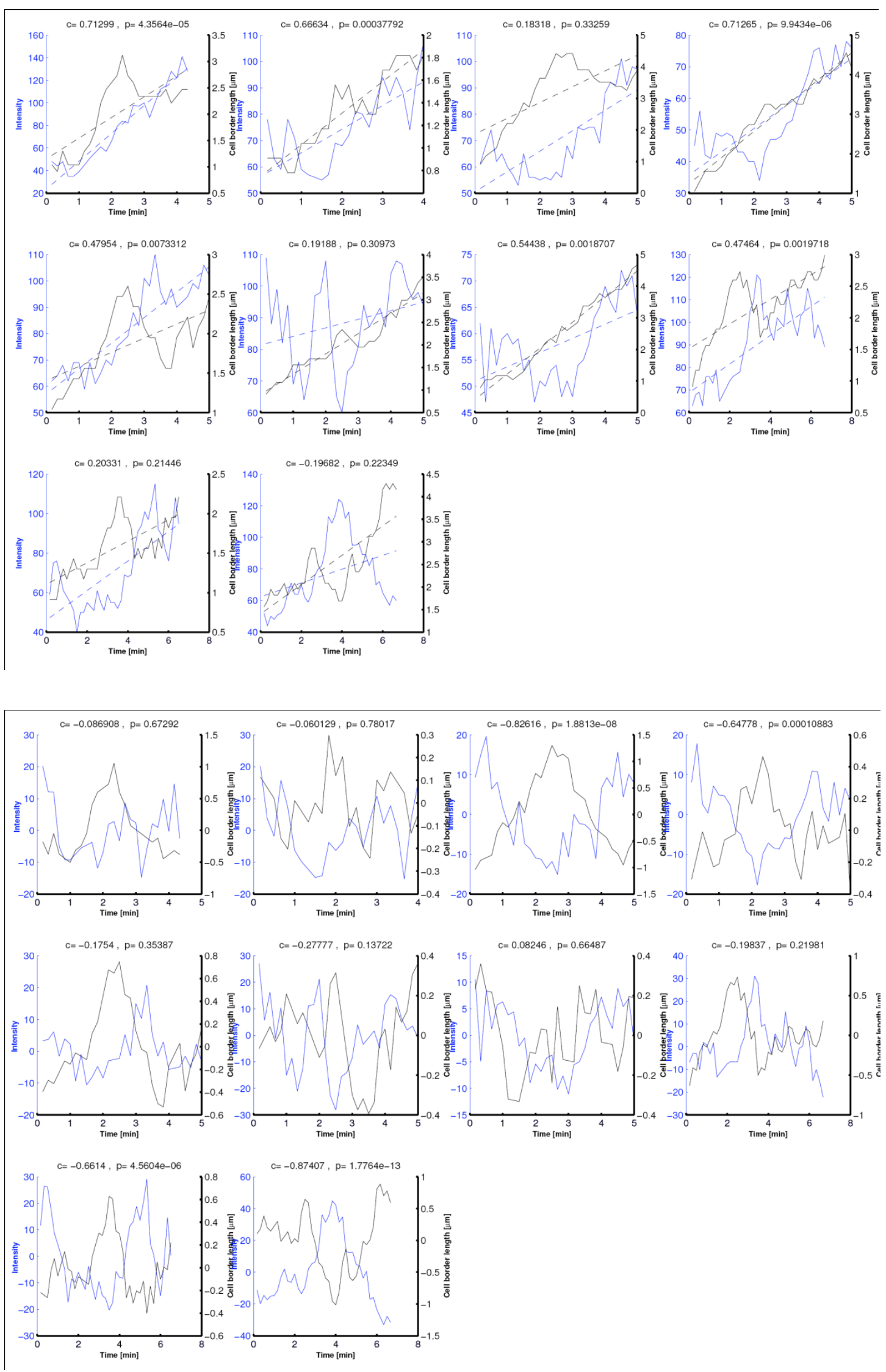

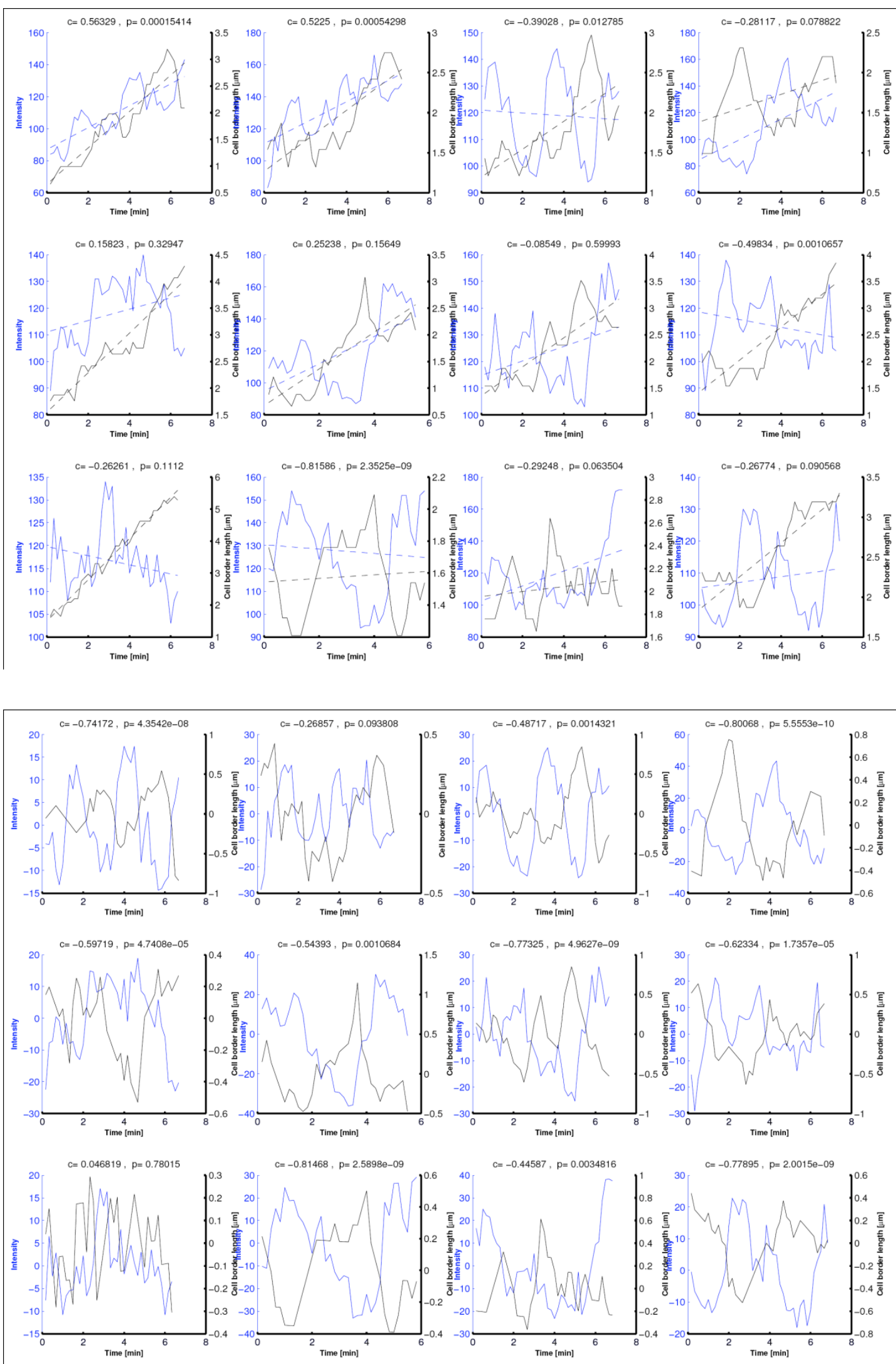

Supplemental figure 3. 32 cases of anticorrelation between E-cadherin amount and the new border length. They are the complete data for Figure 31 A-D 

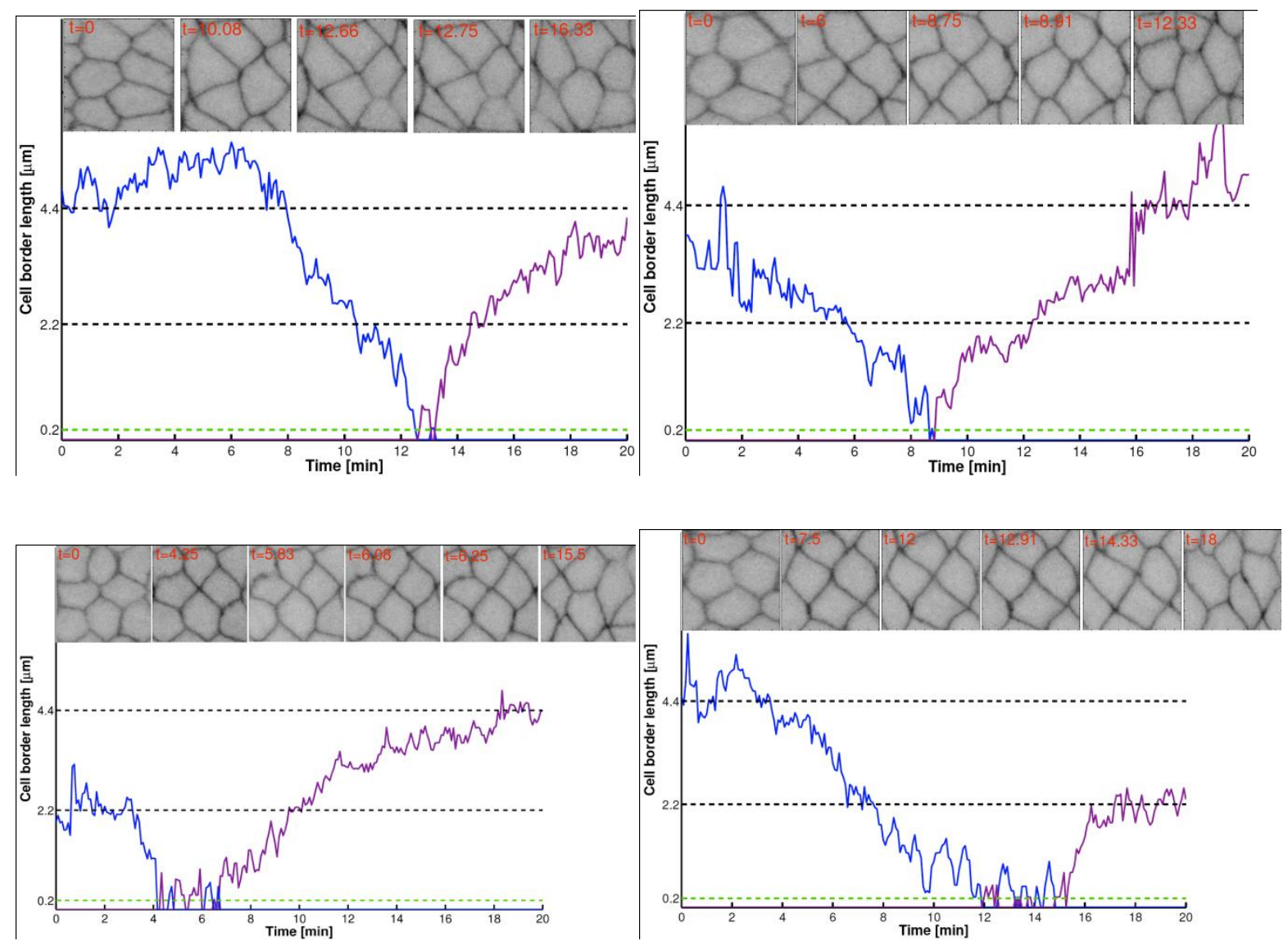

Supplemental figure 4 . 4 cases of cell border length change in the wild type T1 process. 

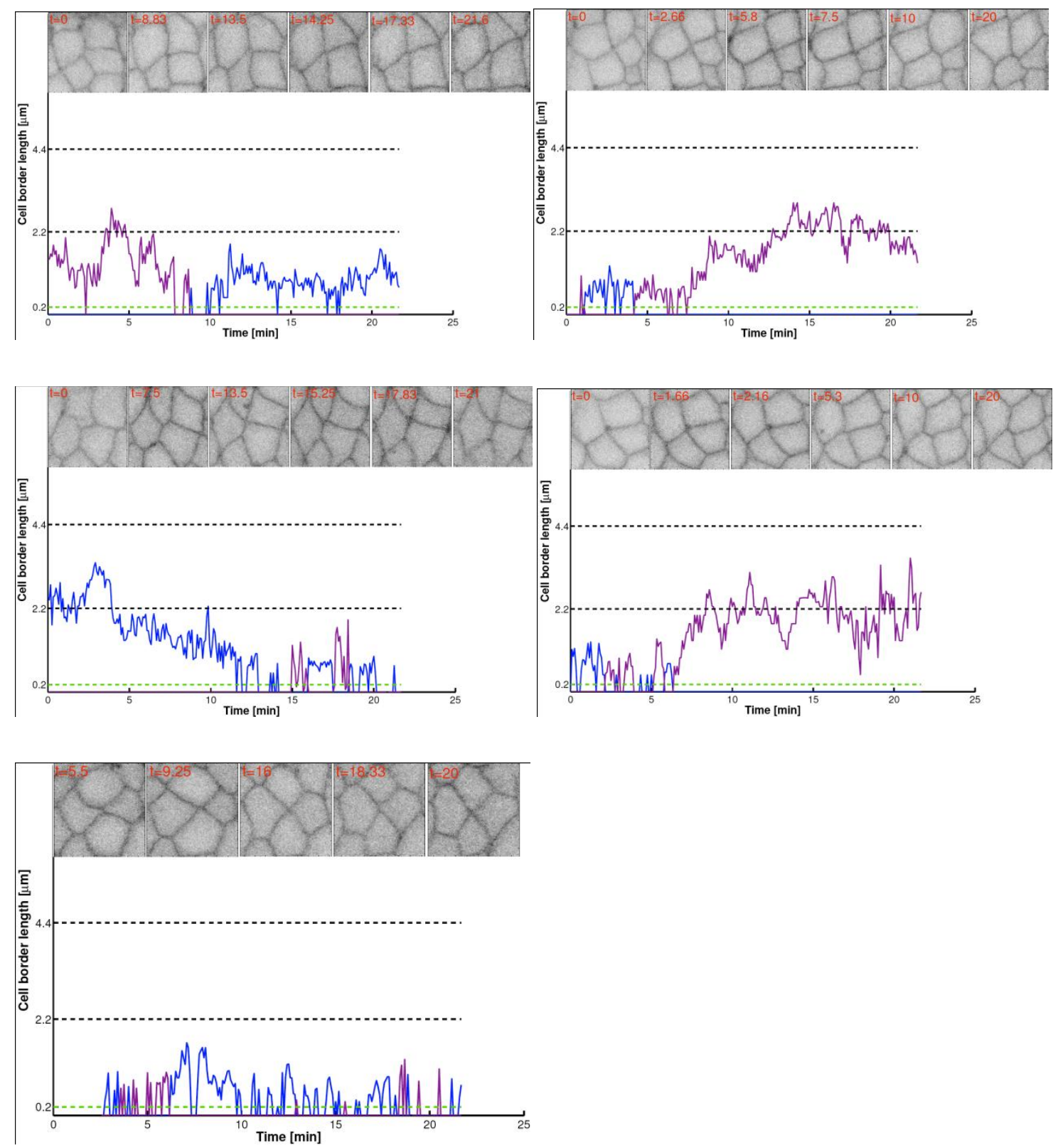

Supplemental figure 5. 5 cases of cell border length change in X-330 mutant T1 process. 

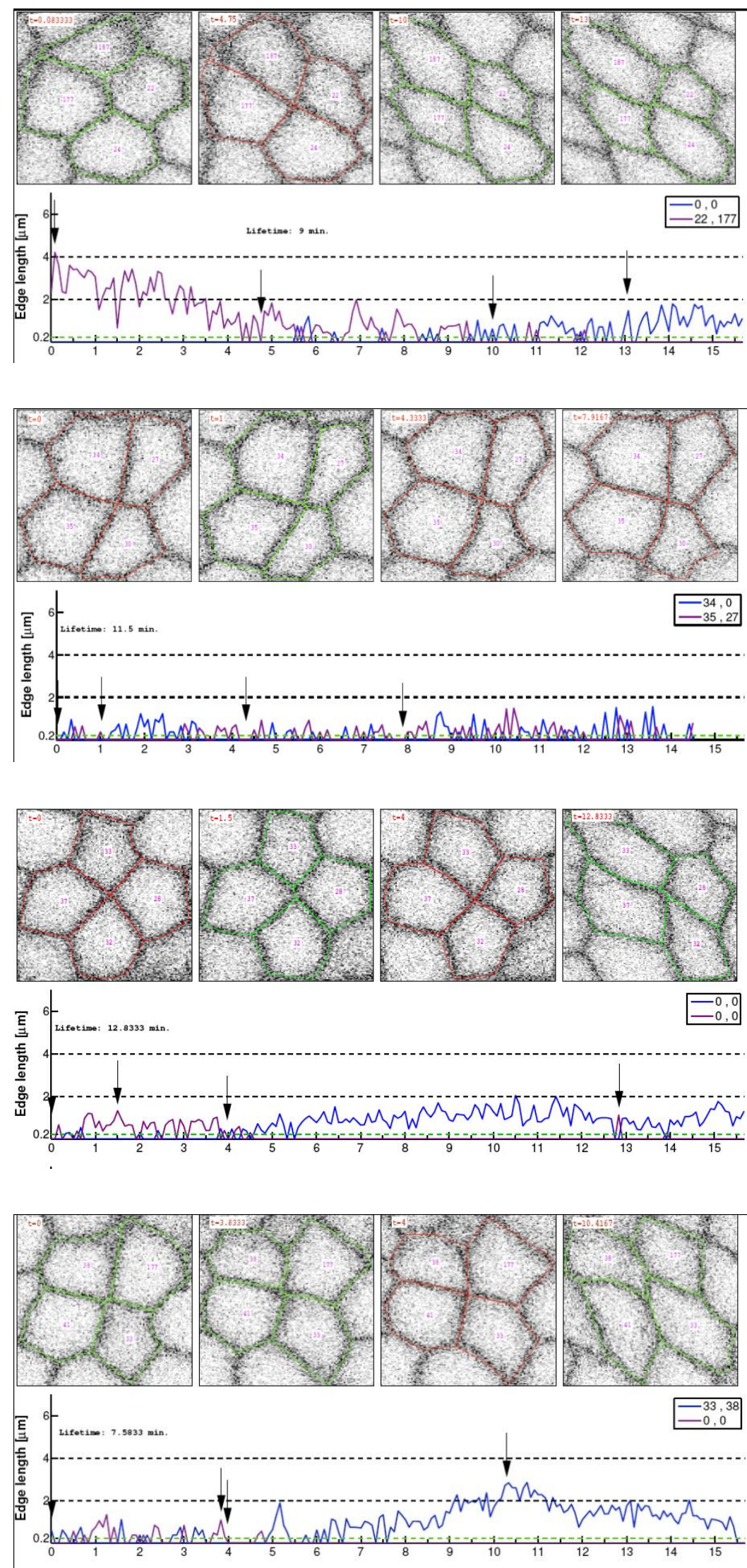

Supplemental figure 6. 4 cases of cell border length change in E-cadherin RNAi T1 process. 


\section{Reference}

Atienza-Samols, S. B., Pine, P. R. and Sherman, M. I. (1980). Effects of tunicamycin upon glycoprotein synthesis and development of early mouse embryos. Dev Biol 79, 19-32.

Bertet, C., Sulak, L. and Lecuit, T. (2004). Myosin-dependent junction remodelling controls planar cell intercalation and axis elongation. Nature 429, 667-71.

Bischof, J., Maeda, R. K., Hediger, M., Karch, F. and Basler, K. (2007). An optimized transgenesis system for Drosophila using germ-line-specific phiC31 integrases. Proc Natl Acad Sci U S A 104, 3312-7.

Blanchard, G. B., Kabla, A. J., Schultz, N. L., Butler, L. C., Sanson, B., Gorfinkiel, N., Mahadevan, L. and Adams, R. J. (2009). Tissue tectonics: morphogenetic strain rates, cell shape change and intercalation. Nat Methods 6, 45864.

Blankenship, J. T., Backovic, S. T., Sanny, J. S., Weitz, O. and Zallen, J. A. (2006). Multicellular rosette formation links planar cell polarity to tissue morphogenesis. Dev Cell 11, 459-70.

Brand, A. H. and Perrimon, N. (1993). Targeted gene expression as a means of altering cell fates and generating dominant phenotypes. Development 118, 401-15.

Butler, L. C., Blanchard, G. B., Kabla, A. J., Lawrence, N. J., Welchman, D. P., Mahadevan, L., Adams, R. J. and Sanson, B. (2009). Cell shape changes indicate a role for extrinsic tensile forces in Drosophila germ-band extension. Nat Cell Biol 11, 859-64.

Chou, T. B., Noll, E. and Perrimon, N. (1993). Autosomal P[ovoD1] dominant female-sterile insertions in Drosophila and their use in generating germ-line chimeras. Development 119, 1359-69.

Chou, T. B. and Perrimon, N. (1992). Use of a yeast site-specific recombinase to produce female germline chimeras in Drosophila. Genetics 131, 643-53. 
Chou, T. B. and Perrimon, N. (1996). The autosomal FLP-DFS technique for generating germline mosaics in Drosophila melanogaster. Genetics 144, 1673-9.

Cook, R. K., Deal, M. E., Deal, J. A., Garton, R. D., Brown, C. A., Ward, M. E., Andrade, R. S., Spana, E. P., Kaufman, T. C. and Cook, K. R. A new resource for characterizing X-linked genes in Drosophila melanogaster: systematic coverage and subdivision of the X chromosome with nested, Y-linked duplications. Genetics 186, 1095-109.

Costa, M., Wilson, E. T. and Wieschaus, E. (1994). A putative cell signal encoded by the folded gastrulation gene coordinates cell shape changes during Drosophila gastrulation. Cell 76, 1075-89.

da Silva, S. M. and Vincent, J. P. (2007). Oriented cell divisions in the extending germ band of Drosophila. Development 134, 3049-54.

Dawes-Hoang, R. E., Parmar, K. M., Christiansen, A. E., Phelps, C. B., Brand, A. H. and Wieschaus, E. F. (2005). folded gastrulation, cell shape change and the control of myosin localization. Development 132, 4165-78.

Fernandes, R. P., Cotanche, D. A., Lennon-Hopkins, K., Erkan, F., Menko, A. S. and Kukuruzinska, M. A. (1999). Differential expression of proliferative, cytoskeletal, and adhesive proteins during postnatal development of the hamster submandibular gland. Histochem Cell Biol 111, 153-62.

Fernandez-Gonzalez, R., Simoes Sde, M., Roper, J. C., Eaton, S. and Zallen, J. A. (2009). Myosin II dynamics are regulated by tension in intercalating cells. Dev Cell 17, 736-43.

Frescas, D., Mavrakis, M., Lorenz, H., Delotto, R. and Lippincott-Schwartz, J. (2006). The secretory membrane system in the Drosophila syncytial blastoderm embryo exists as functionally compartmentalized units around individual nuclei. $J$ Cell Biol 173, 219-30.

Haecker, A., Bergman, M., Neupert, C., Moussian, B., Luschnig, S., Aebi, M. and Mannervik, M. (2008). Wollknauel is required for embryo patterning and 
encodes the Drosophila ALG5 UDP-glucose:dolichyl-phosphate glucosyltransferase. Development 135, 1745-9.

Haeuptle, M. A. and Hennet, T. (2009). Congenital disorders of glycosylation: an update on defects affecting the biosynthesis of dolichol-linked oligosaccharides. Hum Mutat 30, 1628-41.

Hammerschmidt, M. and Wedlich, D. (2008). Regulated adhesion as a driving force of gastrulation movements. Development 135, 3625-41.

Hardin, J. (1989). Local shifts in position and polarized motility drive cell rearrangement during sea urchin gastrulation. Dev Biol 136, 430-45.

Helenius, A. and Aebi, M. (2004). Roles of N-linked glycans in the endoplasmic reticulum. Annu Rev Biochem 73, 1019-49.

Hortsch, M., Patel, N. H., Bieber, A. J., Traquina, Z. R. and Goodman, C. S. (1990). Drosophila neurotactin, a surface glycoprotein with homology to serine esterases, is dynamically expressed during embryogenesis. Development 110, 1327 40.

Ioffe, E. and Stanley, P. (1994). Mice lacking N-acetylglucosaminyltransferase I activity die at mid-gestation, revealing an essential role for complex or hybrid Nlinked carbohydrates. Proc Natl Acad Sci U S A 91, 728-32.

Irvine, K. D. and Wieschaus, E. (1994). Cell intercalation during Drosophila germ band extension and its regulation by pair-rule segmentation genes. Development 120 , $827-41$.

Iwaki, D. D., Johansen, K. A., Singer, J. B. and Lengyel, J. A. (2001). drumstick, bowl, and lines are required for patterning and cell rearrangement in the Drosophila embryonic hindgut. Dev Biol 240, 611-26.

Jaeken, J. (2010). Congenital disorders of glycosylation (CDG): it's (nearly) all in it! J Inherit Metab Dis 34, 853-8. 
Keller, R., Davidson, L., Edlund, A., Elul, T., Ezin, M., Shook, D. and Skoglund, P. (2000). Mechanisms of convergence and extension by cell intercalation. Philos Trans $R$ Soc Lond B Biol Sci 355, 897-922.

Keller, R. E. (1980). The cellular basis of epiboly: an SEM study of deep-cell rearrangement during gastrulation in Xenopus laevis. J Embryol Exp Morphol 60, 201-34.

Knust, E. and Bossinger, O. (2002). Composition and formation of intercellular junctions in epithelial cells. Science 298, 1955-9.

Kolsch, V., Seher, T., Fernandez-Ballester, G. J., Serrano, L. and Leptin, M. (2007). Control of Drosophila gastrulation by apical localization of adherens junctions and RhoGEF2. Science 315, 384-6.

Kukuruzinska, M. A. and Lennon, K. (1995). Diminished activity of the first Nglycosylation enzyme, dolichol-P-dependent $\mathrm{N}$-acetylglucosamine-1-P transferase (GPT), gives rise to mutant phenotypes in yeast. Biochim Biophys Acta 1247, 51-9.

Lecuit, T. and Wieschaus, E. (2002). Junctions as organizing centers in epithelial cells? A fly perspective. Traffic 3, 92-7.

Leptin, M. (1995). Drosophila gastrulation: from pattern formation to morphogenesis. Annu Rev Cell Dev Biol 11, 189-212.

Leptin, M. and Grunewald, B. (1990). Cell shape changes during gastrulation in Drosophila. Development 110, 73-84.

Liwosz, A., Lei, T. and Kukuruzinska, M. A. (2006). N-glycosylation affects the molecular organization and stability of E-cadherin junctions. J Biol Chem 281, 23138-49.

Lohs-Schardin, M., Cremer, C. and Nusslein-Volhard, C. (1979). A fate map for the larval epidermis of Drosophila melanogaster: localized cuticle defects following irradiation of the blastoderm with an ultraviolet laser microbeam. Dev Biol 73, 23955. 
Luschnig, S., Moussian, B., Krauss, J., Desjeux, I., Perkovic, J. and NussleinVolhard, C. (2004). An F1 genetic screen for maternal-effect mutations affecting embryonic pattern formation in Drosophila melanogaster. Genetics 167, 325-42.

Maley, F., Trimble, R. B., Tarentino, A. L. and Plummer, T. H., Jr. (1989). Characterization of glycoproteins and their associated oligosaccharides through the use of endoglycosidases. Anal Biochem 180, 195-204.

Martin, A. C., Kaschube, M. and Wieschaus, E. F. (2009). Pulsed contractions of an actin-myosin network drive apical constriction. Nature 457, 495-9.

Menko, A. S., Zhang, L., Schiano, F., Kreidberg, J. A. and Kukuruzinska, M. A. (2002). Regulation of cadherin junctions during mouse submandibular gland development. Dev Dyn 224, 321-33.

Morize, P., Christiansen, A. E., Costa, M., Parks, S. and Wieschaus, E. (1998). Hyperactivation of the folded gastrulation pathway induces specific cell shape changes. Development 125, 589-97.

Munro, E. M. and Odell, G. M. (2002). Polarized basolateral cell motility underlies invagination and convergent extension of the ascidian notochord. Development 129, $13-24$

Oda, H. and Tsukita, S. (2001). Real-time imaging of cell-cell adherens junctions reveals that Drosophila mesoderm invagination begins with two phases of apical constriction of cells. J Cell Sci 114, 493-501.

Oda, H., Uemura, T., Harada, Y., Iwai, Y. and Takeichi, M. (1994). A Drosophila homolog of cadherin associated with armadillo and essential for embryonic cell-cell adhesion. Dev Biol 165, 716-26.

Oda, H., Uemura, T., Shiomi, K., Nagafuchi, A., Tsukita, S. and Takeichi, M. (1993). Identification of a Drosophila homologue of alpha-catenin and its association with the armadillo protein. $J$ Cell Biol 121, 1133-40. 
Oglesby, L. L., Jain, S. and Ohman, D. E. (2008). Membrane topology and roles of Pseudomonas aeruginosa Alg8 and Alg44 in alginate polymerization. Microbiology 154, 1605-15.

Peifer, M. (1993). The product of the Drosophila segment polarity gene armadillo is part of a multi-protein complex resembling the vertebrate adherens junction. $J$ Cell Sci 105 ( Pt 4), 993-1000.

Pinho, S. S., Seruca, R., Gartner, F., Yamaguchi, Y., Gu, J., Taniguchi, N. and Reis, C. A. (2011). Modulation of E-cadherin function and dysfunction by Nglycosylation. Cell Mol Life Sci 68, 1011-20.

Plummer, T. H., Jr. and Tarentino, A. L. (1991). Purification of the oligosaccharide-cleaving enzymes of Flavobacterium meningosepticum. Glycobiology 1, 257-63.

Rauzi, M., Lenne, P. F. and Lecuit, T. (2010). Planar polarized actomyosin contractile flows control epithelial junction remodelling. Nature 468, 1110-4.

Rauzi, M., Verant, P., Lecuit, T. and Lenne, P. F. (2008). Nature and anisotropy of cortical forces orienting Drosophila tissue morphogenesis. Nat Cell Biol 10, 1401-10.

Ribeiro, C., Neumann, M. and Affolter, M. (2004). Genetic control of cell intercalation during tracheal morphogenesis in Drosophila. Curr Biol 14, 2197-207.

Riggleman, B., Schedl, P. and Wieschaus, E. (1990). Spatial expression of the Drosophila segment polarity gene armadillo is posttranscriptionally regulated by wingless. Cell 63, 549-60.

Roth, S., Hiromi, Y., Godt, D. and Nusslein-Volhard, C. (1991). cactus, a maternal gene required for proper formation of the dorsoventral morphogen gradient in Drosophila embryos. Development 112, 371-88.

Ryder, E., Ashburner, M., Bautista-Llacer, R., Drummond, J., Webster, J., Johnson, G., Morley, T., Chan, Y. S., Blows, F., Coulson, D. et al. (2007). The DrosDel deletion collection: a Drosophila genomewide chromosomal deficiency resource. Genetics 177, 615-29. 
Ryder, E., Blows, F., Ashburner, M., Bautista-Llacer, R., Coulson, D., Drummond, J., Webster, J., Gubb, D., Gunton, N., Johnson, G. et al. (2004). The DrosDel collection: a set of P-element insertions for generating custom chromosomal aberrations in Drosophila melanogaster. Genetics 167, 797-813.

Saxena, I. M., Brown, R. M., Jr., Fevre, M., Geremia, R. A. and Henrissat, B. (1995). Multidomain architecture of beta-glycosyl transferases: implications for mechanism of action. $J$ Bacteriol 177, 1419-24.

Schupbach, T. (1987). Germ line and soma cooperate during oogenesis to establish the dorsoventral pattern of egg shell and embryo in Drosophila melanogaster. Cell 49, 699-707.

Shaik, K. S., Pabst, M., Schwarz, H., Altmann, F. and Moussian, B. (2011). The Alg5 ortholog Wollknauel is essential for correct epidermal differentiation during Drosophila late embryogenesis. Glycobiology 21, 743-56.

Shirayoshi, Y., Nose, A., Iwasaki, K. and Takeichi, M. (1986). N-linked oligosaccharides are not involved in the function of a cell-cell binding glycoprotein E-cadherin. Cell Struct Funct 11, 245-52.

Simpson, P. (1983). Maternal-Zygotic Gene Interactions during Formation of the Dorsoventral Pattern in Drosophila Embryos. Genetics 105, 615-32.

Solnica-Krezel, L. (2005). Conserved patterns of cell movements during vertebrate gastrulation. Curr Biol 15, R213-28.

Solnica-Krezel, L. (2006). Gastrulation in zebrafish -- all just about adhesion? Curr Opin Genet Dev 16, 433-41.

Stathopoulos, A. and Levine, M. (2002). Dorsal gradient networks in the Drosophila embryo. Dev Biol 246, 57-67.

Tepass, U., Gruszynski-DeFeo, E., Haag, T. A., Omatyar, L., Torok, T. and Hartenstein, V. (1996). shotgun encodes Drosophila E-cadherin and is preferentially required during cell rearrangement in the neurectoderm and other morphogenetically active epithelia. Genes Dev 10, 672-85. 
Tepass, U., Tanentzapf, G., Ward, R. and Fehon, R. (2001). Epithelial cell polarity and cell junctions in Drosophila. Annu Rev Genet 35, 747-84.

Tepass, U., Theres, C. and Knust, E. (1990). crumbs encodes an EGF-like protein expressed on apical membranes of Drosophila epithelial cells and required for organization of epithelia. Cell 61, 787-99.

Theodore, M. and Morava, E. (2011). Congenital disorders of glycosylation: sweet news. Curr Opin Pediatr 23, 581-7.

Thisse, B., Stoetzel, C., Gorostiza-Thisse, C. and Perrin-Schmitt, F. (1988). Sequence of the twist gene and nuclear localization of its protein in endomesodermal cells of early Drosophila embryos. Embo J 7, 2175-83.

Uemura, T., Oda, H., Kraut, R., Hayashi, S., Kotaoka, Y. and Takeichi, M. (1996). Zygotic Drosophila E-cadherin expression is required for processes of dynamic epithelial cell rearrangement in the Drosophila embryo. Genes Dev 10, 65971.

Vagin, O., Tokhtaeva, E., Yakubov, I., Shevchenko, E. and Sachs, G. (2008). Inverse correlation between the extent of $\mathrm{N}$-glycan branching and intercellular adhesion in epithelia. Contribution of the Na,K-ATPase beta1 subunit. J Biol Chem 283, 2192-202.

Wallingford, J. B., Fraser, S. E. and Harland, R. M. (2002). Convergent extension: the molecular control of polarized cell movement during embryonic development. Dev Cell 2, 695-706.

Wang, F., Dumstrei, K., Haag, T. and Hartenstein, V. (2004). The role of DEcadherin during cellularization, germ layer formation and early neurogenesis in the Drosophila embryo. Dev Biol 270, 350-63.

Wang, J., Hamblet, N. S., Mark, S., Dickinson, M. E., Brinkman, B. C., Segil, N., Fraser, S. E., Chen, P., Wallingford, J. B. and Wynshaw-Boris, A. (2006). Dishevelled genes mediate a conserved mammalian PCP pathway to regulate convergent extension during neurulation. Development 133, 1767-78. 
Warga, R. M. and Kimmel, C. B. (1990). Cell movements during epiboly and gastrulation in zebrafish. Development 108, 569-80.

Zallen, J. A. and Blankenship, J. T. (2008). Multicellular dynamics during epithelial elongation. Semin Cell Dev Biol 19, 263-70.

Zallen, J. A. and Wieschaus, E. (2004). Patterned gene expression directs bipolar planar polarity in Drosophila. Dev Cell 6, 343-55.

Zhao, H., Liang, Y., Xu, Z., Wang, L., Zhou, F., Li, Z., Jin, J., Yang, Y., Fang, Z., Hu, Y. et al. (2008a). N-glycosylation affects the adhesive function of E-Cadherin through modifying the composition of adherens junctions (AJs) in human breast carcinoma cell line MDA-MB-435. J Cell Biochem 104, 162-75.

Zhao, H., Sun, L., Wang, L., Xu, Z., Zhou, F., Su, J., Jin, J., Yang, Y., Hu, Y. and Zha, X. (2008b). N-glycosylation at Asn residues 554 and 566 of E-cadherin affects cell cycle progression through extracellular signal-regulated protein kinase signaling pathway. Acta Biochim Biophys Sin (Shanghai) 40, 140-8.

Zhou, F., Su, J., Fu, L., Yang, Y., Zhang, L., Wang, L., Zhao, H., Zhang, D., Li, Z. and Zha, X. (2008). Unglycosylation at Asn-633 made extracellular domain of Ecadherin folded incorrectly and arrested in endoplasmic reticulum, then sequentially degraded by ERAD. Glycoconj J 25, 727-40. 


\section{Curriculum Vitae}

\section{Personal data}

Name:

Yujun Zhang

Date of Birth:

April 12, 1982

Place of Birth:

Shanxi, China

Address:

Kellnerweg12, App115, 37077 Göttingen, Germany

Email:

june20020235@hotmail.com

\section{Education}

From 02/ $2009 \quad \mathrm{PhD}$ student at the Department of Developmenta

Biochemistry, University of Göttingen

$\mathrm{PhD}$ thesis title: "E-cadherin Functions in Extension of New

Cell Borders during Cell Intercalation in Drosophila"

Supervisor: Prof.Dr.Joerg Grosshans; International PhD

program; Genes and Development (GGNB)

09/ 2005 - 12/ 2008 Master student at the Max-Planck Junior Scientist Group on

Developmental Biology, Kunming institute of Zoology,

Chinese Academy of Sciences

Master degree thesis title: "Expression and Functional

Analysis of Dkk and Kremen Genes in Amphioxus"

09/ $2001-07 / 2005$ Studies of biology, Shanxi University

Specialization: Biology Science

Graduation: Bachelor in biology

09/1998 - 07/2001 High school, No.15 Middle School of Taiyuan, Shanxi, China 


\section{Publications}

Zhang Y, Mao B, (2010), Embryonic expression and evolutionary analysis of the amphioxus Dickkopf and Kremen family genes. J. Genet. Genomics, 37:637-645

Zhang Y, Mao B (2009), Developmental expression of an amphioxus

(Branchiostoma Belcheri) gene encoding a GATA transcription factor, Zool Res. 30 : 137-143。

Wei Y, Zhang Y, Chen Y, Mao B (2009), Expansion of the actin gene family in amphioxus, Zool Res., 30:473-479。 


\section{Acknowledgements}

First, I'm grateful to my supervisor Prof. Dr. Joerg Grosshans for giving me such interesting topic, continuous support and inspiring supervisions. From him, I have learned not only the experimental considerations, but also the sincere attitude to do work. He was kind and patient to help me with all my questions and ideas. His smile and passion for science deeply impressed me. Many thanks for his support and guidance during these years.

I would like to thank Prof. Dr. Andreas Wodarz and Dr. Halyna Shcherbata for their long-term concerns and helpful suggestions as members of my thesis committee.

I would also like to thank my collaboration partners Prof. Dr. Fred Wolf, Dr. Lars Reichl and Lutz Künneke.Thank Deqing Kong for helping me to do part of western blot work (Fig.26, 28, 29B) as a master student.

I want thank Dr. Stefan Luschnig, Prof. Dr. Yuh-Nung Jan and Dr. Tadashi Uemura for the flies and the DCAD1 antibody. I thank the Bloomington Drosophila stock center at the University of Indiana for sending numerous fly stocks. I thank GGNB for providing me the opportunity to learn more knowledge in different areas and various opportunities to communicate with different people.

I want to thank all the present and previous lab members and the collegues in our department with whom I have lots of happy memories. Dr. Takuma Kanesaki taught me a lot about microscopy and gave me suggestions about my project. Dr. Shuling Yan, Dr. Hung-Wei Sung and Dr. Christian Wenzl gave me good advices and helped me to slove a lot of problems in my study and personal life. I also want to thank our technician Kristina Hänecke and Johannes Sattmann for arranging the experimental facilities well for us. I'm very lucky to be friend with Zhiyi Lv, Sreemukta Acharya, Dr. Maria Polychronidou, Dr. Mahesh Gummalla, Roman Petrovsky, Franziska Winkler, Saskia Spangenberg and Marija Kojic.

I want to thank my mentor of master study Dr. Bingyu Mao. Because of his guidance, 
I was leaded into the magic science world.

I have to express my great gratitude to my parents for their long-term unconditional support for my study and my life. Special thanks to my husband Xin Zou for his support and love. 